\title{
AVALIAÇÃO DO SISTEMA DE VIGILÂNCIA DA PESTE SUÍNA CLÁSSICA NOS ESTADOS DE SANTA CATARINA E RIO GRANDE DO SUL
}

ANA LOURDES ARRAIS DE ALENCAR MOTA

TESE DE DOUTORADO EM SAÚDE ANIMAL

BRASÍLIA/DF

JULHO/2016 
UNIVERSIDADE DE BRASÍLIA

FACULDADE DE AGRONOMIA E MEDICINA VETERINÁRIA

PROGRAMA DE PÓS-GRADUAÇÃO EM SAÚDE ANIMAL

\title{
AVALIAÇÃO DO SISTEMA DE VIGILÂNCIA DA PESTE SUÍNA CLÁSSICA NOS ESTADOS DE SANTA CATARINA E RIO GRANDE DO SUL
}

\author{
ANA LOURDES ARRAIS DE ALENCAR MOTA
}

ORIENTADOR: VÍTOR SALVADOR PICÃO GONÇALVES

CO-ORIENTADORA: FERNANDA CETRANGOLO DÓREA

TESE DE DOUTORADO EM SAÚDE ANIMAL

ÁREA DE CONCENTRAÇÃo: MEDICINA PREVENTIVA E PATOLOGIA VETERINÁRIA LINHA DE PESQUISA: EPIDEMIOLOGIA, PREVENÇÃO E CONTROLE DE DOENÇAS ANIMAIS E GESTÃo DOS RISCOS PARA A SAÚDE PÚBLICA

PUBLICAÇÃO: 006/2016

BRASÍLIA/DF

JULHO/2016 
UNIVERSIDADE DE BRASÍLIA

FACULDADE DE AGRONOMIA E MEDICINA VETERINÁRIA

PROGRAMA DE PÓS-GRADUAÇÃO EM SAÚDE ANIMAL

\section{AVALIAÇÃO DO SISTEMA DE VIGILÂNCIA DA PESTE SUÍNA CLÁSSICA NOS ESTADOS DE SANTA CATARINA E RIO GRANDE DO SUL}

\section{ANA LOURDES ARRAIS DE ALENCAR MOTA}

TESE DE DOUTORADO SUBMETIDA AO PROGRAMA DE PÓS-GRAdUAÇÃo EM SAÚDE ANIMAL, COMO PARTE DOS REQUISITOS NECESSÁRIOS À OBTENÇÃO DO GRAU DE DOUTOR EM SAÚDE ANIMAL.

APROVADA POR:

VITOR SALVADOR PICÃo gONÇALVES, Prof. Dr. (UnB)

(ORIENTADOR)

MÁRCIA DE AGUIAR FERREIRA, Prof ${ }^{\text {a }}$. Dra. (UnB)

(EXAMINADOR INTERNO)

FERNANDO FERREIRA, Prof. Dr. (USP)

(EXAMINADOR EXTERNO)

JORGE CAETANO JÚNIOR, Dr. (Mapa)

(EXAMINADOR EXTERNO)

MAURO RIEGERT BORBA, Prof. Dr. (UFRGS)

(EXAMINADOR EXTERNO)

BRASÍLIA/DF, 25 DE JULHO DE 2016. 


\section{REFERÊNCIA BIBLIOGRÁFICA E CATALOGAÇÃO}

MOTA, A.L.A.A. Avaliação do Sistema de Vigilância da Peste Suína Clássica nos estados de Santa Catarina e Rio Grande do Sul. Brasília: Faculdade de Agronomia e Medicina Veterinária, Universidade de Brasília, 2016, 79 p. Tese de Doutorado.

Documento formal, autorizando reprodução desta tese de doutorado para empréstimo ou comercialização, exclusivamente para fins acadêmicos, que foi passado pelo autor à Universidade de Brasília e acha-se arquivado na Secretaria do Programa. O autor reserva para si os outros direitos autorais de publicação. Nenhuma parte desta tese de doutorado pode ser reproduzida sem a autorização por escrito do autor. Citações são estimuladas desde que citada a fonte.

Ficha catalográfica elaborada automaticamente, com os dados fornecidos pelo(a) autor(a)

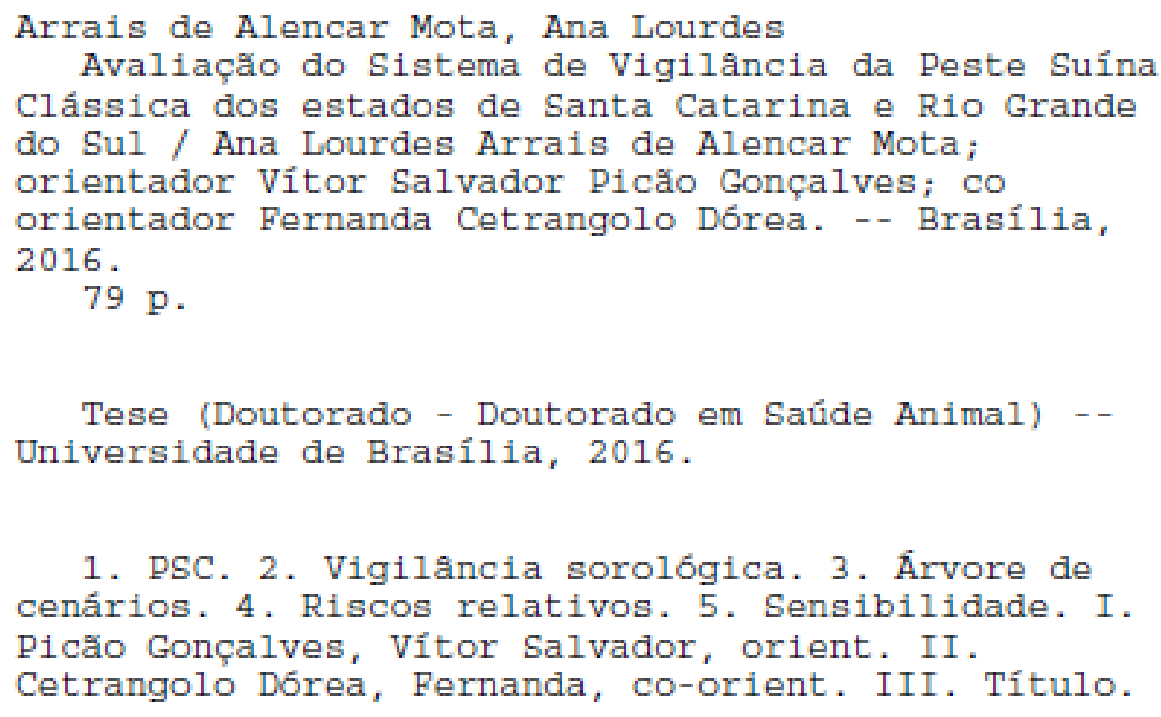

1. PSC. 2. Vigilancia sorol6gica. 3. Ârvore de cenários. 4. Riscos relativos. 5. Sensibilidade. I. Picăo Gonçalves, Vítor Salvador, orient. II.

Cetrangolo Dórea, Fernanda, co-orient. III. Título. 
Ao meu maior presente,

SSadora 


\section{AGRADECIMENTOS}

À Universidade de Brasília, pelo incentivo à minha qualificação profissional e por todo o aprendizado acadêmico e de convivência social alcançados nestes últimos anos.

À minha família, meu marido Luís Fernando e minha pequena Isadora, pelo apoio, compreensão e amor incondicional.

Aos meus pais e irmãs pelo carinho e atenção. Em especial à minha mãe, Alice, que como avó carinhosa e dedicada propiciou que eu me concentrasse na pesquisa tendo a certeza que minha filha não poderia estar em melhores mãos.

Ao meu orientador e amigo, Prof. Vítor Gonçalves, por ter me apresentado o mundo da Epidemiologia Veterinária e pelo estímulo diário ao meu crescimento profissional.

À minha co-orientadora, Fernanda Dórea, que mesmo a quilômetros de distância fez-se muito presente. Obrigada pelos encontros do Journal Club e pelas contribuições para o andamento adequado desta pesquisa.

A todos os meus professores que direta ou indiretamente tornaram este trabalho possível, transmitindo seus conhecimentos e estimulando a reflexão e discussão sobre os diversos tópicos em saúde animal. À professora Lígia Maria Cantarino da Costa pelo apoio e força na reta final da elaboração da tese.

A todos os amigos do Laboratório de Epidemiologia Veterinária (EpiPlan) que dividiram comigo as alegrias e angústias de uma pós-graduação. A Geórgia, Marina, Flávio, Isabella, Karina, Priscilla, Daniela, Bruno, Geraldo, Cátia, Bidiah, Silene e Mariana pela companhia, pelos momentos de estudo em grupo e pelas conversas sempre produtivas.

Ao Ministério da Agricultura, Pecuária e Abastecimento e aos órgãos estaduais de defesa agropecuária do Rio Grande do Sul (SEAPI/RS) e Santa Catarina (CIDASC), pelo apoio nos trabalhos de campo e disponibilização dos dados de vigilância necessários para execução desta pesquisa.

Ao CNPq pelo financiamento do projeto (Edital Universal/2012).

A Deus, por ter me guiado durante toda a minha vida, sendo fonte de força e determinação, mesmo naqueles momentos mais difíceis. 


\section{RESUMO}

O Brasil é o quarto maior produtor e exportador de carne suína do mundo. A maioria das doenças suínas listadas pela OIE é exótica ou já foi erradicada do país. O Programa Nacional de Sanidade dos Suídeos concentra, então, seus esforços em ações de vigilância para a peste suína clássica (PSC), em razão do impacto comercial desta enfermidade. Hoje, a zona livre do país abrange áreas de 16 unidades federativas, recentemente reconhecidas internacionalmente como livres de PSC. As atividades que compõem o sistema de vigilância ativa da doença são: (1) o monitoramento sorológico semestral das granjas de reprodutores; (2) o acompanhamento sorológico das granjas comerciais de suínos; (3) a avaliação sorológica de reprodutores de descarte em abatedouros; e (4) a realização de inquéritos bianuais em criatórios de suínos. O atendimento a notificações de suspeita da doença destaca-se como a principal atividade da vigilância passiva. O objetivo deste trabalho foi desenvolver um método de avaliação quantitativo que comprovasse a eficácia das medidas previstas para a demonstração de ausência da doença e manutenção do status sanitário do país, utilizando inicialmente os dados dos estados do Rio Grande do Sul (RS) e de Santa Catarina (SC). Estes estados concentram cerca de 35\% da população comercial e $70 \%$ da exportação de suínos do país e foram os primeiros a executar e registrar todas as atividades estabelecidas pelo sistema de vigilância da peste suína clássica na zona livre do Brasil. O modelo estocástico foi construído com base na metodologia de descrição por árvores de cenários, usando os dados do sistema de vigilância sorológica aplicada à população comercial de suínos, entre os anos de 2013 e 2015 . Foram coletados dados primários sobre medidas de biosseguridade nas várias tipologias de produção da cadeia produtiva de suínos, com vista a calcular riscos relativos de introdução do vírus nas várias etapas da produção. Os atributos priorizados e quantificados foram a sensibilidade e o valor preditivo negativo (VPN) do sistema de vigilância. Os resultados indicaram sensibilidades anuais médias de até 91,1\% e $98,6 \%$, respectivamente para o RS e SC. Ao final dos três anos alcançou-se um VPN superior a $99,5 \%$, supondo uma prevalência de rebanho de $1 \%$, um risco de introdução da doença durante o ano nesta frequência especificada também de $1 \%$ e uma probabilidade prévia de estar livre da doença desconhecida. Obteve-se um nível de confiança alto na certificação de ambos os estados e pôde-se demonstrar a eficácia das medidas implementadas atualmente pelo RS e SC. Na análise de impacto dos componentes do sistema, os dados de vigilância sorológica em reprodutores de descarte nos abatedouros foram os que mais contribuíram para a sensibilidade final. As demais atividades executadas abrangem atualmente um número menor de animais ou são dirigidas a propriedades de baixo risco, o que limita o impacto para a vigilância anual da 
PSC em toda a população. Os resultados obtidos fornecem subsídios importantes para que as autoridades sanitárias possam otimizar a relação custo-eficácia do sistema de vigilância da PSC.

Palavras-chave: PSC, vigilância sorológica, árvore de cenários, riscos relativos, sensibilidade. 


\begin{abstract}
Brazil is the fourth pork producer and exporter in the world. Most of the OIE listed diseases are exotic or have been eradicated from the country. The National Program for Swine Diseases focuses on surveillance for Classical Swine Fever (CSF), due to its impact on trade. Currently, the free zone in Brazil comprises 15 states and the Federal District, and has been recently recognized by the OIE as CSF free. The active surveillance system has the following components: (1) serological monitoring of accredited breeding farms that sell genetic stock, twice a year; (2) serological surveillance of commercial farms triggered by mortality of piglets above a certain threshold or presence of hemorrhagic lesions; (3) serological monitoring of culled breeding stock at the abattoir; (4) sero-surveys of non-commercial backyard holdings every two years. The response to the notification of disease suspects stands out as the main passive surveillance activity. The present work aims at developing a quantitative analytical method of evaluation of the effectiveness of implemented measures for demonstration of free zones and maintenance of the country's health status, initially using data from states of Rio Grande do Sul (RS) and Santa Catarina (SC). These states hold about 35\% of the population and $70 \%$ of the Brazilian swine meat exports and were the first ones to perform and record all activities established by the Classical Swine Fever Surveillance System in the country's free zone. The stochastic model followed the methodology of scenarios trees and used data from the serological surveillance system applied to the commercial pig population in the states of RS and SC, between the years 2013 and 2015. In addition, we collected primary data on biosecurity measures applied by the main types of commercial swine farms to derive relative risks of introducing the virus at the various stages of the production chain. Sensitivity and negative predictive value (NPV) of the surveillance system were the assessed attributes. Results indicated an average annual sensitivity of up to $91.1 \%$ and $98.6 \%$, respectively for RS and SC. After three years, each state reached a NPV of up to $99,5 \%$, assuming a $1 \%$ risk of disease introduction during a year and given a herd prevalence of $1 \%$ and an unknown prior probability of disease freedom. The CSF active surveillance system is effective as it is and allows for a high level of confidence in the absence of disease. The serological monitoring of culled breeding stock at the abattoir was the component that contributed more to the final sensitivity. The other components are currently performed in fewer animals or are applied to low-risk properties, resulting in lower impact to annual surveillance of CSF in the entire swine population of RS and SC.
\end{abstract}

Key-words: CSF, serological surveillance, scenarios trees, relative risks, surveillance sensitivity. 


\section{LISTA DE TABELAS}

Página

\section{Capítulo 1}

Tabela 1. Sistema de pontuação de vulnerabilidade das granjas suínas à introdução de Peste Suína Clássica.

Tabela 2. Pontuação máxima ponderada que cada granja poderia alcançar por tema incluído no sistema de avaliação de vulnerabilidade

Tabela 3. Estratificação da amostra utilizada para compor o sistema de pontuação de vulnerabilidade das granjas suínas à introdução de agentes patogênicos

Tabela 4. Pontuações ponderadas alcançadas no sistema de avaliação de vulnerabilidade das granjas à introdução de PSC por tipologia produtiva.

Tabela 5. Estimativa dos Riscos Relativos de introdução de Peste Suína Clássica por tipologia produtiva, com e sem atribuição de pesos na escala de avaliação de vulnerabilidade da granja.

\section{Capítulo 2}

Tabela 1. Componentes do Sistema de Vigilância para PSC em SC e no RS.

Tabela 2. Limites críticos nas taxas mensais de mortalidade nas granjas comerciais de suínos para comunicação compulsória ao serviço veterinário oficial.

Tabela 3. Parâmetros das distribuições de Pert utilizadas para descrever os RR para infecção por PSC de cada tipologia produtiva existente nas suinoculturas dos estados do RS e SC.

Tabela 4. Valores de sensibilidade dos testes diagnósticos inseridos no modelo de avaliação do Sistema de Vigilância da Peste Suína Clássica.

Tabela 5. Dados de vigilância sorológica para Peste Suína Clássica nos estados do Rio Grande do Sul e Santa Catarina, nos anos de 2013 a 2015, referentes ao componente 1 do sistema de vigilância (Monitoramento sorológico nas Granjas de Reprodutores Suídeos Certificadas), dada $\mathrm{P}_{\mathrm{H}}^{*}=0,01$. 
Tabela 6. Dados populacionais da suinocultura comercial dos estados do Rio Grande do Sul e Santa Catarina, no início do período de avaliação, e estimativas das Efetivas Probabilidades de Infecção, dada $\mathrm{P}^{*} \mathrm{H}=0,01$, os riscos relativos e proporções populacionais de granjas descritas.

Tabela 7. Dados de vigilância sorológica para Peste Suína Clássica nos estados do 57 Rio Grande do Sul e Santa Catarina, nos anos de 2013 a 2015, referentes ao componente 2 do sistema de vigilância (Acompanhamento sorológico das granjas comerciais), dada $\mathrm{P}^{*} \mathrm{H}=0,01$.

Tabela 8. Dados de vigilância sorológica para Peste Suína Clássica nos estados do 58 Rio Grande do Sul e Santa Catarina, nos anos de 2013 a 2015, referentes ao componente 3 do sistema (Avaliação sorológica em matadouros-frigoríficos).

Tabela 9. Sensibilidade anual e VPN ao final período de avaliação do Sistema de 59 Vigilância de Peste Suína Clássica nos estados do Rio Grande do Sul e Santa Catarina, nos anos de 2013 a 2015, simulando $\mathrm{P}^{*} \mathrm{H}=0,01$.

Tabela 10. Sensibilidade anual média e VPN médio ao final período de avaliação do 60 Sistema de Vigilância de Peste Suína Clássica nos estados do Rio Grande do Sul e Santa Catarina em diversos cenários alternativos de composição do sistema, considerando os dados reais dos anos de 2013 a 2015.

Tabela 11. Sensibilidade anual e VPN ao final período de avaliação do Sistema de Vigilância de Peste Suína Clássica nos estados do Rio Grande do Sul e Santa Catarina, nos anos de 2013 a 2015, simulando $\mathrm{P}^{*} \mathrm{H}=0,005$. 


\section{LISTA DE FIGURAS}

Página

\section{Capítulo 1}

Figura 1. Mapa da subdivisão estadual do RS, segundo a Secretaria de Agricultura, Pecuária e Irrigação (SEAPI/RS). Fonte: RS, 2014

Figura 2. Descrição das pontuações ponderadas alcançadas no sistema de avaliação 32 de vulnerabilidade proposto por tipologia produtiva.

Figura 3. Descrição das pontuações ponderadas alcançadas no sistema de avaliação 32 de vulnerabilidade proposto por sistema produtivo.

\section{Capítulo 2}

Figura 1. Mapa das regiões livres de Peste Suína Clássica no Brasil (BRASIL, 2010).

Figura 2. Componente 1 - Esquema gráfico da construção da árvore de cenários do componente de monitoramento semestral das Granjas de Reprodutores Suídeos Certificadas (GRSC).

Figura 3. Componente 2 - Esquema gráfico da construção da árvore de cenários do componente de vigilância das Granjas Comerciais de Suínos.

Figura 4. Componente 3 - Esquema gráfico da construção da árvore de cenários do componente de vigilância sorológica de reprodutores de descarte em matadourosfrigoríficos. 


\section{LISTA DE ABREVIATURAS E SIGLAS}

ABPA - Associação Brasileira de Proteína Animal

AC - Acre

AM - Amazonas

AR - Riscos Relativos Ajustados

BA - Bahia

CC - Granjas de Ciclo Completo

CIDASC - Companhia Integrada de

Desenvolvimento Agrícola de Santa

Catarina

$\mathrm{Cr}-$ Crechários

CSe - Sensibilidade do Componente do Sistema de Vigilância

CSeU - Sensibilidade unitária

CSF - Classical Swine Fever

EFSA - European Food Safety Authority

EPI - Efetiva Probabilidade de Infecção

GRSC - Granja de Reprodutores Suídeos Certificada

IA - Inseminação Artificial

Mapa - Ministério da Agricultura,

Pecuária e Abastecimento

OIE - Organização Mundial de Saúde

Animal

P* - Prevalência de delineamento

$\mathrm{P}^{*} \mathrm{H}-$ Prevalência de delineamento de rebanho

$\mathrm{P}^{*} \mathrm{U}$ - Prevalência de delineamento animal
$P_{\text {intro }}$ - Probabilidade de introdução da doença em uma determinada frequência durante $\mathrm{o}$ tp

PNSS - Programa Nacional de Sanidade Suídea

PSC - Peste Suína Clássica

RO - Rondônia

RR - Risco Relativo

RS - Rio Grande do Sul

SC - Santa Catarina

SE - Sergipe

SEAPI/RS - Secretaria de Agricultura, Pecuária e Irrigação do Rio Grande do Sul

SeH - Sensibilidade de Rebanho

SIE - Serviço de Inspeção Estadual

SIF - Serviço de Inspeção Federal

SSC - Componente do Sistema de Vigilância

SSe - Sensibilidade do Sistema de Vigilância

SV - Sistema de Vigilância

TO - Tocantins

Tp - Período de tempo da avaliação do sistema de vigilância

$\operatorname{Tr}$ - Granjas de Terminação

UPL - Unidade Produtora de Leitões

VPN - Valor Preditivo Negativo 


\section{SUMÁRIO}

\section{Página}

INTRODUÇÃO 15

Capítulo 1- ESTIMATIVA DE RISCOS RELATIVOS PARA INTRODUÇÃO DE 20 PESTE SUÍNA CLÁSSICA NA SUINOCULTURA DAS PRINCIPAIS REGIÕES PRODUTORAS DO RIO GRANDE DO SUL

Resumo $\quad 20$

Introdução

$\begin{array}{ll}\text { Materiais e Métodos } & 23\end{array}$

$\underline{\text { Resultados }} \quad 30$

Discussão e Conclusão

Referências $\quad 36$

Capítulo 2- AVALIAÇÃO DO SISTEMA DE VIGILÂNCIA DA PESTE SUÍNA 40

CLÁSSICA NOS ESTADOS DE SANTA CATARINA E RIO GRANDE DO SUL

$\begin{array}{ll}\text { Resumo } & 40\end{array}$

$\begin{array}{ll}\text { Introdução } & 41\end{array}$

Materiais e Métodos

$\underline{\text { Resultados }} \quad 54$

$\begin{array}{ll}\text { Discussão } & 61\end{array}$

$\begin{array}{ll}\text { Conclusão } & 64\end{array}$

Referências $\quad 65$

$\begin{array}{ll}\text { REFERENNCIAS } & 70\end{array}$

$\begin{array}{ll}\text { ANEXOS } & 77\end{array}$

Entrevista - Avaliação da Biosseguridade das propriedades produtoras de suínos no $\quad 77$ RS. 


\section{INTRODUÇÃO}

O Acordo Sanitário e Fitossanitário (SPS) da Organização Mundial do Comércio (OMC) exige que no comércio internacional as medidas tomadas para proteger a saúde vegetal, animal ou humana devem ser baseadas em princípios científicos e não devem ser mantidas na ausência de provas suficientes que as justifiquem (WTO, 1995). Para tanto, os países têm cumprido esta norma aplicando de forma mais frequente medidas baseadas em avaliações de risco, ou seja, têm buscado demonstrar o seu estado de doença (presente ou ausente) ou de cada um dos seus parceiros comerciais, estimando os perigos e probabilidades do acordo comercial alterar de forma significativa a condição sanitária do país.

A demonstração de zona ou país livre de doença costuma basear-se ou na análise quantitativa de resultados de inquéritos soroepidemiológicos ou em avaliações qualitativas de evidências oriundas de múltiplas fontes, incluindo fontes complexas não representativas (MARTIN; CAMERON; GREINER, 2007). Na primeira abordagem metodológica, os dados de um levantamento transversal são utilizados para estimar a probabilidade dos resultados negativos serem alcançados caso a doença esteja realmente presente em um nível especificado (CANNON, 2001). Se a probabilidade for inferior a uma prevalência predeterminada, a população é considerada livre. A segunda abordagem é focada em uma avaliação qualitativa de múltiplas fontes de dados, sob a supervisão de especialistas. Estes dados podem ser oriundos de populações não representativas, como de registros de laboratórios, amostragem em abatedouros ou mesmo de número de atendimentos a suspeitas de doença de notificação obrigatória do serviço veterinário oficial (MARTIN; CAMERON; GREINER, 2007).

Essas abordagens têm sido acolhidas pela OIE (Organização Mundial de Saúde Animal) e aplicadas pelos serviços governamentais de saúde animal dos diversos países para amparar as reivindicações de status sanitário livre em fase final de programas de erradicação de doenças ou para manutenção da classificação para aqueles que já possuem a ausência de determinada doença reconhecida internacionalmente. No entanto, sabe-se que cada uma dessas abordagens possui limitações significativas. Inquéritos estruturados usando amostragem representativa podem ser caros e os resultados dependem da premissa de que a doença estaria distribuída de forma aleatória e constante com prevalência incompatível com uma zona livre. Uma avaliação qualitativa pode considerar diversas fontes de evidência, mas seus resultados podem ser muito subjetivos e influenciados pela forma como seus parâmetros 
foram estimados e pelas opiniões de especialistas, possuindo geralmente desfechos dicotômicos com um nível de incerteza desconhecida e uma baixa taxa de reprodutibilidade.

Portanto, surgiu nos últimos anos uma necessidade de métodos de avaliação que fundamentem as ausências de doença, incluindo e integrando dados de vigilância baseada em pesquisas aleatórias e não aleatórias de forma mais objetiva (ZEPEDA et al., 2005).

\section{A Suinocultura brasileira e a Peste Suína Clássica (PSC):}

Nas últimas décadas, a produção brasileira de suínos teve um considerável crescimento no comércio globalizado. Atualmente, o Brasil é o quarto maior produtor e exportador de carne suína do mundo e tem realizado diversos investimentos tecnológicos em sua cadeia produtiva, principalmente nas regiões sul, sudeste e centro-oeste, onde se encontram os seus maiores produtores (ABPA, 2016). Somente no ano de 2015 mais de 3,6 milhões de toneladas de carne suína foram produzidas no país e cerca de 555 mil toneladas exportadas (ABPA, 2016).

O controle sanitário tem sido crucial para garantir a qualidade dos produtos e a competitividade da suinocultura do Brasil no cenário internacional (FREITAS et al., 2007). Apesar da suinocultura nacional não conviver com a maioria das enfermidades que limitam o comércio internacional (BRASIL, 2016), sobretudo nas áreas de grande potencial exportador, o acesso ao mercado de muitos países ainda está vedado ao produto brasileiro. Isto se deve em parte a fatores puramente comerciais, mas também ao fato de alguns países ainda considerarem que as garantias sanitárias oferecidas pelo Brasil são insuficientes. Assim, o Programa Nacional de Sanidade Suídea (PNSS) atualmente concentra seus esforços em demonstrar, de forma mais objetiva, a qualidade da suinocultura nacional, em relação ao seu risco de apresentar as principais doenças da espécie com grande poder de difusão e consequências econômicas ou sanitárias graves (BRASIL, 2016; OIE, 2016).

Das doenças da lista de notificação obrigatória da OIE, a doença vesicular dos suínos, encefalite por vírus Nipah, gastroenterite transmissível, síndrome respiratória e reprodutiva suína e triquinelose nunca foram diagnosticadas no Brasil, sendo consideradas exóticas, e a peste suína Africana encontra-se erradicada desde 1984 (BRASIL, 2016). A principal enfermidade foco do PNSS atualmente é a Peste Suína Clássica (PSC) (BRASIL, 2016; BRASIL, 2004a). 
A Peste Suína Clássica é uma doença infecciosa causada por um Pestivirus, da família Flaviviridae, que acomete suídeos domésticos e silvestres, e é considerada estratégica do ponto de vista sanitário por ser responsável por grandes perdas produtivas e econômicas no comércio internacional, devido a sua alta infectividade e letalidade (RIDPATH, FLORES, 2007; OIE, 2009). A transmissão desta doença ocorre principalmente por contato direto entre animais infectados e suscetíveis via oronasal, mas também pode ocorrer por via indireta, através de pessoas e veículos, carne contaminada e mal cozida fornecida a leitões ou até mesmo por via aerógena em curtas distâncias (até $1 \mathrm{~km}$ ), como já descrita em áreas com alta densidade de suínos (BRONSVOORT; ALBAN; GREINER, 2008; RIBBENS et al., 2004). As infecções podem se apresentar de forma aguda, subaguda, crônica ou inaparente, dependendo da virulência da cepa do vírus e do estado imunológico e idade dos animais acometidos (OIE, 2015a; LOHSE; NIELSEN; UTTENTHAL, 2012). Os principais sinais clínicos da doença são febre alta, inapetência, apatia, conjuntivite, constipação seguida por diarreia, presença de hemorragias petequeais em múltiplos órgãos, além de grave imunossupressão. Animais adultos geralmente exibem padrões menos graves da doença do que os leitões e possuem uma maior taxa de sobrevivência. Em rebanhos de cria infectados por cepas de baixa virulência, baixos índices reprodutivos pode ser o único sinal da presença da peste suína clássica na população (RIDPATH, FLORES, 2007; OIE, 2009).

No Brasil, há registros da PSC desde o final do século XIX (BRASIL, 1988). Na terço final do século XX, a introdução da Peste Suína Africana na década de 70 e sua erradicação em 1984 acarretaram avanços também no controle da PSC, com a redução progressiva do número de focos por ano e melhor estruturação da rede laboratorial oficial para diagnóstico de ambas as enfermidades (BRASIL, 2014). O processo de implantação de zonas livres de Peste Suína Clássica no Brasil começou em 1992, com a proibição da vacinação em algumas áreas do país e a aplicação da vacina de forma obrigatória ou voluntária nas demais (BRASIL, 2004a; BRASIL, 2016). Em 1994, o Rio Grande do Sul, Santa Catarina e Paraná foram os primeiros estados reconhecidos nacionalmente como uma zona livre da doença (BRASIL, 2014). Hoje, a zona livre da doença no país, reconhecida internacionalmente pela OIE, é composta pelo Acre, Bahia, Distrito Federal, Espírito Santo, Goiás, Mato Grosso, Mato Grosso do Sul, Minas Gerais, Paraná, Rio de Janeiro, Rio Grande do Sul, Rondônia, Santa Catarina, São Paulo, Sergipe e Tocantins e pelos municípios de Guajará, de Boca do Acre, e parte do de Canutama e de Lábrea pertencentes ao estado do Amazonas (OIE, 2016; BRASIL, 2010). O último foco registrado na zona considerada livre do Brasil foi em 1998, em São 
Paulo. E a última notificação nacional da Peste Suína Clássica foi em 2009, no Rio Grande do Norte (BRASIL, 2014).

As estratégias de atuação para a erradicação e a manutenção da zona livre preveem notificação obrigatória da suspeita de ocorrência da enfermidade; assistência imediata aos focos; controle do trânsito de suídeos e seus produtos e subprodutos; destruição de suínos positivos e seus contatos, além de suas excretas e carcaças; realização de inquéritos soroepidemiológicos para caracterização de zonas livres; proibição da utilização de vacina contra a PSC em todo o território nacional, exceto em zonas e momentos definidos pelo Ministério da Agricultura, Pecuária e Abastecimento (Mapa); controle da produção e fiscalização da comercialização de vacinas; manipulação do vírus da PSC restrita a laboratórios de diagnóstico ou de produção de vacinas oficialmente autorizados; além da manutenção de um sistema de vigilância e de informação, abrangendo todos os níveis da produção (BRASIL, 2004a; BRASIL, 2009).

\section{O sistema de vigilância da Peste Suína Clássica na zona livre do Brasil:}

O Sistema de Vigilância da PSC na zona livre do Brasil é estabelecido pela Norma Interna $\mathrm{n}^{\circ} 05$ do Departamento de Saúde Animal do Ministério da Agricultura, Pecuária e Abastecimento (Mapa) (BRASIL, 2009). São propostas atividades como: (1) o monitoramento sorológico semestral nas Granjas de Reprodutores Suídeos Certificadas (GRSC), (2) o acompanhamento das granjas comerciais de suínos, desencadeado pela notificação de altas taxas de mortalidade ou presença de lesões hemorrágicas múltiplas, (3) a vigilância em matadouros-frigoríficos pela avaliação sorológica de reprodutores de descarte encaminhados para abate; (4) e a realização de inquéritos soroepidemiológicos bianuais em criatórios de suínos. $\mathrm{O}$ atendimento a notificações de suspeita da doença destaca-se como principal atividade da vigilância passiva (BRASIL, 2004b; BRASIL, 2009).

Todas estas atividades são preconizadas com a finalidade de levantar dados que confirmem uma vigilância eficaz da doença e que possam indicar a manutenção da condição de zona livre de PSC, diante de uma rotina de avaliação das atividades estabelecidas (BRASIL, 2004c; BRASIL, 2009). No entanto, na prática é observada uma grande heterogeneidade nas formas de realização das atividades de vigilância previstas na norma oficial para PSC entre os estados que compõem atualmente a zona livre de PSC do Brasil. Somente alguns estados têm executado as atividades de forma rotineira e estão aptos a 
fornecer dados para uma avaliação mais objetiva do sistema, e mesmo assim, nenhuma avaliação quantitativa do Sistema de Vigilância da PSC no Brasil foi ainda realizada.

O objetivo deste trabalho foi, então, desenvolver um modelo que representasse, avaliasse e quantificasse a qualidade do sistema de vigilância para peste suína clássica da zona livre do Brasil, focando inicialmente em dois estados, o Rio Grande do Sul e Santa Catarina. Estes estados concentram cerca de $35 \%$ da população comercial e $70 \%$ da exportação de suínos do país (ABPA, 2016) e encontram-se relativamente mais avançados na execução e registro de todas as atividades estabelecidas pelo sistema de vigilância.

Reconhecendo a importância da acurácia dos parâmetros inseridos em um modelo de avaliação para a utilização prática das suas conclusões (SOUZA MONTEIRO et al., 2012), no capítulo 1 é descrita a metodologia utilizada para fundamentar as diferenças de risco de introdução da PSC nas diversas tipologias de produção de suínos sob vigilância. Entrevistas estruturadas foram realizadas com produtores de suínos de regiões do Rio Grande do Sul para levantamento de dados sobre biosseguridade e controle sanitário aplicados na produção e para captura de dados primários complementares que pudessem guiar as estimativas de riscos relativos (RR) entre os setores da suinocultura local. Os resultados alcançados colaboraram para o cálculo das diferentes Efetivas Probabilidades de Infecção (EPI), aplicadas no delineamento analítico da avaliação do Sistema de Vigilância da PSC nos estados de Santa Catarina e Rio Grande do Sul. No capítulo 2, é, então, apresentado o método proposto de avaliação do SV da peste suína clássica da zona livre do Brasil, utilizando os dados das atividades de vigilância sorológica dos estados foco da avaliação entre os anos de 2013 e 2015. Todo o sistema de vigilância foi descrito com auxílio de árvores de cenários, simulando uma possível reintrodução da doença na região estudada, desde a ocorrência da infecção na granja até a detecção do caso pelo sistema. Os atributos do sistema de vigilância priorizados e quantificados foram: a sensibilidade e o valor preditivo negativo. A eficácia e eficiência das medidas previstas atualmente foram discutidas com base no nível de confiança encontrado na ausência da doença em ambos os estados ao final do período de avaliação. 


\section{Capítulo 1}

\section{ESTIMATIVA DE RISCOS RELATIVOS PARA INTRODUÇÃO DE PESTE SUÍNA CLÁSSICA NA SUINOCULTURA DAS PRINCIPAIS REGIÕES PRODUTORAS DO RIO GRANDE DO SUL}

\section{$\underline{\text { Resumo }}$}

O sucesso da produção comercial de suínos depende, dentre outros aspectos produtivos, de um bom programa preventivo de doenças e de biosseguridade local. Neste trabalho buscamos associar as medidas rotineiras de cuidados e proteção da produção das diferentes tipologias de granjas comerciais do Rio Grande do Sul a uma escala de vulnerabilidade da propriedade à introdução do vírus da Peste Suína Clássica. Foram amostradas aleatoriamente 188 granjas, entre Unidades Produtoras de Leitões (UPL), Crechários (Cr), Terminações (Tr) e Granjas de Ciclo Completo (CC), das regionais de Estrela, Palmeira das Missões, Erechim e Santa Rosa, conforme subdivisão estadual da Secretaria de Agricultura, Pecuária e Irrigação do Rio Grande do Sul (SEAPI/RS). A partir dos dados levantados pelas entrevistas estruturadas aplicadas aos produtores sorteados criouse um sistema de pontuação crescente com amplitude total igual a 100 pontos, no qual as granjas com melhores condições de biosseguridade foram relacionadas a menores conjuntos de pontos na escala de vulnerabilidade criada. Medidas associadas a maior risco de introdução da doença, como o trânsito animal, a densidade de propriedades na região, o nível de isolamento das instalações e o contato com agentes veiculadores do vírus, foram ponderadas no sistema de pontuação de forma a contribuírem mais para a diferenciação dos riscos entre as tipologias produtivas estudadas. Assim, o estudo visou demonstrar de forma semi-quantitativa a relação entre a ausência de algumas medidas preventivas e o aumento do risco potencial de acometimento da população por agravos sanitários, como a introdução da Peste Suína Clássica, já discutida e ressaltada por alguns estudos descritivos e por especialistas da produção suinícola como pontos críticos de controle da qualidade da produção. Os riscos relativos da suinocultura gaúcha foram calculados pela razão das pontuações alcançadas por cada tipologia de granja estudada por aquela em média alcançada na mesma escala de vulnerabilidade por uma granja GRSC, considerada padrão de excelência para produção segura, segundo a legislação em vigor. A comparação dos valores médios alcançados pelas UPL (RR=3,7), $\mathrm{Cr}(\mathrm{RR}=2,8), \operatorname{Tr}(\mathrm{RR}=3,4)$ e $\mathrm{CC}(\mathrm{RR}=4,5)$ pela análise de variância indicou 
um p-valor $<0,001$. O pós-teste de Bonferroni apontou que somente a diferença entre a pontuação média alcançada pelas UPL e as Tr não foram estatisticamente significativas $(\mathrm{p}=0,17)$. Assim, a metodologia empregada destacou os crechários como a tipologia produtiva comercial menos vulnerável à introdução do vírus da Peste Suína Clássica e as granjas de ciclo completo como sendo as mais sujeitas a surtos da doença, pela menor frequência de aplicação de práticas preventivas e presença de infraestrutura básica de proteção da produção.

Palavras-chave: biosseguridade, vulnerabilidade, peste suína clássica, risco relativo, sistema de pontuação.

\section{Introducão}

O sucesso da produção comercial de suínos depende, dentre outros aspectos produtivos, de um bom programa preventivo de doenças e monitoramento diário dos animais e da infraestrutura, a fim de atingir níveis adequados de higiene e saúde (DIAS et al., 2011; PINTO; URCELAY, 2003). O conceito de biosseguridade refere-se à aplicação de tais medidas (CASAL et al., 2007), com foco na obtenção de um produto de qualidade e competitivo no cenário nacional e internacional.

O cumprimento de um conjunto de boas práticas de produção na granja traz rentabilidade à atividade e protege não apenas o rebanho, mas toda a cadeia produtiva de suínos (SIEKKINEN et al., 2012). Conjuntamente, previne a introdução de doenças exóticas, como a Peste Suína Clássica e a Febre Aftosa (PINTO; URCELAY, 2003), e a disseminação de doenças infeciosas endêmicas na região (BOKLUND et al., 2004), sendo o elo principal para a aplicação de uma medicina preventiva (GELAUDE et al., 2014).

Atualmente, o Brasil é o quarto maior produtor e exportador de carne suína do mundo (ABPA, 2016). O Rio Grande do Sul é a segunda unidade federativa do país com maior participação na suinocultura nacional, possui um efetivo de mais de 6,3 milhões de suínos e é responsável por mais de 30\% das exportações brasileiras desta espécie (ABPA, 2016). A produção de suínos neste estado é confinada e cerca de 95\% dos animais e 80\% das granjas estão sob um sistema de produção integrado (RS, 2014), no qual as agroindústrias de abate e processamento de carne fornecem os insumos, genética, logística e assistência técnica e o produtor se responsabiliza pelas instalações e mão de obra. Recentemente, o RS foi reconhecido internacionalmente como livre de PSC (OIE, 2016), no entanto a ampliação das suas relações comerciais ainda encontra-se dependente da apresentação de fontes de dados 
mais objetivos que evidenciem a preocupação da suinocultura local com as questões de biosseguridade e que também demonstrem as condições sanitárias alcançadas. Assim, diante de uma demanda conjunta do serviço veterinário oficial do estado (Secretaria de Agricultura, Pecuária e Irrigação - SEAPI/RS) e a Associação Brasileira de Proteína Animal (ABPA), foi realizado em 2015 um levantamento das condições de produção das granjas comerciais do Rio Grande do Sul (DORNELAS, 2015).

Quanto à biosseguridade das granjas suínas deste estado, Dornelas (2015) descreveu que as granjas integradas, que produzem em múltiplos sítios, possuem em geral melhores condições que aquelas que criam e vendem os animais de forma independente e caracterizamse pela produção em ciclo completo (CC). Considerando uma avaliação individualizada dos sítios, as creches $(\mathrm{Cr})$ apresentaram de forma mais frequente uma biosseguridade externa melhor, quando comparadas às granjas de terminação (Tr) e às granjas produtoras de leitões (UPL). Estas últimas, apesar de serem a base da cadeia produtiva, demonstraram ter infraestrutura mais precária que as demais do sistema produtivo integrado e uma preocupação menor com o isolamento da granja, evidenciando níveis de biosseguridade apenas ligeiramente diferentes das granjas independentes de ciclo completo (DORNELAS, 2015). Em relação a um estudo anterior realizado por Delphino (2009), notou-se um avanço na implementação de algumas práticas, como o isolamento das instalações por cerca telada, o estabelecimento de entrada única por meio de vestuário e banheiro, o controle de visitas e o uso de uniforme exclusivo, principalmente nas Tr. No entanto, todas estas conclusões foram obtidas pela simples comparação das frequências de presença ou ausência de determinadas características produtivas ou infraestruturas, sendo insuficiente para uma avaliação conjunta do nível e qualidade das práticas implementadas em cada granja comercial e para comparar a eficácia de proteção sanitária para um determinado agente etiológico entre as tipologias produtivas.

Assim, a partir desses resultados descritivos, o presente trabalho teve como objetivos estimar a importância de cada uma das medidas de biosseguridade analisadas para a proteção da granja contra a introdução da Peste Suína Clássica e criar um sistema de pontuação para uma avaliação semi-quantitativa da vulnerabilidade das mesmas à introdução da doença. Considerando que padrões de biosseguridade podem refletir o potencial risco de acometimento da granja por agravos sanitários (PINTO; URCELAY, 2003), a criação desta ferramenta analítica também teve como finalidade estimar diferenças de riscos aos quais as 
diversas tipologias produtivas presentes no Rio Grande do Sul estão expostas, propondo um método de obtenção de riscos relativos entre subpopulações.

\section{Materiais e Métodos}

\section{Amostragem:}

O levantamento das questões de biosseguridade para construção do sistema de pontuação para análise de vulnerabilidade das granjas foi realizado por meio de entrevistas estruturadas aos produtores de suínos locais (ANEXO A), aplicadas durante os meses de setembro e outubro de 2015. A população alvo do estudo foram as suinoculturas comerciais do Rio Grande do Sul, localizadas nas regionais de Estrela, Santa Rosa, Erechim e Palmeira das Missões, conforme subdivisão estadual da Secretaria de Agricultura, Pecuária e Irrigação (SEAPI/RS). Estas regionais originam cerca de 60\% da produção de suínos abatidos sob Sistema de Inspeção Federal (SIF) no estado (RS, 2014) e possuem uma boa representatividade em relação às diversas tipologias produtivas existentes, conforme o cadastro de propriedades do órgão oficial (RS, 2014).

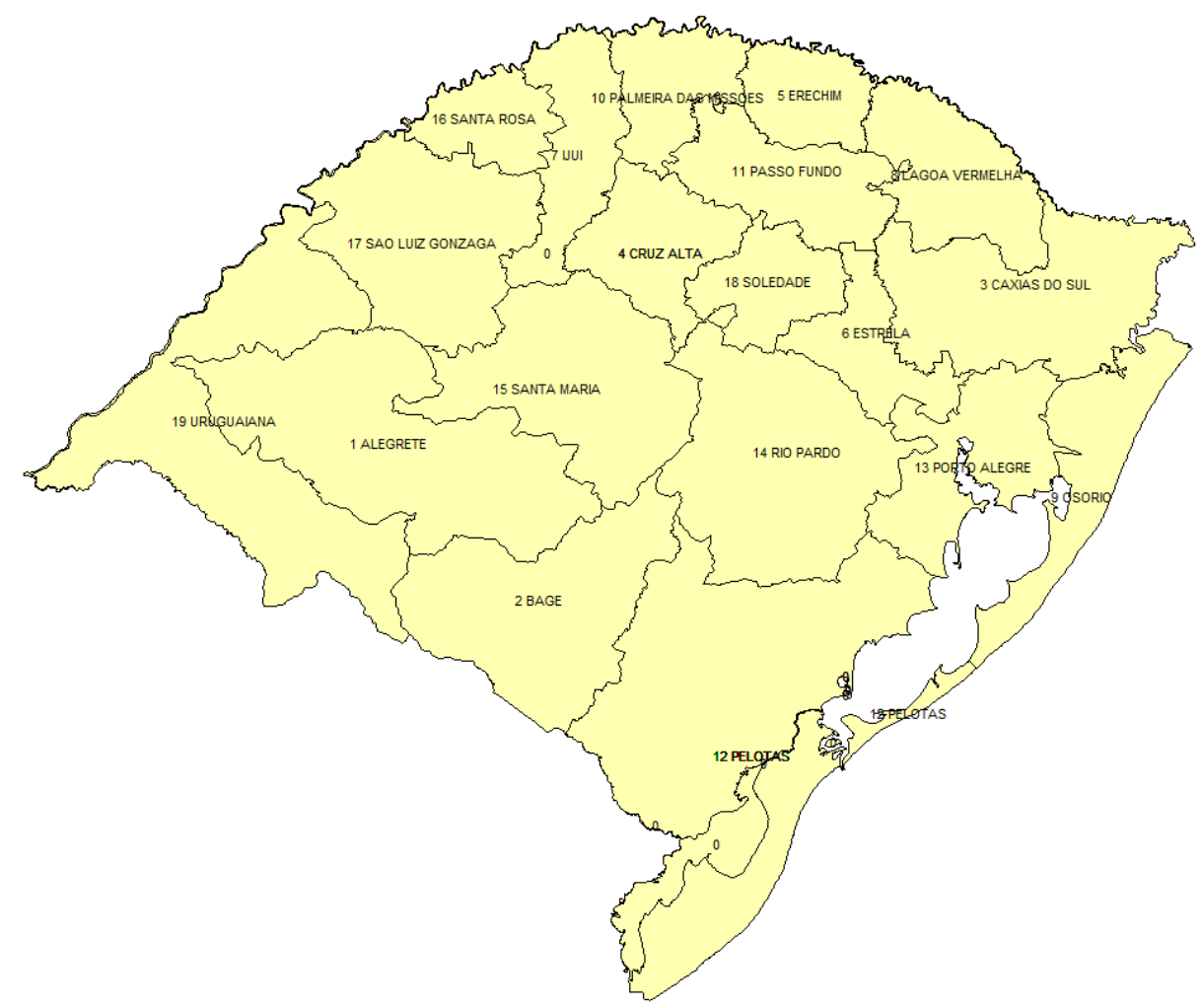

Figura 1. Mapa da subdivisão estadual do RS, segundo a Secretaria de Agricultura, Pecuária e Irrigação (SEAPI/RS). Fonte: RS, 2014 
Definida esta população de estudo, foi realizada uma amostragem aleatória estratificada, ponderada por regional, para as seguintes tipologias produtivas comerciais identificadas no RS: Unidades Produtoras de Leitões (UPL), Crechários (Cr), Granjas de Terminação (Tr). Para o levantamento nas granjas de ciclo completo (CC), a seleção foi direcionada para as maiores propriedades classificadas nesta tipologia nas regionais selecionadas. Isto para abranger principalmente aquelas CC com finalidade comercial, já que é comum criatórios de subsistência serem lançados erroneamente no sistema de cadastro de propriedades rurais como granjas de ciclo completo.

O cálculo do tamanho da amostra para cada uma das quatro tipologias produtivas foi obtido com auxílio do programa Epitools® (SEARGENT, 2009), considerando um nível de confiança de 95\%, uma precisão absoluta de $15 \%$ e uma estimativa de frequência de ocorrência de um parâmetro levantado pela entrevista igual a 50\%, conforme a fórmula:

$$
\mathrm{n}=\frac{z^{2} \times p \times(1-p)}{d^{2}}
$$

Onde n é o tamanho da amostra, z é 1,96 (valor da distribuição normal padrão correspondente ao nível de confiança de 95\%), p é a prevalência e d é a precisão desejada.

A fórmula acima sugeriu uma amostra de 43 propriedades. Inicialmente, foram selecionadas 50 propriedades de cada tipologia produtiva (UPL, Cr, Tr e CC), a partir do cadastro de propriedades da Secretaria de Agricultura, Pecuária e Irrigação (SEAPI/RS), que contém o registro de todas as propriedades suinícolas do Estado do Rio Grande do Sul. A substituição de amostras foi realizada diante da incapacidade de identificação da propriedade inicialmente selecionada ou mudança de foco produtivo da granja e seguiu o critério de manutenção da tipologia produtiva e sistema de produção inicialmente sorteados, buscando encontrar outra granja nas proximidades do mesmo município da descartada.

A entrevista incluiu perguntas sobre localização e proximidades da granja, medidas de biosseguridade, principalmente externas, e conhecimento do entrevistado sobre algumas doenças de notificação obrigatória. O formato e inserção dos temas abordados foram debatidos previamente entre especialistas da área e representantes do serviço veterinário oficial federal e estadual, que indicaram a relevância de cada tópico para a descrição da situação produtiva local. Os entrevistados foram escolhidos por trabalharem diretamente com os suínos nas granjas, preferencialmente o proprietário, e todos concordaram com a sua participação na pesquisa. 


\section{Sistema de pontuação:}

A partir da entrevista aplicada, perguntas foram utilizadas na íntegra ou agrupadas para compor um sistema de pontuação em escala crescente de vulnerabilidade da granja quanto à introdução da Peste Suína Clássica (Tabela 1). As questões sobre ambiência e localização da propriedade foram registradas de acordo com as noções de distância mencionadas pelos entrevistados. Uma imagem de satélite impressa no raio de $1 \mathrm{~km}$ da propriedade sorteada foi apresentada durante a entrevista par auxiliar a visualização da região e indicação das propriedades e instalações vizinhas.

Tabela 1. Sistema de pontuação de vulnerabilidade das granjas suínas à introdução de Peste Suína Clássica.

\begin{tabular}{|c|c|c|c|}
\hline Categoria & Peso & Questão & Pontuação \\
\hline \multirow[t]{9}{*}{$\begin{array}{c}\text { Localização } \\
\text { e } \\
\text { Ambiência }\end{array}$} & 1 & $\begin{array}{l}\text { Qual a distância da estrada mais próxima em } \\
\text { que se transportam suínos? }\end{array}$ & $\begin{array}{l}0:>500 \mathrm{~m} \\
1: 100 \text { a } 500 \mathrm{~m} \\
2:<100 \mathrm{~m}\end{array}$ \\
\hline & 1 & $\begin{array}{l}\text { Qual a distância da propriedade mais próxima } \\
\text { com suínos? }\end{array}$ & $\begin{array}{l}0:>3500 \mathrm{~m} \\
1: 1000 \text { a } 3500 \mathrm{~m} \\
2: 500 \text { a } 999 \mathrm{~m} \\
3:<500 \mathrm{~m}\end{array}$ \\
\hline & 1 & $\begin{array}{l}\text { A propriedade mais próxima com suínos } \\
\text { também tem finalidade comercial? }\end{array}$ & $\begin{array}{l}\text { 0: sim } \\
\text { 1: não }\end{array}$ \\
\hline & 2 & $\begin{array}{l}\text { Quantas propriedades com suínos existem no } \\
\text { raio de } 1 \mathrm{~km} \text { ? }\end{array}$ & $\begin{array}{l}0: 1 \text { propriedade } \\
1: 2 \text { ou } 3 \\
2:>4 \text { propriedades }\end{array}$ \\
\hline & 2 & $\begin{array}{l}\text { Na propriedade ou na propriedade vizinha mais } \\
\text { próxima existem suínos de fundo de quintal? }\end{array}$ & $\begin{array}{l}\text { 0: não possui } \\
\text { 1: possui }\end{array}$ \\
\hline & 1 & $\begin{array}{l}\text { Qual a distância do abatedouro-frigorífico mais } \\
\text { próximo de suínos? }\end{array}$ & $\begin{array}{l}0:>3500 \mathrm{~m} \\
1: 1000 \text { a } 3500 \mathrm{~m} \\
2: 500 \text { a } 999 \mathrm{~m} \\
3:<500 \mathrm{~m}\end{array}$ \\
\hline & 1 & A granja possui cinturão-verde? & $\begin{array}{l}0: \text { sim } \\
1: \text { não }\end{array}$ \\
\hline & 1 & Existem outros animais na propriedade? & $\begin{array}{l}\text { 0: não } \\
\text { 1: sim, espécies que não possuem } \\
\text { doenças importantes comuns com } \\
\text { suínos } \\
\text { 2: sim, espécies que também } \\
\text { podem apresentar PSC (suínos } \\
\text { asselvajados/subsistência) }\end{array}$ \\
\hline & 2 & $\begin{array}{l}\text { Há contato entre estes outros animais e os } \\
\text { suínos da granja? }\end{array}$ & $\begin{array}{l}\text { 0: não } \\
\text { 1: sim, espécies que não possuem } \\
\text { doenças importantes comuns com } \\
\text { suínos } \\
\text { 2: sim, espécies que também } \\
\text { podem apresentar PSC (suínos } \\
\text { asselvajados/subsistência) }\end{array}$ \\
\hline
\end{tabular}




\begin{tabular}{|c|c|c|c|}
\hline \multirow[t]{10}{*}{$\begin{array}{c}\text { Bens e } \\
\text { Instalações }\end{array}$} & 1 & Existe placa de acesso proibido? & $\begin{array}{l}\text { 0: sim } \\
\text { 1: não }\end{array}$ \\
\hline & 2 & $\begin{array}{l}\text { Existe cerca externa ao redor de todas as } \\
\text { instalações? }\end{array}$ & $\begin{array}{l}\text { 0: sim, cerca telada } \\
\text { 1: sim, cerca de arame ou elétrica } \\
\text { 2: não }\end{array}$ \\
\hline & 2 & $\begin{array}{l}\text { O embarque e o desembarque dos animais é } \\
\text { feito por rampa de acesso no perímetro da } \\
\text { cerca? }\end{array}$ & $\begin{array}{l}\text { 0: sim } \\
1: \text { não }\end{array}$ \\
\hline & 2 & $\begin{array}{l}\text { O acesso ao galpão é realizado somente por uma } \\
\text { via, com demarcação clara de zona limpa/suja? }\end{array}$ & $\begin{array}{l}\text { 0: sim, a entrada é via vestuário } \\
\text { com chuveiro } \\
\text { 1: sim, mas a entrada não é via } \\
\text { vestuário com chuveiro } \\
\text { 2: não }\end{array}$ \\
\hline & 1 & A granja possui livro de visitas? & $\begin{array}{l}\text { 0: sim } \\
\text { 1: não }\end{array}$ \\
\hline & 2 & A propriedade possui um quarentenário? & $\begin{array}{l}\text { 0: possui } \\
\text { 1: não possui }\end{array}$ \\
\hline & 2 & Utiliza tela anti-pássaros adequadamente? & $\begin{array}{l}\text { 0: sim } \\
\text { 1: não }\end{array}$ \\
\hline & 2 & $\begin{array}{l}\text { A ração é acondicionada em silo que possibilita } \\
\text { entrega externa à cerca de isolamento da granja? }\end{array}$ & $\begin{array}{l}\text { 0: sim } \\
\text { 1: não }\end{array}$ \\
\hline & 1 & $\begin{array}{l}\text { Existe uma área destinada ao isolamento dos } \\
\text { animais doentes no galpão? }\end{array}$ & $\begin{array}{l}\text { 0: sim } \\
\text { 1: não }\end{array}$ \\
\hline & 1 & $\begin{array}{l}\text { Os locais de tratamento dos dejetos são } \\
\text { protegidos de acesso animal? }\end{array}$ & $\begin{array}{l}\text { 0: sim } \\
\text { 1: não }\end{array}$ \\
\hline \multirow[t]{6}{*}{$\begin{array}{l}\text { Manejo e } \\
\text { controle } \\
\text { sanitário }\end{array}$} & 1 & $\begin{array}{l}\text { Existe a prática de reprodução dos animais na } \\
\text { propriedade? }\end{array}$ & $\begin{array}{l}\text { 0: não } \\
\text { 1: sim, IA ou monta natural com } \\
\text { machos da própria granja } \\
\text { 2: sim, utiliza monta natural com } \\
\text { machos de outras granjas }\end{array}$ \\
\hline & 2 & $\begin{array}{l}\text { Todos os funcionários e visitantes usam calçado } \\
\text { e uniforme exclusivo para ingressar nas } \\
\text { instalações? }\end{array}$ & $\begin{array}{l}\text { 0: sim } \\
1: \text { não }\end{array}$ \\
\hline & 2 & $\begin{array}{l}\text { Todos os funcionários e visitantes tomam banho } \\
\text { para ingressar no galpão? }\end{array}$ & $\begin{array}{l}\text { 0: sim, tanto funcionários quanto } \\
\text { visitantes } \\
\text { 1: não, a prática é aplicada } \\
\text { somente para visitantes } \\
\text { 2: não, nenhuma circunstância }\end{array}$ \\
\hline & 2 & $\begin{array}{l}\text { Os caminhões e veículos que entram na granja } \\
\text { sofrem desinfecção? }\end{array}$ & $\begin{array}{l}\text { 0: sim, ou não entram veículos na } \\
\text { granja (descarregamento de } \\
\text { animais e de ração é pelo } \\
\text { perímetro da cerca) } \\
\text { 1: não }\end{array}$ \\
\hline & 2 & $\begin{array}{l}\text { A introdução de animais na propriedade é feita } \\
\text { sempre mediante testes diagnósticos prévios? }\end{array}$ & $\begin{array}{l}\text { 0: não introduz animais } \\
\text { 1: introduz somente reprodutores } \\
\text { oriundos de GRSC } \\
\text { 2: introduz animais de empresa } \\
\text { integrada, com mesmo status } \\
\text { sanitário } \\
\text { 3: introduz de várias origens }\end{array}$ \\
\hline & 1 & $\begin{array}{l}\text { Há a convivência de vários lotes na } \\
\text { propriedade? }\end{array}$ & $\begin{array}{l}\text { 0: não, todos-dentro-todos-fora } \\
\text { 1: sim }\end{array}$ \\
\hline
\end{tabular}




\begin{tabular}{|c|c|c|}
\hline 1 & Realiza sempre vazio sanitário entre os lotes? & $\begin{array}{l}\text { 0: sim, mínimo de } 7 \text { dias } \\
\text { 1: sim, menos de } 7 \text { dias } \\
\text { 2: não realiza }\end{array}$ \\
\hline 2 & $\begin{array}{l}\text { A mão de obra do quarentenário das instalações } \\
\text { é exclusiva? }\end{array}$ & $\begin{array}{l}\text { 0: sim } \\
\text { 1: não/não possui }\end{array}$ \\
\hline 1 & $\begin{array}{l}\text { Faz controle de insetos e roedores } \\
\text { regularmente? }\end{array}$ & $\begin{array}{l}\text { 0: } \operatorname{sim} \\
\text { 1: as vezes } \\
\text { 2: não }\end{array}$ \\
\hline 2 & $\begin{array}{l}\text { Os funcionários da suinocultura lidam com } \\
\text { outros animais? }\end{array}$ & $\begin{array}{l}\text { 0: não } \\
1: \operatorname{sim}\end{array}$ \\
\hline 2 & $\begin{array}{l}\text { Os funcionários possuem criação de suínos e/ou } \\
\text { bovinos? }\end{array}$ & $\begin{array}{l}\text { 0: não possui } \\
\text { 1: possui }\end{array}$ \\
\hline 2 & $\begin{array}{l}\text { A origem da ração tem controle de qualidade } \\
\text { (comercial ou fábrica de ração institucional)? }\end{array}$ & $\begin{array}{l}\text { 0: Fábrica comercial/integradora } \\
\text { com responsável técnico e } \\
\text { controle de qualidade } \\
\text { 1: Fabricação caseira da ração }\end{array}$ \\
\hline 2 & $\begin{array}{l}\text { É oferecido restos de alimentos/ lavagem aos } \\
\text { suínos? }\end{array}$ & $\begin{array}{l}0: \text { não } \\
1: \operatorname{sim}\end{array}$ \\
\hline 1 & $\begin{array}{l}\text { O transporte da ração é realizado em caminhão } \\
\text { graneleiro? }\end{array}$ & $\begin{array}{l}\text { 0: sim } \\
\text { 1: não, caminhão convencional, } \\
\text { mas com finalidade exclusiva } \\
\text { (não transporta animais) } \\
\text { 2: não, caminhão sem finalidade } \\
\text { exclusiva }\end{array}$ \\
\hline 1 & $\begin{array}{l}\text { Os materiais que ingressam no galpão sempre } \\
\text { sofrem desinfecção? }\end{array}$ & $\begin{array}{l}\text { 0: sim } \\
1: \text { não }\end{array}$ \\
\hline 1 & $\begin{array}{l}\text { É utilizada fonte de superfície para fornecer } \\
\text { água aos animais? }\end{array}$ & $\begin{array}{l}\text { 0: não, somente poço } \\
\text { artesiano/rede pública } \\
1: \operatorname{sim}\end{array}$ \\
\hline 1 & Dá destinação correta aos dejetos? & $\begin{array}{l}\text { 0: sim } \\
\text { 1: não (sem adequação ambiental) }\end{array}$ \\
\hline 1 & $\begin{array}{l}\text { Dá destinação correta às carcaças e restos } \\
\text { animais? (compostagem ou fossa) }\end{array}$ & $\begin{array}{l}\text { 0: sim } \\
1: \text { não }\end{array}$ \\
\hline 2 & $\begin{array}{l}\text { A situação sanitária dos animais é acompanhada } \\
\text { por uma assistência técnica regularmente? }\end{array}$ & $\begin{array}{l}\text { 0: sim, pelo menos } 1 \text { vez a cada } \\
15 \text { dias } \\
\text { 1: sim, pelo menos } 1 \text { vez a cada } \\
\text { mês } \\
\text { 2: sim, menos de uma vez por } \\
\text { mês } \\
\text { 3: não possui }\end{array}$ \\
\hline 2 & $\begin{array}{l}\text { Há a prática de acionar a assistência técnica, } \\
\text { quando identificado algum problema? }\end{array}$ & $\begin{array}{l}\text { 0: sim, mesmo com somente um } \\
\text { animal doente } \\
\text { 1: sim, quando um grupo de } \\
\text { animais adoece. } \\
\text { 2: sim, somente após tentativa de } \\
\text { tratamento próprio } \\
\text { 3: não possui/não aciona }\end{array}$ \\
\hline 1 & $\begin{array}{l}\text { A entrada é restrita a funcionários e técnicos } \\
\text { responsáveis? (não entram familiares alheios, } \\
\text { nem vizinhos) }\end{array}$ & $\begin{array}{l}\text { 0: sim, } \\
1: \text { não }\end{array}$ \\
\hline 2 & $\begin{array}{l}\text { O transporte de animais é realizado em } \\
\text { caminhão exclusivo? }\end{array}$ & $\begin{array}{l}\text { 0: sim, veículo exclusivo para } \\
\text { transporte de suínos da }\end{array}$ \\
\hline
\end{tabular}




\begin{tabular}{ll}
\hline & propriedade \\
& $1:$ sim, veículo exclusivo para \\
& animais da mesma integradora \\
& $2:$ sim, veículo que transporta \\
& suínos de várias propriedades sem \\
& um vínculo comum (empresa) \\
& $3:$ não, veículo sem finalidade \\
& exclusiva \\
\hline $1 \quad$ Os dados zootécnicos são controlados e & $0:$ sim \\
& $1:$ não
\end{tabular}

O sistema incorporou 42 critérios de pontuação e foi aplicado individualmente a cada granja amostrada. A presença de barreiras sanitárias ou ações que protegessem melhor a propriedade da entrada da Peste Suína Clássica foram associadas à pontuação mínima (zero) da escala. Medidas que aumentassem o risco de exposição da granja, receberam pontuações crescentes, considerando o mesmo critério de avaliação. Por exemplo, caso a granja não realizasse o registro de entrada de pessoas em livro de controle de visitas receberia um ponto na avaliação da questão, se tivesse essa prática incorporada à sua rotina não receberia nenhum ponto adicional à sua escala de vulnerabilidade. Em relação a critérios que possuíssem mais de duas categorias de resposta, como a presença de cerca ao redor das instalações, a escala de pontos foi crescente ponto a ponto de acordo com o risco; se a propriedade possuísse cerca externa telada não receberia nenhum ponto na avaliação, caso possuísse outro tipo de cerca, como de arame ou elétrica, a sua nota seria um (1) e se não houvesse nenhuma infraestrutura com esta finalidade, seriam atribuídos dois pontos àquela propriedade. Os pontos de corte das categorias foram baseados nas recomendações técnicas legais nacionais e estaduais vigentes internacionais de referência (BRASIL, 2002; FUNDESA, 2016; SIPS, 2016; FAO, OIE, 2010).

Considerando que nem todas as ações possuem o mesmo peso quanto à proteção e exposição das propriedades, as questões que envolveram manejos já comprovadamente associados a surtos de doenças infecciosas exóticas e que estavam relacionadas às vias de introdução da PSC (BOKLUND et al., 2004; CASAL et al., 2007; ELBERS et al., 1999), como o trânsito animal, a densidade de propriedades nas proximidades, o nível de isolamento das instalações e o contato com outras espécies animais, foram ponderadas de forma a contribuírem mais para a pontuação de vulnerabilidade criada. O peso maior foi atribuído também considerando o perfil da população estudada (DORNELAS, 2015) e o conhecimento das diferenças das propriedades da região que realmente indicavam uma maior preocupação e 
cuidado com a biosseguridade. Por exemplo, de acordo com diretrizes nacionais e internacionais, recomenda-se que a distância de uma suinocultura para a propriedade vizinha seja no mínimo de 500m (FAO, OIE, 2010; SIPS, 2006), para sua melhor proteção. No entanto, as distâncias observadas entre as propriedades rurais nas regiões suinícolas do Rio Grande do Sul costumam ser bem menores. Mais de 50\% das propriedades amostradas apresentaram distâncias menores que 400 metros da propriedade com suínos vizinha. Porém, esta característica produtiva é atualmente justificada pela própria cultura produtiva local de pequenas propriedades rurais, não estando diretamente associada a uma menor preocupação ou cuidado por parte do produtor com questões de biossegurança. Assim, este critério de pontuação não foi enquadrado dentre aqueles que mais influenciariam a escala de comparação de vulnerabilidade, por não se tratar de uma característica com boa discriminação da qualidade da produção e maior risco de introdução de doenças, como a Peste Suína Clássica, na população estudada.

A amplitude do sistema de pontuação, considerando os pesos, foi de 100 pontos (Tabela 2). Os critérios relacionados ao manejo e controle sanitário aplicados na propriedade somaram cerca de $60 \%$ da pontuação máxima do sistema, enquanto aqueles relacionados aos temas de localização e ambiência e bens e instalações apresentaram um menor impacto na escala de vulnerabilidade das granjas, porém equilibrado entre eles. Assumiu-se que o risco de introdução da Peste Suína Clássica nas granjas comerciais do RS poderia estar mais associado aos cuidados e práticas rotineiras na produção, do que a presença de infraestruturas específicas ou a uma determinada localidade no estado. As propriedades que alcançaram uma pontuação maior foram classificadas como mais vulneráveis à introdução do vírus da PSC.

Tabela 2. Pontuação máxima ponderada que cada granja poderia alcançar por tema incluído no sistema de avaliação de vulnerabilidade.

\begin{tabular}{lc}
\hline TEMA & $\begin{array}{c}\text { Pontuação máxima } \\
\text { ponderada }\end{array}$ \\
\hline Localização e ambiência & 22 \\
Bens e instalações & 21 \\
Manejo e controle sanitário & 57 \\
\hline
\end{tabular}




\section{Estimativa dos Riscos Relativos:}

Cada propriedade amostrada alcançou seu valor no sistema de pontuação de vulnerabilidade por meio da soma dos valores atribuídos a cada um dos critérios de avaliação e seus referidos pesos. Para cada tipologia produtiva (UPL, $\mathrm{Tr}, \mathrm{Cr}$ e CC) foi calculada a pontuação média, mínima e máxima alcançadas, assim como os respectivos desvios-padrões e distribuição em percentis.

Para a comparação dos índices de vulnerabilidade média de cada tipologia produtiva, foi simulada a pontuação alcançada por uma Granja de Reprodutores Suídeos Certificada (GRSC), considerando os requisitos para sua classificação em tipo "A" segundo a Instrução Normativa 19 (2002). As GRSC são as únicas granjas que possuem uma legislação específica que orienta e avalia as questões de biosseguridade que devem obrigatoriamente ser implementadas no Brasil (BRASIL, 2002). As demais granjas comerciais possuem orientação técnica e muitas vezes seguem as exigências das empresas integradoras, no entanto, é perceptível a variabilidade dos padrões de biosseguridade nesta população.

Considerando como base de comparação uma granja GRSC padrão tipo “A”, os riscos relativos para cada tipologia produtiva estudada foram calculados pela razão das pontuações alcançadas. Para fins de avaliação da influência dos pesos atribuídos a cada uma das variáveis que incorporaram o sistema de pontuação de vulnerabilidade, os riscos relativos mínimos, máximos e médios foram calculados, considerando a pontuação ponderada e simples.

A análise estatística e a construção do sistema de pontuação foram realizadas com auxílio dos programas Stata ${ }^{\circledR} 12$ (STATACORP, 2011) e Microsoft Excel (MICROSOFT CORPORATION, 2008) que permitiram a construção do banco de dados e obtenção simplificada dos cálculos propostos.

\section{$\underline{\text { Resultados }}$}

No total foram realizadas 188 entrevistas, sendo 82 (44\%) na regional de Estrela, 32 (17\%) em Palmeira das Missões, 29 (15\%) em Santa Rosa, e 45 (24\%) em Erechim (Tabela 3). Dessas propriedades, 132 eram integradas a empresas e 56 eram independentes, sendo que dentre as últimas estão todas as granjas de ciclo completo, 14 UPLs e três terminações da amostra. 
Tabela 3. Estratificação da amostra utilizada para compor o sistema de pontuação de vulnerabilidade das granjas suínas à introdução de PSC por tipologia produtiva.

\begin{tabular}{lcc|cc|ccc|cccc}
\hline \multirow{2}{*}{ REGIONAL } & \multicolumn{10}{c}{ Tipologia Produtiva } \\
\cline { 2 - 11 } & \multicolumn{2}{c}{ UPL } & \multicolumn{1}{c}{ Creche } & \multicolumn{1}{c}{ Terminação } & \multicolumn{2}{c}{ CC } & \multicolumn{2}{c}{ Total } \\
\cline { 2 - 11 } & Ex & $\mathbf{A m}$ & Ex & Am & Ex & Am & Ex & Am & Ex & Am \\
\hline Estrela & 112 & $\mathbf{1 2}$ & 209 & $\mathbf{3 7}$ & 1207 & $\mathbf{2 5}$ & 68 & $\mathbf{8}$ & 1596 & $\mathbf{8 2}$ \\
Palmeira das missões & 57 & $\mathbf{9}$ & 34 & $\mathbf{6}$ & 413 & $\mathbf{1 1}$ & 256 & $\mathbf{6}$ & 760 & $\mathbf{3 2}$ \\
Santa Rosa & 44 & $\mathbf{7}$ & 14 & $\mathbf{3}$ & 456 & $\mathbf{1 0}$ & 82 & $\mathbf{9}$ & 596 & $\mathbf{2 9}$ \\
Erechim & 158 & $\mathbf{1 9}$ & 30 & $\mathbf{2}$ & 469 & $\mathbf{8}$ & 188 & $\mathbf{1 6}$ & 845 & $\mathbf{4 5}$ \\
\hline \multicolumn{1}{c}{ Total } & 371 & $\mathbf{4 7}$ & 287 & $\mathbf{4 8}$ & 2545 & $\mathbf{5 4}$ & 594 & $\mathbf{3 9}$ & 3797 & $\mathbf{1 8 8}$ \\
\end{tabular}

*Ex: Número de granjas existentes; Am: Número de granjas amostradas no cadastro de propriedades da SEAPI/RS no final de 2014.

A amostragem de granjas de ciclo completo com finalidade comercial no estado do RS indicou uma tendência de redução desta tipologia produtiva na suinocultura local. Cerca de $10 \%$ das granjas selecionadas tiveram que ser substituídas durante o processo de visitação por não produzirem mais suínos da maternidade à terminação. A diferença entre o número amostral calculado e o número de granjas efetivamente entrevistadas nesta tipologia é justificada pela ausência de outras propriedades de ciclo completo no município e arredores das inicialmente sorteadas.

As pontuações alcançadas no sistema de avaliação de vulnerabilidade por cada uma das quatro tipologias produtivas estudadas e pelos sistemas produtivos, integrado e independente, estão descritas nas Figuras 2 e 3, respectivamente. A comparação dos valores médios de pontuação (x) obtidos pelas UPL, creches, terminações e granjas de ciclo completo, assim como dos riscos relativos, pela análise de variância indicou diferenças significativas entre as tipologias, com um p-valor $<0,001$ (Tabela 4 e 5). A aplicação do pós-teste de Bonferonni apontou que somente a diferença entre a pontuação média alcançada pelas UPL e as $\operatorname{Tr}$ não foi estatisticamente significativa $(\mathrm{p}=0,17)$. A análise por sistema produtivo indicou melhores condições de biosseguridade entre as granjas integradas $(x=44,3)$ do que entre as independentes $(\mathrm{x}=64,5)(\mathrm{p}<0,001)$. 


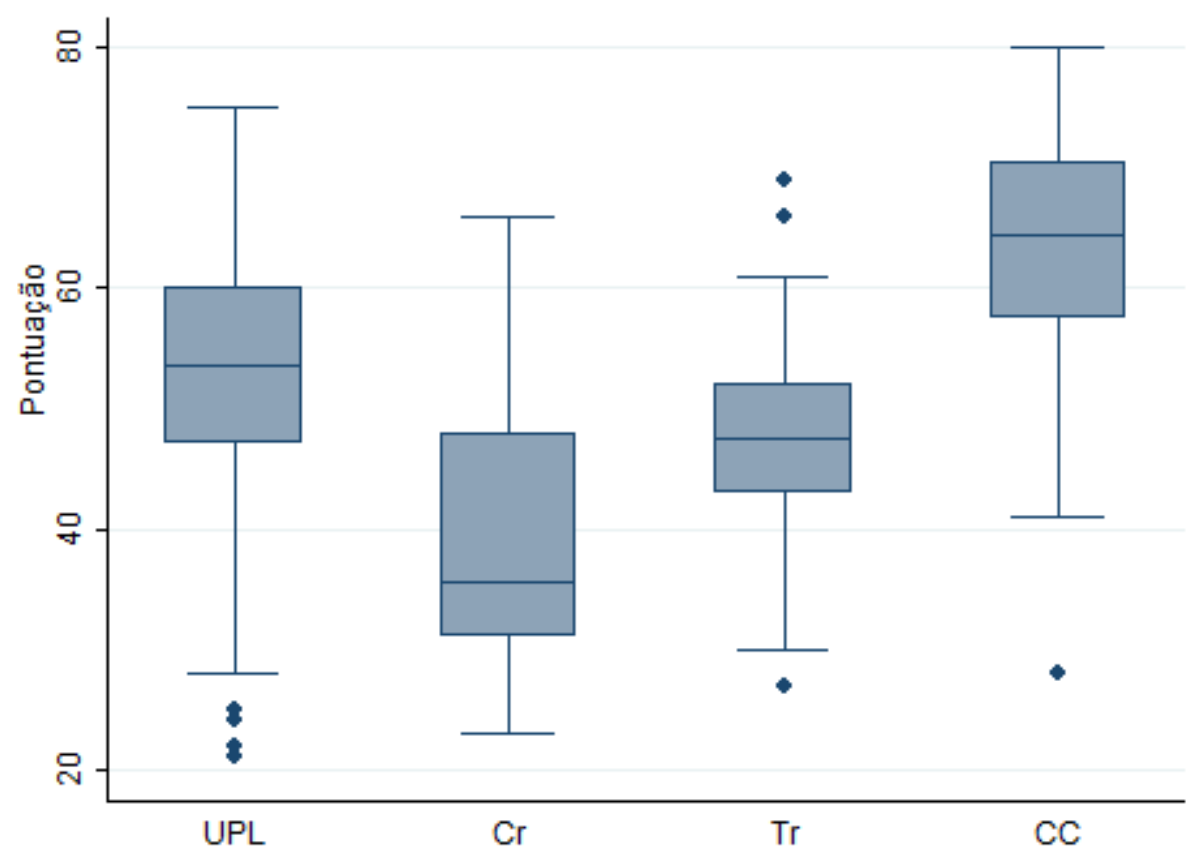

Figura 2. Descrição das pontuações ponderadas alcançadas no sistema de avaliação de vulnerabilidade proposto por tipologia produtiva.

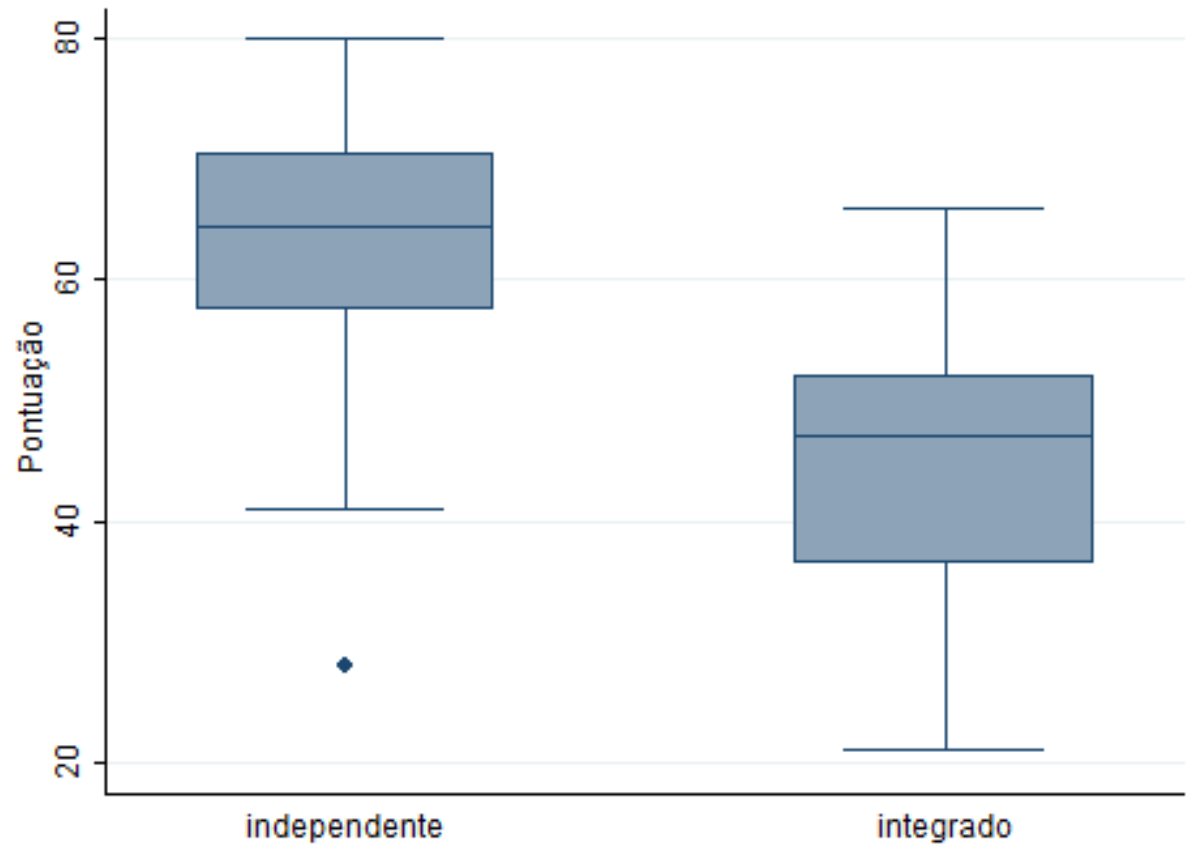

Figura 3. Descrição das pontuações ponderadas alcançadas no sistema de avaliação de vulnerabilidade proposto por sistema produtivo. 
Tabela 4. Pontuações ponderadas alcançadas no sistema de avaliação de vulnerabilidade das granjas à introdução de PSC por tipologia produtiva.

\begin{tabular}{lcccc}
\hline \multirow{2}{*}{ PONTUAÇõES } & \multicolumn{4}{c}{ Tipologia Produtiva } \\
\cline { 2 - 5 } & UPL & Creche & Terminação & CC \\
\hline Mínima & 21 & 23 & 27 & 28 \\
Média & $\mathbf{5 2 , 1}$ & $\mathbf{3 8 , 8}$ & $\mathbf{4 7 , 2}$ & $\mathbf{6 2 , 9}$ \\
Máxima & 75 & 66 & 69 & 80 \\
\hline
\end{tabular}

A granja GRSC tipo “A”, base de comparação para o cálculo dos riscos relativos deste trabalho, somou 14 pontos no sistema de pontuação ponderada proposta. Somaria somente 11 pontos, caso o peso 2 não tivesse sido atribuído a alguns critérios do sistema de pontuação. Os resultados dos cálculos dos riscos relativos para introdução de PSC para as UPL, Cr, Tr e CC, comparadas com a granja GRSC padrão "A”, podem ser visualizados na tabela 5.

Tabela 5. Estimativa dos Riscos Relativos de introdução de Peste Suína Clássica por tipologia produtiva, com e sem atribuição de pesos na escala de avaliação de vulnerabilidade da granja.

\begin{tabular}{ccccc}
\hline \multirow{2}{*}{$\begin{array}{c}\text { TSCOS } \\
\text { RELATIVOS }\end{array}$} & UPL & Creche & Terminação & CC \\
\cline { 2 - 5 } COM PESOS: & & & 1,9 & 2,0 \\
\hline Mínimo & 1,5 & 1,6 & $\mathbf{3 , 4}$ & $\mathbf{4 , 5}$ \\
Médio & $\mathbf{3 , 7}$ & $\mathbf{2 , 8}$ & 4,9 & 5,7 \\
Máximo & 5,4 & 4,7 & & \\
\hline SEM PESOS: & & & 1,6 & 1,9 \\
\hline Mínimo & 1,5 & 1,4 & $\mathbf{2 , 9}$ & $\mathbf{4 , 0}$ \\
Médio & $\mathbf{3 , 4}$ & $\mathbf{2 , 5}$ & 4,2 & 5,1 \\
Máximo & 4,8 & 4,0 & & \\
\hline
\end{tabular}

\section{Discussão e Conclusão}

Observando as pontuações do sistema criado para avaliação de vulnerabilidade das granjas, nota-se a grande diversidade dos padrões de biosseguridade existente na suinocultura comercial do Rio Grande do Sul. Estes resultados corroboram as conclusões da análise descritiva preliminar dos dados (DORNELAS, 2015), propondo um método alternativo semiquantitativo para estimativa das diferenças de risco de introdução do vírus da PSC na 
produção de suínos local, considerando o conjunto de práticas e cuidados aplicados rotineiramente por cada propriedade amostrada.

O sistema integrado de produção apresentou de modo geral menor vulnerabilidade à introdução da PSC do que àquele que segue o mercado spot, sem contratos formais entre agroindústrias, terceiros ou mini-integradores. As granjas integradas apresentaram maior controle de qualidade na fabricação e transporte da ração utilizada, na aquisição e distribuição dos animais, além de possuírem em média mais assistência técnica e melhores condições de isolamento físico, pela presença de cercas teladas ao redor dos galpões e o uso de telas antipássaros. Isto é relevante, já que mais de 90\% (RS, 2014) da produção comercial do estado atualmente é oriunda de granjas integradas. No entanto, é importante salientar que as propriedades independentes fazem parte da cadeia produtiva, ainda que de forma incipiente, e podem comercializar esporadicamente com o sistema integrado pelo fornecimento de leitões (DORNELAS, 2015), indicando um perigo para a suinocultura comercial do Rio Grande do Sul.

Observando os resultados por tipologia produtiva, as creches foram as granjas que apresentaram melhores condições de biosseguridade em todos os tópicos que compuseram o sistema de pontuação e consequentemente foram, em média, as menos vulneráveis à introdução de PSC na escala de avaliação. Vale ressaltar que a subdivisão da produção em múltiplos sítios, incluindo a creche, faz parte de uma suinocultura mais recente e tecnificada, que provavelmente já incorpora uma preocupação maior com a proteção sanitária dos animais e com o estabelecimento de uma medicina preventiva. As terminações demonstraram condições semelhantes às UPL, apesar destas últimas terem obtido um desvio-padrão da pontuação média alcançada $\left(\sigma_{\mathrm{UPL}}=13,4\right)$ ligeiramente maior que as demais $\left(\sigma_{\mathrm{CR}}=10,9 ; \sigma_{\mathrm{T}}=\right.$ 8,12 e $\left.\sigma_{\mathrm{CC}}=10,4\right)$, indicando uma ocorrência menos uniforme das práticas avaliadas. Nas unidades produtoras de leitões a prática do vazio sanitário, o controle de visitantes, a cloração da água e o isolamento das instalações por cerca telada e tela anti-pássaros ainda é menos frequente do que nas demais granjas de produção em múltiplos sítios. As granjas de ciclo completo foram associadas a uma maior vulnerabilidade, pela menor frequência de práticas e infraestruturas básicas que protegem a produção, como o isolamento físico das instalações, o uso de uniforme exclusivo para o trabalho no interior do galpão, o controle rotineiro de roedores e o acompanhamento da produção por técnico especializado. 
Apesar do sistema de pontuação ter sido criado com base apenas em alguns aspectos de biosseguridade, levantados durante a aplicação das entrevistas nas propriedades amostradas, e considerar pesos sem um embasamento quantitativo na literatura científica, suas conclusões sofreram pouca influência desta subjetividade inserida. A retirada dos pesos do sistema de avaliação de vulnerabilidade à introdução de doenças infecciosas reduziu a média das pontuações alcançadas pelas tipologias produtivas, mas as estimativas dos riscos relativos não diferiram significativamente. A escala crescente dos riscos relativos médios entre creches, terminações, UPL e ciclos completos foi mantida, com valores próximos aos estimados considerando a ponderação proposta. Os riscos relativos mínimos e máximos também sofreram pouca influência da metodologia de pontuação adotada, mantendo amplitudes semelhantes às dos resultados considerando o peso, apenas demonstrando de forma menos evidente o possível efeito mais protetor de algumas ações preventivas.

Considerando que a ausência de certos cuidados e a falta de padronização quanto à biosseguridade pode aumentar o risco potencial de introdução e disseminação de doenças na cadeia produtiva de suínos (AMASS; CLARK, 1999; BOKLUND; DAHL; ALBAN, 2013; BOKLUND et al., 2004; LAANEN et al., 2013; RELUN et al., 2015; RIBBENS et al., 2008), o sistema de pontuação ponderado buscou refletir implicações de associações comprovadas entre o manejo e a incidência de algumas doenças comuns na suinocultura (MAES et al , 2008; FRAILE et al , 2010; MEYNS et al , 2011), com foco na introdução da Peste Suína Clássica - PSC (BOKLUND et al., 2009; ELBERS et al., 1999). A compra de animais e outros meios de contato direto e indireto entre diferentes populações são descritos como alguns dos mais importantes fatores de risco de introdução de patógenos na granja (CASAL et al., 2007). Casal et al (2007) já citavam a importância da aplicação de medidas restritivas de acesso e de higiene para o controle de doenças, como a proibição de contato dos tratadores com animais de outras origens, o uso de roupas e botas exclusivas para o interior do galpão e o controle de veículos e visitantes. O número alto de propriedades com animais suscetíveis no perímetro da granja e sua proximidade física com as demais também podem implicar em riscos crescentes para a produção (MINTIENS et al., 2003; ELBERS et al., 1999; BRASIL, 2002) e também foram considerados importantes na avaliação de vulnerabilidade, recebendo um peso maior para estimativa dos riscos.

A utilização de uma escala com nível de mensuração ordinal para uma avaliação de vulnerabilidade para introdução do vírus da PSC pode auxiliar a criação de indicadores de risco e guiar uma avaliação mais objetiva da qualidade da produção de suínos no estado do 
Rio Grande do Sul. Mas, devemos reconhecer os desafios de mensurar uma característica produtiva complexa, que envolve diversas medidas de biosseguridade. As tentativas de quantificar o efeito de cada um de seus componentes sempre terão suas limitações. A estimativa de riscos relativos, com base em resultados de pontuações que sugiram a qualidade de proteção da produção, não pretende calcular riscos absolutos, mas é adequada para a comparação das condições de vulnerabilidade e biosseguridade entre as diversas etapas da produção. Esta análise comparativa sugere o quão mais vulnerável uma tipologia produtiva está em relação às outras, sem necessariamente atribuir os riscos de introdução da doença a cada uma delas.

O estudo demonstra a existência de diferenças significativas na aplicação de medidas de biosseguridade entre os sistemas de produção e as diversas tipologias produtivas comerciais das principais regiões produtoras de suínos do Rio Grande do Sul, destacando a necessidade de melhorias principalmente nas UPL, que são a base de toda a cadeia produtiva exportadora. Além disso, ressalta a importância das estimativas de riscos relativos e a utilidade destas informações para orientação de programas sanitários e de sistemas de vigilância em saúde animal.

Os resultados e métodos aqui apresentados fazem parte da primeira etapa de um projeto que visa avaliar o sistema de vigilância da Peste Suína Clássica na zona livre do Brasil. Os RR alcançados guiarão o cálculo do impacto de cada uma das atividades previstas atualmente para manutenção da condição sanitária alcançada, considerando os diversos estratos da sua população alvo e suas diversidades.

\section{$\underline{\text { Referências }}$}

AMASS, S. F.; CLARK, L. K. Biosecurity considerations for pork production units. Journal of Swine Health and Production, v. 7, n. 5, p. 217-228, 1999.

Associação Brasileira de Proteína Animal (ABPA). Relatório Anual de atividades. 2016. Disponível em: http://abpa-br.com.br/storage/files/versao_final_para_envio_digital_1925a _final_abpa_relatorio_anual_2016_portugues_web1.pdf Acessado em: 21 jun 2016.

BOKLUND, A et al. Comparing the epidemiological and economic effects of control strategies against classical swine fever in Denmark. Preventive veterinary medicine, v. 90, n. 3-4, p. 180-93, 1 ago. 2009. 
BOKLUND, A; DAHL, J.; ALBAN, L. Assessment of confidence in freedom from Aujeszky's disease and classical swine fever in Danish pigs based on serological sampling-effect of reducing the number of samples. Preventive veterinary medicine, v. 110, n. 2, p. 214-22, 1 jun. 2013.

BOKLUND, A. et al. Biosecurity in 116 Danish fattening swineherds: Descriptive results and factor analysis. Preventive Veterinary Medicine, v. 66, n. 1-4, p. 49-62, 2004.

BRASIL. Ministério da Agricultura, Pecuária e Abastecimento. Secretaria de Defesa Agropecuária. Instrução normativa no 19, de 15 de fevereiro de 2002. Ementa: Aprova as Normas a serem cumpridas para a Certificação de Granjas de Reprodutores Suídeos.

CASAL, J. et al. Biosecurity measures on swine farms in Spain: Perceptions by farmers and their relationship to current on-farm measures. Preventive Veterinary Medicine, v. 82, n. 12, p. 138-150, 2007.

DELPHINO, M.K.V.C. Avaliação da biosseguridade das propriedades produtoras de suínos. Relatório. 2009.

DIAS, A. C. et al. Manual Brasileiro de Boas Práticas Agropecuárias na Produção de Suínos. 1a. ed. Concordia: Embrapa Suínos e Aves, 2011.

DORNELAS, M.F. Avaliação da Biossegurança em Granjas Suínas Comerciais do Rio Grande do Sul. 2015. 89p. (Monografia de graduação em Medicina Veterinária) Universidade de Brasília, Brasília, 2015.

ELBERS, A. R. W. et al. The classical swine fever epidemic $1997 \pm 1998$ in the Netherlands : descriptive epidemiology. Preventive veterinary medicine, v. 42, 1999.

FAO; OIE. Good practices for biosecurity in the pig sector. [s.l: s.n.], 2010.

FRAILE, L., ALEGRE, A., LÓPEZ-JIMÉNEZ, R., NOFRARÍAS, M., SEGALÉS, J. Risk factors associated with pleuritis and cranio-ventral pulmonary consolidation in slaughter-ages pigs. The Veterinary Journal, v.184, p. 326-333. 2010.

FUNDESA. Fundo de Desenvolvimento e Defesa Sanitária Animal. Recomendações Básicas de Biosseguridade na Produção de Suínos. Disponível em: 
$\underline{\text { http://www.fundesa.com.br/_arquivos/criterios_basicos_biosseguranca_da_suinocultura.pdf }}$ Acessado em: 11 mai 2016.

GELAUDE, P. et al. Biocheck.UGent: a quantitative tool to measure biosecurity at broiler farms and the relationship with technical performances and antimicrobial use. Poultry science, v. 93, n. 11, p. 2740-51, 2014.

LAANEN, M. et al. Relationship between biosecurity and production/antimicrobial treatment characteristics in pig herds. Veterinary Journal, v. 198, n. 2, p. 508-512, 2013.

MAES, D., SEGAlES, J., MEYNS, T., SIBILA, M., PIETERS, M., HAESEBROUCK, F. Control of Mycoplasma hyopneumoniae infections in pigs. Veterinary Microbiology, v.126, p. 297-309. 2008.

MEYNS, T., VAN STEELANT, J., ROLLY, E., DEWULF, J., HAESEBROUCK, F., MAES, D. A cross-sectional study of risk factors associated with pulmonary lesions in pigs at slaughter. The Veterinary Journal, v.187, p. 388-392. 2011.

MICROSOFT CORPORATION. 2008. Microsoft Office Excel, versão 2007. Parte do Microsoft Office Enterprise 2007.

MINTIENS, K. et al. Risk analysis of the spread of classical swine fever virus through 'neighbourhood infections' for different regions in Belgium. Preventive Veterinary Medicine, v.60 p. 27-36, 2003.

PINTO, C. J.; URCELAY, V. S. Biosecurity practices on intensive pig production systems in Chile. Preventive Veterinary Medicine, v. 59, n. 3, p. 139-145, 2003.

RELUN, A. et al. Multivariate analysis of traditional pig management practices and their potential impact on the spread of infectious diseases in Corsica. Preventive Veterinary Medicine, v. 121, n. 3-4, p. 246-256, 2015.

RIBBENS, S. et al. A survey on biosecurity and management practices in Belgian pig herds. Preventive veterinary medicine, v. 83, n. 3-4, p. 228-41, 17 mar. 2008.

Rio Grande do Sul (RS). Secretaria de Agricultura, Pecuária e Irrigação. Sistema de Vigilância Sanitária na Zona Livre de Peste Suína Clássica. Relatório Anual. 2014 
SERGEANT, ESG, 2009. Epitools epidemiological calculators. AusVet Animal Health Services and Australian Biosecurity Cooperative Research Centre for Emerging Infectious Disease. Disponível em: http://epitools.ausvet.com.au.

SIEKKINEN, K. M.; HEIKKILÄ, J.; TAMMIRANTA, N.; ROSENGREN. H. Measuring the costs of biosecurity on poultry farms: A case study in broiler production in Finland. Acta Vet. Scand., vol 54, n.12, 2012.

SIPS. Sindicato das Indústrias de Produtos Suínos do Rio Grande do Sul. Manual de Procedimentos Sanitários para a Suinocultura. Disponível em: http://www.sips.com.br/relatorio.php?ID=8 Acessado em: 11 mai 2016.

STATACORP. 2011. Stata: Release 12. Statistical Software. College Station, TX: StataCorp LP. 


\section{Capítulo 2}

\section{AVALIAÇÃO DO SISTEMA DE VIGILÂNCIA DA PESTE SUÍNA CLÁSSICA NOS ESTADOS DE SANTA CATARINA E RIO GRANDE DO SUL}

\section{$\underline{\text { Resumo }}$}

O Brasil é o quarto maior produtor e exportador de carne suína do mundo. A maioria das doenças suínas listadas pela OIE é exótica ou já foi erradicada do país. O Programa Nacional de Sanidade dos Suídeos concentra, então, seus esforços em ações de vigilância para a peste suína clássica (PSC), em razão do impacto comercial desta enfermidade. Hoje, a zona livre do país abrange áreas de 16 unidades federativas, recentemente reconhecidas internacionalmente como livres de PSC. As atividades que compõem o sistema de vigilância ativa da doença são: (1) o monitoramento sorológico semestral das granjas de reprodutores; (2) o acompanhamento sorológico das granjas comerciais de suínos; (3) a avaliação sorológica de reprodutores de descarte em abatedouros; e (4) a realização de inquéritos bianuais em criatórios de suínos. O atendimento a notificações de suspeita da doença destaca-se como a principal atividade da vigilância passiva. O objetivo deste trabalho foi desenvolver um método de avaliação quantitativo que comprovasse a eficácia das medidas previstas para a demonstração de ausência da doença e manutenção do status sanitário do país, utilizando inicialmente os dados dos estados do Rio Grande do Sul (RS) e de Santa Catarina (SC). Estes estados concentram cerca de $35 \%$ da população comercial e $70 \%$ da exportação de suínos do país e foram os primeiros a executar e registrar todas as atividades estabelecidas pelo sistema de vigilância da peste suína clássica na zona livre do Brasil. O modelo estocástico foi construído com base na metodologia de descrição por árvores de cenários, usando os dados do sistema de vigilância sorológica aplicada à população comercial de suínos, entre os anos de 2013 e 2015. Foram coletados dados primários sobre medidas de biosseguridade nas várias tipologias de produção da cadeia produtiva de suínos, com vista a calcular riscos relativos de introdução do vírus nas várias etapas da produção. Os atributos priorizados e quantificados foram a sensibilidade e o valor preditivo negativo (VPN) do sistema de vigilância. Os resultados indicaram sensibilidades anuais médias de até $91,1 \%$ e $98,6 \%$, respectivamente para o RS e SC. Ao final dos três anos alcançou-se um VPN superior a 99,5\%, supondo uma prevalência de rebanho de $1 \%$, um risco de introdução da doença durante o ano nesta frequência especificada também de $1 \%$ e uma probabilidade prévia de estar livre da doença desconhecida. Obteve-se um nível de confiança alto na certificação de ambos os estados e pôde-se demonstrar a eficácia das 
medidas implementadas atualmente pelo RS e SC. Na análise de impacto dos componentes do sistema, os dados de vigilância sorológica em reprodutores de descarte nos abatedouros foram os que mais contribuíram para a sensibilidade final. As demais atividades executadas abrangem atualmente um número menor de animais ou são dirigidas a propriedades de baixo risco, o que limita o impacto para a vigilância anual da PSC em toda a população. Os resultados obtidos fornecem subsídios importantes para que as autoridades sanitárias possam otimizar a relação custo-eficácia do sistema de vigilância da PSC.

Palavras-chave: PSC, vigilância sorológica, riscos relativos, árvore de cenários sensibilidade.

\section{Introducão}

O Brasil é atualmente o quarto maior produtor e exportador de carne suína do mundo. Somente no ano de 2015 mais de 3,6 milhões de toneladas de carne suína foram produzidas no país e cerca de 555 mil toneladas, exportadas (ABPA, 2016). A credibilidade e a competitividade do mercado brasileiro no cenário mundial estão diretamente relacionadas ao controle sanitário e às medidas de vigilância estabelecidas para garantir a qualidade da suinocultura no país (FREITAS et al., 2007; STÄRK et al., 2002). O comércio internacional de animais vivos e seus produtos representam uma ameaça potencial significativa de propagação de doenças entre países e importadores exigem comprovações cada vez mais objetivas da situação sanitária do país exportador em relação a certos agentes patogênicos (SCHUPPERS et al., 2012; WTO, 1995).

O Programa Nacional de Sanidade Suína (PNSS) concentra, assim, seus esforços nas doenças que se caracterizam por ter grande poder de difusão, consequências econômicas ou sanitárias graves e repercussão negativa no comércio globalizado. Das doenças da lista de notificação obrigatória da OIE, a doença vesicular dos suínos, a encefalite por vírus Nipah, a síndrome respiratória e reprodutiva suína e a triquinelose nunca foram diagnosticadas no Brasil, sendo consideradas exóticas; e a peste suína Africana encontra-se erradicada desde 1984 (BRASIL, 2016). Desse modo, a enfermidade foco do programa nacional é a Peste Suína Clássica (PSC).

Hoje, todos os estados da região sul, sudeste e centro-oeste do Brasil e alguns estados da região norte ( $\mathrm{AC}, \mathrm{RO}, \mathrm{TO}$ e áreas do $\mathrm{AM})$ e nordeste (BA e $\mathrm{SE}$ ) constituem a zona livre de Peste Suína Clássica (PSC) do país (OIE, 2016) (Figura 1). A vacinação contra a doença é 
proibida há mais de 15 anos e a última notificação de foco nesta região data de 1998, no estado de São Paulo (BRASIL, 2014). As atividades de vigilância são estabelecidas de acordo com as diretrizes de vigilância para PSC da Organização Mundial de Saúde Animal (OIE, 2015a) e preveem um rápido atendimento às notificações de suspeitas e processamento laboratorial das amostras para identificação do agente infeccioso, além de uma série de medidas de acompanhamento sanitário da produção e controle de trânsito animal e de produtos suídeos. Abrangem as populações suínas domésticas e silvestres e englobam etapas de vigilância clínica e sorológica, seguindo um conjunto representativo de medidas de vigilância em zonas livres de PSC (BRASIL, 2009; OIE, 2015a).

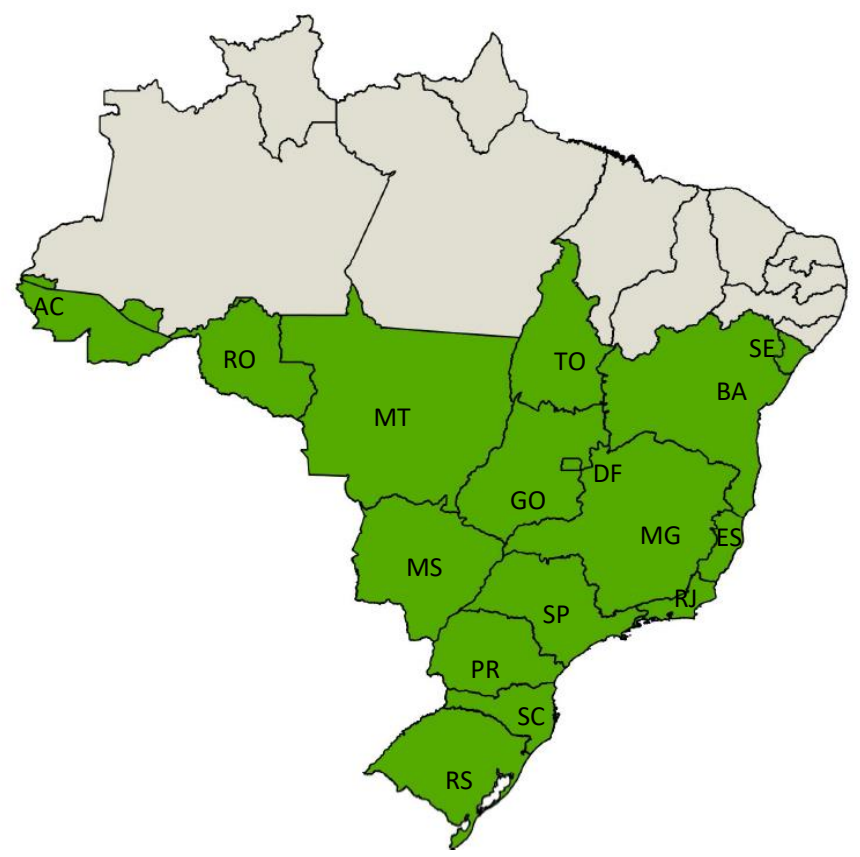

Figura 1. Mapa das regiões livres de Peste Suína Clássica no Brasil (BRASIL, 2010).

Todas estas atividades geram uma série de dados que fundamentam continuamente a manutenção da condição da área livre de PSC, pela ausência sistemática de resultados positivos desde a implantação oficial do sistema de vigilância da doença no Brasil em 2009 (BRASIL, 2009). No entanto, nenhuma avaliação objetiva do sistema, que inclua as evidências técnicas fornecidas pelas atividades executadas, foi ainda realizada.

O uso de métodos cientificamente embasados para avaliar sistemas de vigilância de doenças animais facilita e melhora a credibilidade internacional de uma zona livre, além de reduzir a dependência de inquéritos sorológicos periódicos para tal finalidade. Assim, buscouse desenvolver um modelo analítico estocástico que representasse e avaliasse o Sistema de Vigilância para Peste Suína Clássica no país, focando nos estados do Rio Grande do Sul e Santa Catarina. Objetivou-se também avaliar a eficácia relativa de cada um dos componentes 
de vigilância previstos atualmente, com vista a subsidiar o planejamento e otimização do sistema de vigilância ativa da Peste Suína Clássica.

O trabalho foi desenvolvido em parceria com os órgãos de defesa sanitária dos estados do Rio Grande do Sul e Santa Catarina, a Secretaria de Agricultura do Rio Grande do Sul e a Companhia Integrada de Desenvolvimento Agrícola de Santa Catarina (CIDASC), respectivamente. Estes dois estados compõem aproximadamente $4,5 \%$ da área territorial do Brasil, mas concentram cerca de $35 \%$ da população comercial e $70 \%$ das exportações de suínos do país (ABPA, 2016). Possuem sistemas produtivos bastante semelhantes, baseados numa suinocultura integrada, na qual as agroindústrias de abate e processamento de carne fornecem os insumos, genética, logística e assistência técnica e o produtor se responsabiliza pelas instalações e mão de obra (ABPA, 2016). Encontram-se mais avançados na execução e registro de todas as atividades estabelecidas pelo Sistema de Vigilância da Peste Suína clássica na zona livre do Brasil, e aptos a fornecer dados para uma avaliação quantitativa. $\mathrm{O}$ último foco da doença nesta região ocorreu há 25 anos no Município de Arroio do Meio (RS). No estado de SC, a última ocorrência de PSC foi em 1990 (BRASIL, 2014). Em maio de 2015, os dois estados, antes das demais unidades federativas do país, foram reconhecidos internacionalmente pela Organização Mundial de Saúde Animal (OIE) como livres de Peste Suína Clássica (OIE, 2016).

\section{$\underline{\text { Materiais e Métodos }}$}

\section{Descrição do Sistema de Vigilância da PSC e fonte dos dados utilizados para elaboração do modelo de avaliação nos estados de Santa Catarina e Rio Grande do Sul:}

O conjunto de ações preconizadas pelo Sistema de Vigilância da PSC na zona livre do Brasil é estabelecido na Norma Interna $n^{\circ} 05$ do Departamento de Saúde Animal do Ministério da Agricultura, Pecuária e Abastecimento (Mapa) (BRASIL, 2009). As atividades executadas nos estados de SC e RS foram identificadas e organizadas em cinco componentes de vigilância com a colaboração e apreciação da gerência federal e das estaduais do PNSS, assim como do setor privado da indústria de suínos (Tabela 1). Quatro componentes foram identificados como procedimentos operacionais da vigilância ativa (GUBERTI, STANCAMPIANO, FERRARI, 2014), ou seja, são realizados continuamente ou de forma periódica pelas autoridades veterinárias locais. O outro componente incorporou a sequência de atendimento às notificações de casos suspeitos ao serviço veterinário oficial, usualmente denominada como vigilância passiva (GUBERTI, STANCAMPIANO, FERRARI, 2014). 
Tabela 1. Componentes do Sistema de Vigilância para PSC em SC e no RS.

\begin{tabular}{lcc}
\hline \multicolumn{1}{c}{ COMPONENTE } & População-alvo & Tipo de Vigilância \\
\hline $\begin{array}{l}\text { 1. Monitoramento semestral nas } \\
\text { GRSC }\end{array}$ & Suínos das GRSC & Ativa, Periódica \\
\hline $\begin{array}{l}\text { 2. Acompanhamento sorológico } \\
\text { nas granjas comerciais de suínos }\end{array}$ & Suínos de UPL, CC, Cr & Ativa, Contínua \\
\hline $\begin{array}{l}\text { 3. Avaliação sorológica em } \\
\text { matadouros-frigoríficos }\end{array}$ & Reprodutores de descarte & Ativa, Contínua \\
\hline $\begin{array}{l}\text { 4. Inquéritos bianuais em criatórios } \\
\text { de suínos }\end{array}$ & Suínos de criações de & Ativa, Periódica \\
\hline $\begin{array}{l}\text { 5. Atendimento às notificações de } \\
\text { casos suspeitos ao serviço } \\
\text { veterinário oficial }\end{array}$ & Suínos da zona livre de PSC & Passiva, Contínua \\
\hline
\end{tabular}

${ }^{1}$ GRSC = Granjas de Reprodutores Suídeos Certificadas; UPL= Unidades Produtoras de Leitões; $\mathrm{CC}=$ Granjas de Ciclo Completo; $\mathrm{Cr}=$ Crechários; Tr= Granjas de Terminação

No Brasil, a comercialização e distribuição de suídeos destinados à reprodução somente é permitida quando estes são procedentes de Granjas de Reprodutores Suídeos Certificadas (GRSC). O primeiro componente do sistema de vigilância da PSC na região estudada considera a realização das provas sorológicas semestrais nesta tipologia de granja para fins de certificação de uma série de enfermidades, dentre elas a PSC (BRASIL, 2002). Todas as GRSC ativas do Rio Grande do Sul e Santa Catarina são semestralmente testadas, conforme número amostral de animais apresentado na Instrução Normativa nº19, de 2002 (BRASIL, 2002), sendo em torno de 50 suínos em propriedades com mais de 180 reprodutores e 57 animais, naquelas com mais de 1000 reprodutores. Os animais testados no segundo semestre são escolhidos preferencialmente pela sua não participação nas provas sorológicas na primeira avaliação do ano.

O acompanhamento sorológico nas granjas comerciais de suínos é realizado a partir da comunicação do aumento nas taxas de mortalidade e presença de lesões hemorrágicas suspeitas de PSC pelos médicos veterinários habilitados que prestam assistência aos estabelecimentos de criação de suídeos (Tabela 2). Atualmente nos estados do Rio Grande do 
Sul e de Santa Catarina, a coleta de amostras de soro sanguíneo dos animais para a vigilância ativa da PSC na região é sempre realizada, independentemente da fundamentação clínica da suspeita por parte do serviço oficial. O número de animais a serem amostrados no interior do estabelecimento de criação é estabelecido conforme tamanho da população local pela NI ${ }^{\circ}$ 05, de 2009 (BRASIL, 2009), sendo no máximo 35 animais, numa granja com mais de 600 suínos. As amostras são colhidas na fase de produção que apresentou a suspeita, priorizando a coleta de soro daqueles animais com debilidade orgânica ou com histórico de problemas sanitários e reprodutivos. E todas as instalações e baias existentes devem ter animais testados.

Tabela 2. Limites críticos nas taxas mensais de mortalidade nas granjas comerciais de suínos para comunicação compulsória ao serviço veterinário oficial.

\begin{tabular}{cc}
\hline FASE DE PRODUÇÃO & Taxa de Mortalidade Mensal \\
\hline Reprodutores & $>2 \%$ \\
Leitões de maternidade & $>15 \%$ \\
Leitões de creche & $>7 \%$ \\
Leitões de terminação (sem vazio sanitário) & $>9 \%$ \\
Leitões de terminação (com vazio sanitário) & $>9 \%$ no lote (em 4 meses) \\
\hline
\end{tabular}

Os dados do componente de vigilância em matadouros-frigoríficos são provenientes da coleta de amostra de soro de um reprodutor de descarte por caminhão de carga que chega ao abatedouro com essa categorial animal. Atualmente, a coleta e registro do número de animais amostrados é realizada em estabelecimentos de inspeção federal ou estadual ao longo de todo o ano, porém, sem nenhum registro da repetibilidade das granjas de origem dos animais testados.

O inquérito bianual em criatórios de suínos e avaliação indireta da infecção de animais silvestres é realizado em cada estado da federação de acordo com o planejamento amostral indicado pelo Mapa, considerando a listagem de propriedades de subsistência da região. A amostragem é direcionada, ou seja, baseada em risco, e a escolha das propriedades fica a cargo do serviço veterinário oficial, que deve selecionar preferencialmente aqueles criatórios limítrofes a áreas de reserva ambiental e em regiões de maior risco sanitário de acordo com o plano de contingência para PSC (BRASIL, 2004b; BRASIL, 2009).

Os três componentes da vigilância sorológica aplicadas à população suína comercial do Rio Grande do Sul e Santa Catarina foram considerados no modelo quantitativo de avaliação do sistema: (1) o monitoramento sorológico nas Granjas de Reprodutores Suídeos 
Certificadas (GRSC), realizado semestralmente por amostragem do rebanho efetivo; (2) o acompanhamento das granjas comerciais de suínos desencadeado pela notificação de índices sanitários sugestivos de PSC, em Unidades Produtoras de Leitões (UPL), em Granjas de Ciclo Completo (CC), em Crechários (Cr) e em Granjas de Terminação (Tr); e (3) a vigilância em matadouros-frigoríficos pela avaliação sorológica de reprodutores de descarte encaminhados para abate (BRASIL, 2004b; BRASIL, 2009).

Os dados dos inquéritos bianuais nos criatórios não foram incluídos no sistema de avaliação do sistema, mas pode-se de antemão afirmar que incrementam a confiança na demonstração da ausência da PSC nos dois estados, a cada dois anos. Acrescentam informações a respeito da situação sanitária da população de suínos de subsistência e indiretamente da população de suídeos silvestres, conforme a ausência de resultados positivos nos três levantamentos já realizados, desde o estabelecimento oficial do sistema de vigilância (BRASIL, 2014).

A incorporação da vigilância passiva e clínica em um sistema de avaliação objetivo dependem de muitos fatores, incluindo a probabilidade de ocorrência de sinais clínicos detectáveis nos animais infectados, o conhecimento da doença pelos atores do sistema e sua motivação para notificar, assim como a sensibilidade dos métodos diagnósticos, incluindo a do exame clínico. Portanto, torna-se difícil quantificar sua eficácia e avaliar o seu desempenho em relação à detecção da doença. Assumiu-se que quantificar atributos, como a sensibilidade, da vigilância passiva incorreria em resultados sujeitos a vieses e pouco confiáveis para fornecer informações sobre a situação real de uma infecção na população (HADORN, STÄRK, 2008). Além disso, em um cenário no qual não há indícios de circulação do vírus da Peste Suína Clássica e os animais não são vacinados, a avaliação das principais atividades de vigilância sorológica com a finalidade de comprovação da condição de zona livre da doença é perfeitamente justificável. É provável que as cepas de alta virulência sejam detectadas rapidamente pelo sistema de vigilância clínica, enquanto as de baixa virulência, que podem gerar formas inaparentes da doença, tornam a vigilância sorológica imprescindível para aumentar o nível de confiança na demonstração de ausência da doença (MARTIN et al., 2007).

Foram disponibilizados e utilizados para avaliação do Sistema de Vigilância da PSC nos estados do Rio Grande do Sul e de Santa Catarina os dados de vigilância sorológica destes estados, entre os anos de 2013 e 2015. 


\section{Definição do foco e dos atributos quantificados na avaliação: Sensibilidade e Valor Preditivo Negativo (VPN) do sistema de vigilância}

Nenhuma metodologia encontra-se estabelecida e padronizada para avaliação de sistemas de vigilância em saúde animal (DREWE et al., 2012; GROSBOIS et al., 2015; RISKSUR, 2013). No total, existem 35 atributos descritos na literatura que podem ser avaliados, conforme publicação do grupo de excelência em sistemas de vigilância em saúde animal baseados em risco da União Européia- RISKSUR (RISKSUR, 2013). Todos estão altamente correlacionados, mas podem ser agrupados em quatro grandes categorias: organizacionais, funcionais, de eficácia e econômicos (RISKSUR, 2013). Dentre os mais descritos estão os atributos de eficácia e os econômicos, e a inclusão de cada um deles no sistema de avaliação deve estar diretamente relacionada com os objetivos específicos do sistema de vigilância e da avaliação. Considerando o guia de priorização desenvolvido pelo RISKSUR (2013) e definido como objetivo da avaliação do Sistema de Vigilância da PSC da zona livre do Brasil a demonstração de ausência de doença, os parâmetros do sistema escolhidos para compor o modelo de avaliação foram: a sensibilidade e o VPN. Estes dois atributos são considerados os mais relevantes para esta finalidade de avaliação.

A avaliação da sensibilidade do Sistema de Vigilância para PSC adotado nos estados de Santa Catarina e Rio Grande do Sul seguiu o método proposto por Martin, Cameron e Greiner (2007), que desenvolveram um modelo analítico para múltiplas fontes de dados a partir de sua descrição por árvores de cenários, usando distribuições de probabilidade. Verificou-se que o mapeamento de sistemas de vigilância complexos por árvore de cenários é um método que possui bons parâmetros de objetividade, transparência e praticidade, além de permitir a obtenção de resultados quantitativos e a inclusão de fatores epidemiológicos e econômicos na avaliação final do modelo (MARTIN et al, 2007; STÄRK et al., 2002). Pode incorporar informações oriundas tanto de atividades de vigilância ativa, quanto passiva, assim como de fontes de dados aleatórias ou de amostragens direcionadas, facilitando o alcance de uma boa representatividade na avaliação (MARTIN; CAMERON; GREINER, 2007).

Cada atividade componente do processo de vigilância foi descrita considerando uma possível reintrodução da doença na região estudada, desde a ocorrência da infecção na granja até a detecção do caso, como um conjunto de eventos com probabilidades específicas e uma probabilidade final de correta identificação sorológica da Peste Suína Clássica, como exemplificado nas Figuras 2, 3 e 4. Assim, a sensibilidade de detecção de pelo menos um caso 
positivo, caso a população estivesse infectada, pôde ser calculada para cada Componente do Sistema de Vigilância (SSC) separadamente, tanto para Rio Grande do Sul como para Santa Catarina.

O método empregado baseou-se em duas premissas, que foram confirmadas e estabelecidas para o alcance das conclusões da avaliação do sistema de Vigilância da PSC: (1) os resultados finais do Sistema de Vigilância eram consistentes com a condição de livre da doença da região avaliada (ou seja, todos os animais testados apresentaram sorologia negativa); (2) a especificidade do sistema de vigilância considerada foi de $100 \%$. O primeiro pressuposto é evidente, porque caso houvesse provas credíveis de que a doença estivesse presente, não seria possível demonstrar a sua ausência. A suposição de especificidade perfeita não é crítica já que a metodologia pode ser ajustada para abordar situações em que a especificidade do sistema é inferior a 100\%, no entanto, tem bom embasamento lógico, já que retira de discussão a probabilidade de ocorrência de resultados falsos positivos (MARTIN; CAMERON; GREINER, 2007), que levariam erroneamente a um processo de emergência sanitária. Considerou-se também que testes diagnósticos positivos sem sinais clínicos compatíveis com a doença normalmente são seguidos de investigação epidemiológica complementar até que a possibilidade de circulação do vírus possa ser descartada ou confirmada.

A abordagem descrita por Martin, Cameron e Greiner (2007) também permitiu incorporar o impacto das diferentes tipologias produtivas sob vigilância existentes na área estudada, pela atribuição de Riscos Relativos (RR) distintos para cada origem de dados. Os RR foram ponderados de acordo com a proporção da população alvo da atividade componente, de modo que o somatório dos Riscos Relativos Ajustados (AR) médios multiplicados pelos estratos da população foi igual a um, conforme a fórmula:

$$
\sum_{l=1}^{L}\left(A R_{l} \times \operatorname{PrP}_{l}\right)=1
$$

Onde $L$ é o número de estratos $\operatorname{PrP}_{l}$ a proporção de unidades que se enquadram no estrato $l$.

A sensibilidade de cada SSC (CSe) foi calculada considerando frequências esperadas de doença na população alvo, chamada de prevalência de delineamento ( $\mathrm{P}^{*}$ ) (MARTIN; CAMERON; GREINER, 2007). As prevalências de delineamento foram atribuídas tanto ao nível unitário $\left(\mathrm{P}_{\mathrm{U}}^{*}\right)$, indicando a proporção de animais doentes na população, quanto em nível 
de rebanho $\left(\mathrm{P}_{\mathrm{H}}^{*}\right)$ e foram inseridas no modelo de forma pontual (MARTIN; CAMERON; GREINER, 2007). Para incorporar ao modelo analítico o efeito de agrupamento de casos e quantificar a CSe considerando as diferenças de cada estrato de risco da população, a Efetiva Probabilidade de Infecção (EPI) foi calculada para cada tipologia produtiva de granja sob vigilância, multiplicando a $\mathrm{P}^{*}{ }_{\mathrm{H}}$ pelo AR aplicável (MARTIN; CAMERON; GREINER, 2007).

Para o cálculo das CSe foi necessário inicialmente estimar a probabilidade de uma unidade amostral primária (suíno) ser aleatoriamente escolhida na população e ter um resultado positivo no processo de vigilância ( $\mathrm{CSeU})$, ou seja, no protocolo diagnóstico aplicado. Isto foi obtido pelo produto de todas as probabilidades para cada ramo (da infecção à detecção) da árvore de cenário, e soma subsequente de todos os valores referentes aos ramos com resultado positivo. Nesta etapa também foi considerada a sensibilidade de rebanho $(\mathrm{SeH})$ alcançada em cada granja amostrada, considerando os animais testados. Finalmente, a CSe foi calculada como se segue, estimando a probabilidade de pelo menos uma granja testada no componente desencadear o alerta sanitário:

$$
S e H=1-\left(1-P^{*}{ }_{U} \times C S e U\right)^{n}, \text { tal que } C S e=1-\prod_{j}^{J}\left(1-E P I_{j} \times S e H_{j}\right)
$$

Onde n é o número de unidades amostrais primárias (suínos) de cada granja testada durante o período de avaliação, J é o número de granjas sob vigilância do Componente e $\mathrm{j}$ indica os valores associados à granja específica.

Como no processo de vigilância foram testados vários grupos representativos de $n$ unidades, independentes uns dos outros no que se refere à probabilidade de infecção, a sensibilidade do componente (CSe) foi calculada como a probabilidade de uma ou mais granjas positivas serem detectadas, dado que a população estava infectada.

Sob a hipótese de que todos os SSC do sistema de vigilância são independentes, as CSe foram combinadas para uma sensibilidade global do sistema de vigilância (SSe) usando a seguinte equação, conforme descrito por Martin, Cameron e Greiner (2007):

$$
S S e=1-\prod_{j=1}^{J}\left(1-C S e_{j}\right)
$$

Onde $J$ é o número de componentes do Sistema de Vigilância e $\mathrm{CSe}_{j}$ é a sensibilidade do componente $j$. 
Assim, o poder de detecção de casos pelo sistema de vigilância foi definido como sua sensibilidade e estimado considerando as sensibilidades de todos os seus componentes (HADORN, STÄRK, 2008).

Uma vez obtido o resultado de sensibilidade do sistema de vigilância da PSC no Rio Grande do Sul e em Santa Catarina, foi também estimada uma probabilidade prévia dos estados avaliados estarem livres da doença (prior) e definido o risco de introdução da doença em uma determinada frequência $\left(\mathrm{P}^{*} \mathrm{H}\right)$ durante o período de avaliação (Pintro). Assim, foi possível calcular o Valor Preditivo Negativo para cada período de avaliação (tp) do Sistema de Vigilância de Peste Suína Clássica, considerando a SSe alcançada no mesmo período e aplicando lógica bayesiana, conforme fórmulas abaixo:

$$
P_{\text {inftp }}=\left(1-\text { prior }_{t p-1}\right)+\text { Pintro }_{t p}-\left(\left(1-\text { prior }_{t p-1}\right) \times \text { Pintro }_{t p}\right)
$$

tal que,

$$
V P N=\frac{1-P_{\text {inftp }}}{\left(1-P_{\text {inftp }}\right)+P_{\text {inftp }}\left(1-S S e_{t p}\right)}=\frac{1-P_{\text {inftp }}}{1-P_{\text {inftp }} \times S S e_{t p}}
$$

Onde prior é a probabilidade da população não estar infectada antes da ação de vigilância, $\mathrm{P}_{\text {inf }}$ é a estimativa de infecção ajustada pela probabilidade de introdução durante o período de vigilância, SSe é a sensibilidade do sistema de vigilância alcançada durante o período de avaliação e tp é a indicação do período de avaliação.

O cálculo do VPN do segundo período de avaliação considerou como probabilidade prévia da região estar livre da doença (prior), o resultado do nível de confiança na zona livre alcançado ao final do primeiro período. Assim, foi possível obter níveis de confiança crescentes na certificação da região, pelo acúmulo de resultados negativos ao longo do tempo.

A última etapa da avaliação do sistema de vigilância buscou mensurar o impacto de cada uma das atividades atualmente adotadas para as conclusões obtidas, por meio de simulações no modelo analítico desenvolvido. Testou-se com auxílio de cenários hipotéticos o aumento ou redução das atividades executadas em cada componente, avaliando sua eficiência e eficácia. A construção dos cenários tentou refletir os principais questionamentos dos órgãos de defesa sanitárias do RS e SC quanto à importância de cada componente de vigilância, buscando orientar e sugerir medidas que pudessem otimizar o Sistema de Vigilância da PSC no Brasil. 
A análise dos dados foi realizada usando os programas Microsoft Excel (MICROSOFT CORPORATION, 2008) e @Risk Professional 6.0.1 (PALISADE CORPORATION, 2012), utilizando 10000 interações para cada simulação do modelo proposto.

\section{Período de avaliação e parâmetros inseridos no modelo de avaliação do Sistema de Vigilância da PSC dos estados do Rio Grande do Sul e Santa Catarina}

O período de tempo de avaliação (tp) do sistema de vigilância da PSC nos estados do RS e SC foi definido como anual. As informações sobre os diversos componentes do sistema de vigilância normalmente são compiladas em bancos de dados nesta frequência para transmissão da informação à estância central de defesa sanitária animal (Mapa), e atualmente não permitem a identificação da data específica de realização de cada uma das atividades executadas. Martin, Cameron e Greiner (2007) sugerem avaliações mensais de sistemas de vigilância de doenças de rápida disseminação, como a PSC, porém explicam que a escolha de um tp menor é relevante mais para o estímulo à análise rotineira dos dados e para a divulgação mais frequente dos resultados, não afetando substancialmente as conclusões alcançadas. Os autores descrevem que o processo bayesiano sequencial de revisão dos níveis de confiança na ausência de doença ao longo do tempo produz estimativas finais idênticas de VPN para um mesmo conjunto de dados coletado de forma continuada, independente da sua frequência de agrupamento. Sendo assim, é possível afirmar que a escolha do período anual de avaliação das atividades de vigilância do sistema de vigilância da PSC na zona livre do Brasil, com a finalidade de demonstração de ausência de doença, alcança estimativas finais de confiança na certificação da região estudada semelhantes àquelas geradas considerando o volume de trabalho executado mensalmente (MARTIN; CAMERON; GREINER, 2007).

A prevalência de delineamento atribuída ao nível unitário $\left(\mathrm{P}^{*} \mathrm{U}\right)$, indicando a proporção de animais doentes numa granja infectada, foi de 5\% (MARTIN et al., 2007). Já a prevalência de rebanhos infectados $\left(\mathrm{P}^{*} \mathrm{H}\right)$, caso a doença fosse reintroduzida nos estados do Rio Grande do Sul e Santa Catarina, foi estimada em 1\%, e posteriormente em 0,5\% (MARTIN; CAMERON; GREINER, 2007; MARTIN et al., 2007; BRASIL, 2014).

Os riscos relativos para as diversas tipologias de granja inseridas no sistema de vigilância, em ambos os estados, foram incorporados no sistema de avaliação pela utilização de distribuições de Pert, considerando os aspectos de biosseguridade e a vulnerabilidade à introdução de PSC das granjas do Rio Grande do Sul em estudo realizado em 2015. Delphino 
(2009), em uma avaliação da biosseguridade das propriedades produtoras de suínos no país, já havia indicado uma semelhança entre a suinocultura do RS e SC. Em 2015, foram amostradas aleatoriamente 188 granjas, entre Unidades Produtoras de Leitões (UPL), Crechários (Cr), Terminações (Tr) e Granjas de Ciclo Completo (CC), das regionais de Estrela, Palmeira das Missões, Erechim e Santa Rosa, conforme subdivisão estadual da SEAPI/RS. Estas regionais originam cerca de $60 \%$ da produção de suínos abatidos sob Sistema de Inspeção Federal (SIF) do RS (RS, 2014) e possuem uma boa representatividade em relação às diversas tipologias produtivas existentes, conforme o cadastro de propriedades do órgão oficial (RS, 2014). A partir dos resultados de entrevistas estruturadas aplicadas aos produtores locais criou-se um sistema de pontuação crescente com amplitude total igual a 100 pontos, no qual as granjas com melhores condições de biosseguridade foram relacionadas a um menor valor numérico na escala de vulnerabilidade. Medidas associadas a um maior risco de PSC, como o trânsito animal, a densidade de propriedades na região, o nível de isolamento das instalações e o contato com outros animais, foram ponderadas de forma a contribuírem mais para a diferenciação dos riscos (MAES et al , 2008; FRAILE et al , 2010; MEYNS et al , 2011; BOKLUND et al., 2009; ELBERS et al., 1999; CASAL et al., 2007). Os riscos relativos foram calculados pela razão das pontuações alcançadas por cada tipologia de granja por aquela em média alcançada na mesma escala de vulnerabilidade por uma granja GRSC tipo “A”, padrão de excelência para produção segura segundo a legislação local (BRASIL, 2002). Os valores mínimos, máximos e médios (mais prováveis) obtidos por cada tipologia de granja estudada serviram de base para os parâmetros das distribuições de Pert utilizadas (Tabela 3).

Tabela 3. Parâmetros das distribuições de Pert utilizadas para descrever os RR para infecção por PSC de cada tipologia produtiva existente nas suinoculturas dos estados do RS e SC.

\begin{tabular}{cccc}
\hline TIPO DE & \multirow{2}{*}{ Mínimo } & Mais provável & Máximo \\
GRANJA & & 3,7 & 5,4 \\
\hline UPL & 1,5 & 2,8 & 4,7 \\
Cr & 1,6 & 4,5 & 5,7 \\
CC & 2,0 & 3,4 & 4,9 \\
Tr & 1,9 & \\
\hline
\end{tabular}

Os valores de sensibilidade dos testes diagnósticos previstos pelo Sistema de Vigilância da PSC para o país (BRASIL, 2009), ELISA, como teste de triagem, e vírusneutralização revelada por peroxidase, como confirmatório (OIE, 2014), também foram descritos por meio de distribuições de Pert. Os parâmetros inseridos de valores mínimos, 
máximos e mais prováveis estão apresentados na Tabela 4. O valor mais provável de sensibilidade do ELISA foi de 94\%, descrito por Schroeder et al. (2012) como a porcentagem de amostras positivas corretamente detectadas pelo kit-diagnóstico da marca Idexx Herdchek E2, o mesmo utilizado nos laboratórios oficiais no Brasil. Os valores de sensibilidade da virusneutralização consideraram sua indicação de método sorológico mais sensível e padrão ouro pela revisão científica sobre Peste suína clássica publicada pela EFSA (European Food Safety Authority) (2009). Os mínimos e máximos foram estabelecidos a fim de refletir o nível de incerteza nos valores mais prováveis, com base em opiniões de especialistas envolvidos no processo de vigilância do RS e SC.

Tabela 4. Valores de sensibilidade dos testes diagnósticos inseridos no modelo de avaliação do Sistema de Vigilância da Peste Suína Clássica.

\begin{tabular}{cccc}
\hline \multirow{2}{*}{ TESTE DIAGNÓSTICO } & \multicolumn{3}{c}{ Sensibilidade } \\
\cline { 2 - 4 } & Mínima & Mais provável & Máxima \\
\hline ELISA & 0,90 & 0,94 & 0,990 \\
Vírusneutralização (SN) & 0,95 & 0,98 & 0,995 \\
\hline
\end{tabular}

A probabilidade prévia do RS e de SC estarem livres da PSC (prior), no início de 2013, foi especificada em 0,5. Considerando os resultados finais e a metodologia empregada nos inquéritos para demonstração de ausência de doença realizados no início do processo de certificação como zona livre da doença dos estados, a prior poderia ser estimada em até 0,95, porém optou-se por criar um cenário conservador e de condição sanitária desconhecida para a estimativa do VPN do sistema de vigilância no RS e em SC. Valores elevados de prior proporcionariam uma confiança na ausência de doença alta, independentemente de um bom nível de SSe (MARTIN; CAMERON; GREINER, 2007). O risco de introdução da doença durante o ano (Pintro), nas prevalências de rebanho determinadas, foi considerado constante durante todo o período de avaliação e simulado em $1 \%$. A estimativa deste valor foi baseada na suposição de risco baixo, dado o histórico de mais de 25 anos de ausência de focos na região, assim como as condições sanitária e comercial desfavoráveis das fronteiras internacionais à transmissão e introdução da PSC no Rio Grande do Sul e Santa Catarina (BRASIL, 2014). 


\section{$\underline{\text { Resultados }}$}

Nas figuras 2, 3 e 4 estão representados por árvores de cenários os três componentes da vigilância sorológica do Sistema de Vigilância de PSC nos estados do RS e SC, aplicados à população de suínos comerciais.
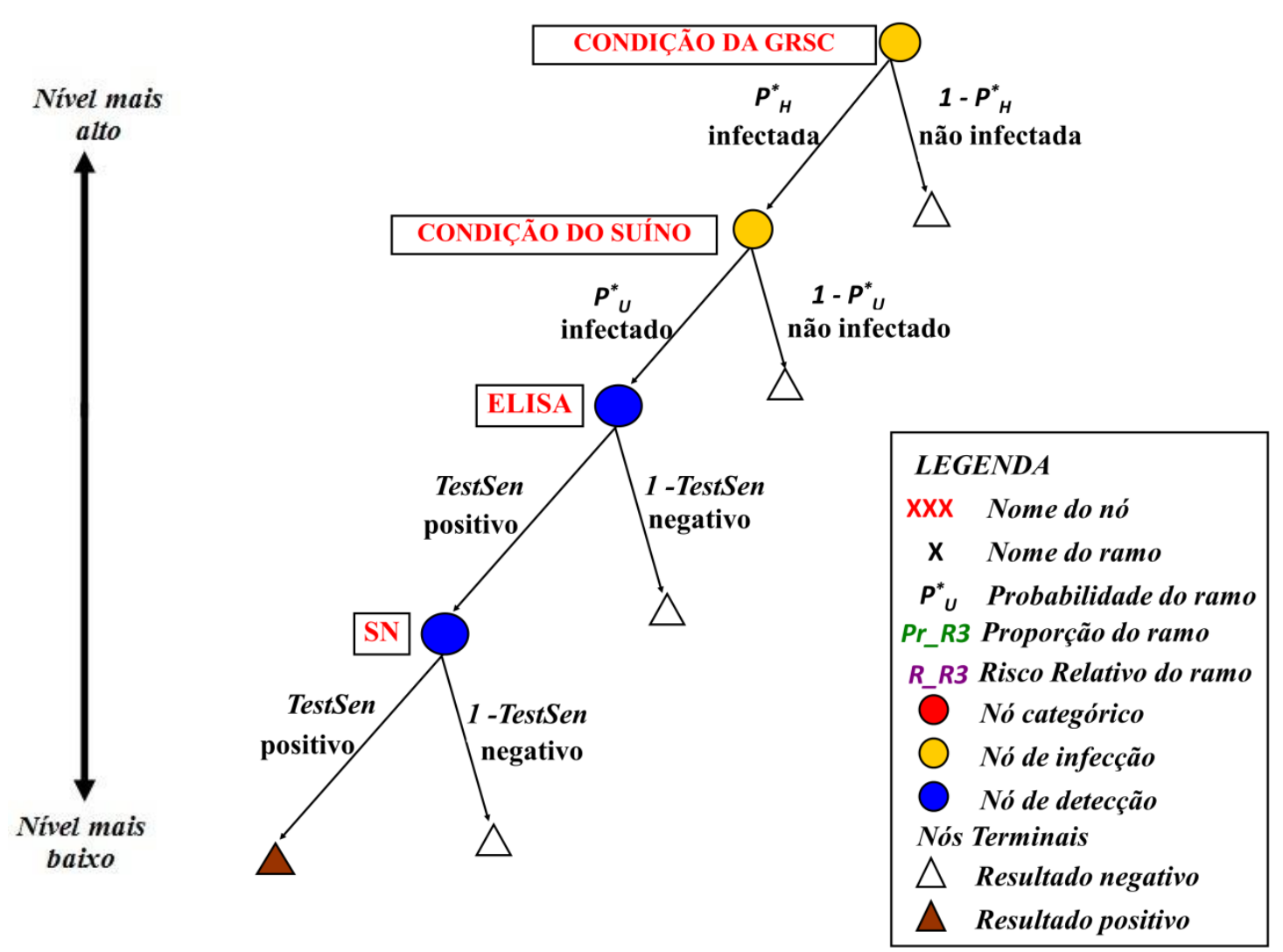

Figura 2. Componente 1 - Esquema gráfico da construção da árvore de cenários do componente de monitoramento semestral das Granjas de Reprodutores Suídeos Certificadas (GRSC).

Para a avaliação do componente 1 (Figura 2), de monitoramento sorológico das GRSC, foram considerados quatro parâmetros para o cálculo da sensibilidade final do componente: a prevalência de delineamento de granjas infectadas $\left(\mathrm{P}^{*} \mathrm{H}\right)$ e de suínos infectados $\left(\mathrm{P}^{*} \mathrm{U}\right)$, dada a reintrodução da PSC na região estudada, e as sensibilidades dos testes diagnósticos previstos pelo Sistema de Vigilância da PSC para do país (BRASIL, 2009), ELISA, como teste de triagem, e vírusneutralização revelada por peroxidase, como confirmatório (OIE, 2014) (Tabela 4). Neste componente de vigilância não foram descritas categorias de risco diferenciadas para a população-alvo, pois se tratam de propriedades muito homogêneas, independentemente da região onde se localizam. Todas as GRSC devem seguir 
uma série de normas sanitárias e de biosseguridade para manter seu certificado para comercialização (BRASIL, 2002) e pequenas variações de medidas de proteção da produção não foram consideradas. A prevalência de animais intra-rebanho utilizada foi de $5 \%$ e a Efetiva Probabilidade de Infecção (EPI) das GRSC foi, em média, de 0,3\% (Tabela 6), considerando a proporção de GRSC existentes nos estados no início do período de avaliação e o RR da tipologia, previamente ajustado (AR) pela $\mathrm{P}^{*} \mathrm{H}$ global de 1\% (BRASIL, 2002; KLINKENBERG et al., 2005; MARTIN et al., 2007).

Durante os anos de 2013 a 2015, as médias anuais de granjas visitadas e amostras coletadas foram de 80 GRSC e 9618 suínos no estado do RS e 165 GRSC e 23808 suínos em SC, respectivamente. A sensibilidade de rebanho $(\mathrm{SeH})$ média anual neste componente em ambos os estados foi próxima a $98 \%$ e as sensibilidades do componente foram estimadas conforme descrito na Tabela 5.

Tabela 5. Dados de vigilância sorológica para Peste Suína Clássica nos estados do Rio Grande do Sul e Santa Catarina, nos anos de 2013 a 2015, referentes ao componente 1 do sistema de vigilância (Monitoramento sorológico nas Granjas de Reprodutores Suídeos Certificadas), dada $\mathrm{P}_{\mathrm{H}}^{*}=1 \%$.

\begin{tabular}{c|cccc|c|cc}
\hline \multirow{2}{*}{ COMPONENTE 1 } & \multicolumn{3}{|c|}{ RS } & \multicolumn{3}{c}{ SC } \\
\cline { 2 - 7 } & 2013 & 2014 & 2015 & 2013 & 2014 & 2015 \\
\hline GRSC monitoradas & 81 & 79 & 78 & 162 & 169 & 166 \\
\hline Suínos testados & 9065 & 10171 & 8308 & 18050 & 21965 & 31408 \\
\hline CSe & $22,7 \%$ & $20,3 \%$ & $19,8 \%$ & $37,1 \%$ & $38,4 \%$ & $38,2 \%$ \\
\hline IC 95\% & {$[18,9-27,8]$} & {$[16,8-24,9]$} & {$[16,4-24,3]$} & {$[31,5-44,5]$} & {$[32,6-45,9]$} & {$[32,5-45,7]$} \\
\hline
\end{tabular}

$\mathrm{Na}$ avaliação do segundo componente do sistema de vigilância, aquele aplicado às granjas comerciais (Figura 3), tornou-se dispensável a inserção na árvore de cenários do componente dos ramos de probabilidade de notificação e fundamentação da suspeita, já que $100 \%$ das comunicações durante o período de avaliação geraram amostras sorológicas para testes laboratoriais conforme descrição do componente e informação transmitida pela SEAPI/RS e pela CIDASC. Porém, foram incorporadas as EPI's dos diferentes tipos de granja envolvidos no processo, considerando as proporções estaduais destas tipologias em relação à população-alvo e os RR ajustados (AR) delas. Os dados inseridos no modelo estão apresentados na Tabela 6. Os resultados das sensibilidades do componente por ano para cada estado estão apresentados na Tabela 7. 


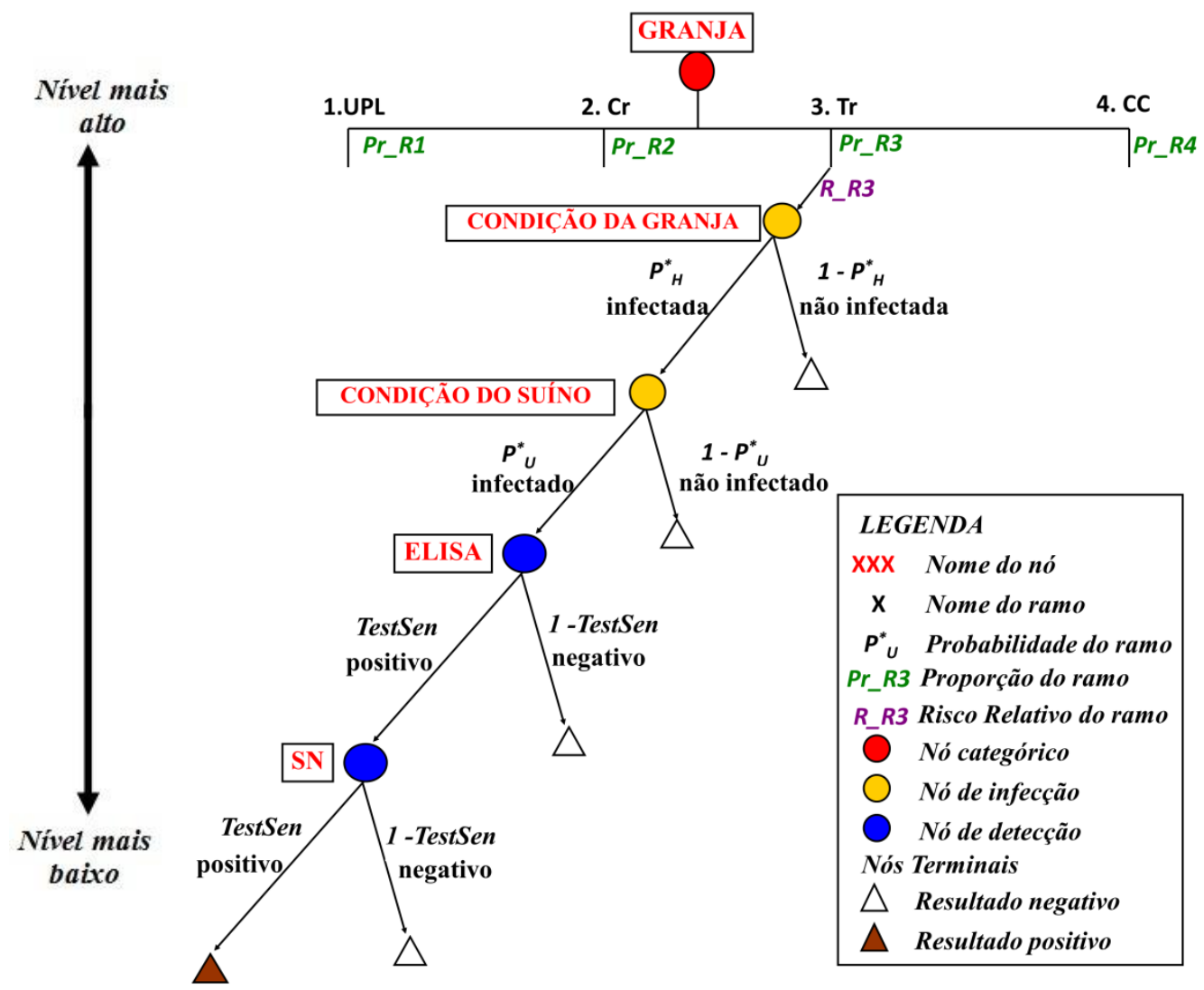

Figura 3. Componente 2 - Esquema gráfico da construção da árvore de cenários do componente de vigilância das Granjas Comerciais de Suínos.

Tabela 6. Dados populacionais da suinocultura comercial dos estados do Rio Grande do Sul e Santa Catarina, no início do período de avaliação, e estimativas das Efetivas Probabilidades de Infecção, dada $\mathrm{P}^{*} \mathrm{H}=1 \%$, os riscos relativos e proporções populacionais de granjas descritas.

\begin{tabular}{c|c|c|c|c|c|c}
\hline \multirow{2}{*}{ TIPOLOGIA } & \multicolumn{4}{|c|}{ RS } & \multicolumn{3}{c}{ SC } \\
\cline { 2 - 7 } DE GRANJA & Existentes & $\%$ & EPI [95\%] & Existentes & $\%$ & EPI [95\%] \\
\hline GRSC & 81 & 1,4 & $\begin{array}{c}0,003 \\
{[0,002-0,0036]}\end{array}$ & 169 & 1,5 & $\begin{array}{c}0,003 \\
{[0,002-0,0037]}\end{array}$ \\
\hline UPL & 605 & 9,8 & $\begin{array}{c}0,011 \\
{[0,006-0,015]}\end{array}$ & 2465 & 22,5 & $\begin{array}{c}0,011 \\
{[0,006-0,014]}\end{array}$ \\
\hline Cr & 373 & 6,0 & $\begin{array}{c}0,008 \\
{[0,005-0,012]}\end{array}$ & 701 & 6,4 & $\begin{array}{c}0,008 \\
{[0,005-0,012]}\end{array}$ \\
\hline CC & 913 & 14,8 & $\begin{array}{c}0,012 \\
{[0,008-0,017]}\end{array}$ & 786 & 7,2 & $\begin{array}{c}0,012 \\
{[0,008-0,017]}\end{array}$ \\
\hline Tr & 4212 & 68,1 & $\begin{array}{c}0,009 \\
{[0,008-0,011]}\end{array}$ & 6830 & 62,4 & $\begin{array}{c}0,009 \\
{[0,008-0,011]}\end{array}$ \\
\hline
\end{tabular}


Tabela 7. Dados de vigilância sorológica para Peste Suína Clássica nos estados do Rio Grande do Sul e Santa Catarina, nos anos de 2013 a 2015, referentes ao componente 2 do sistema de vigilância (Acompanhamento sorológico das granjas comerciais), dada $\mathrm{P}^{*} \mathrm{H}=1 \%$.

\begin{tabular}{c|ccc|c|c|cc}
\hline \multirow{2}{*}{ COMPONENTE 2 } & \multicolumn{3}{|c|}{ RS } & \multicolumn{3}{c}{ SC } \\
\cline { 2 - 8 } & 2013 & 2014 & 2015 & 2013 & 2014 & 2015 \\
\hline Granjas monitoradas & 98 & 78 & 55 & 41 & 30 & 36 \\
\hline Suínos testados & 3254 & 2535 & 1835 & 1382 & 1017 & 1446 \\
\hline Cse & $51,4 \%$ & $42,4 \%$ & $32 \%$ & $27,2 \%$ & $20,7 \%$ & $24,1 \%$ \\
\hline IC 95\% & {$[50,8-52]$} & {$[41,8-42,9]$} & {$[31,6-32,4]$} & {$[25,7-28,9]$} & {$[20,2-21,3]$} & {$[22,2-26,1]$} \\
\hline
\end{tabular}
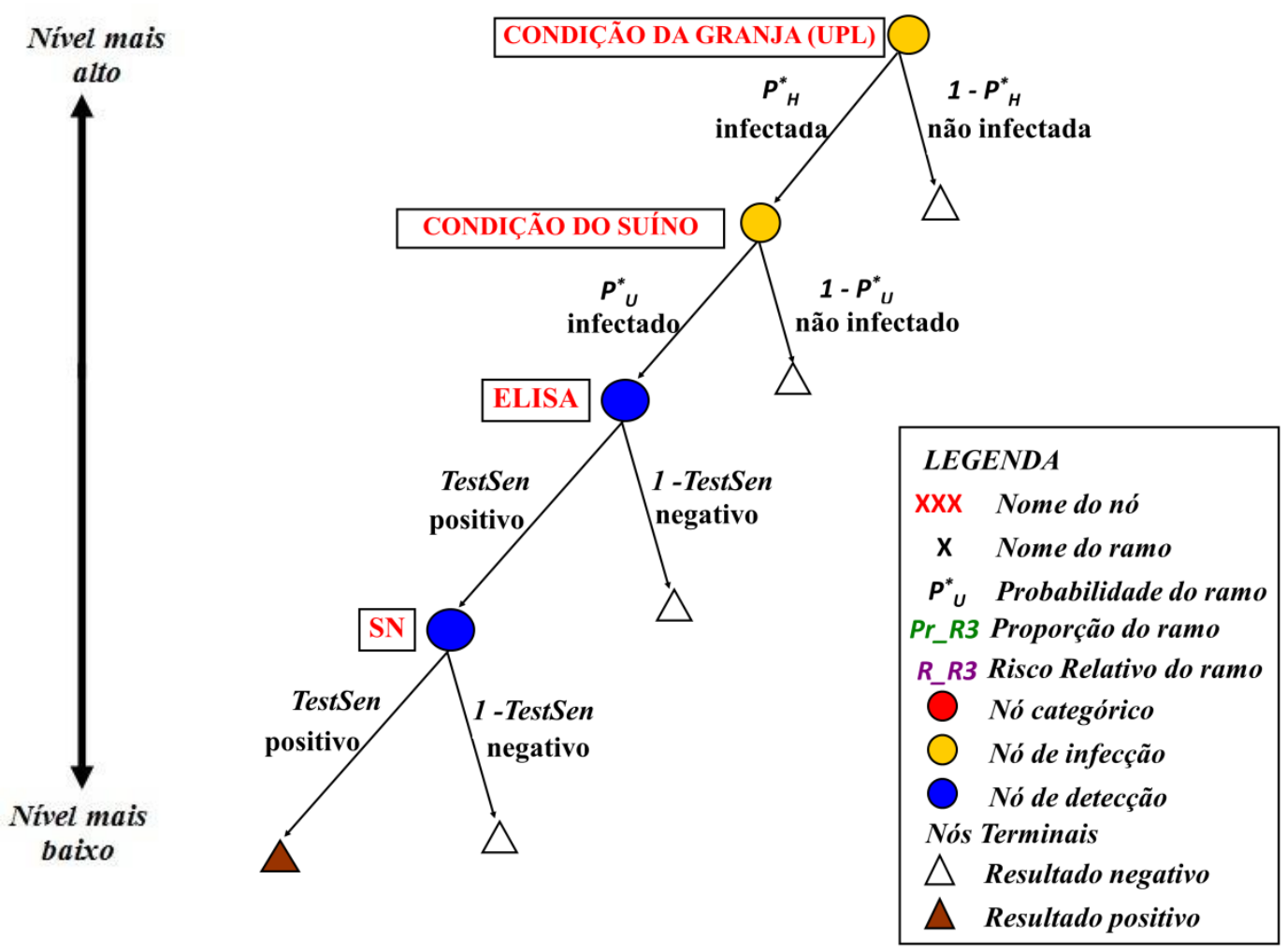

Figura 4. Componente 3 - Esquema gráfico da construção da árvore de cenários do componente de vigilância sorológica de reprodutores de descarte em matadouros-frigoríficos.

Para a avaliação da sensibilidade da vigilância em matadouros-frigoríficos (Figura 4), este foi reconhecido como um componente de vigilância baseado em risco que tem uma maior probabilidade de detecção de casos crônicos, inaparentes ou de baixa virulência, já que possui como população-alvo animais mais velhos, encaminhados para abate e que por algum motivo não têm mais índices reprodutivos adequados (OIE, 2009). O encaminhamento do animal ao abate supôs nenhuma suspeita clínica e ação de vigilância em andamento na 
propriedade, já que a granja estaria interditada para trânsito e abate até o descarte da doença. Para sua estimativa de sensibilidade, utilizamos as mesmas EPI e prevalência de animais $\left(\mathrm{P}^{*} \mathrm{U}\right)$ das granjas UPL, iguais em média a $1,1 \%$ e $5 \%$, respectivamente. Esta tipologia produtiva representa majoritariamente a origem dos reprodutores testados e suas estimativas geram um cenário mais conservador para avaliação da sensibilidade do componente, se comparado à origem em granjas de ciclo completo. A atribuição dos parâmetros estimados para as granjas de ciclo completo simularia uma EPI mais elevada e consequentemente uma probabilidade de detecção da doença ligeiramente maior, caso ela estivesse presente na região, favorecendo o alcance de uma maior sensibilidade para o componente.

Os dados deste componente de vigilância são provenientes da coleta de amostra de soro de um reprodutor de descarte por caminhão de carga que chega ao frigorífico com essa categorial animal, atualmente, sem nenhum controle da repetibilidade das granjas de origem dos animais testados. Apesar dos resultados poderem refletir a situação sanitária recorrente de algumas propriedades que possuem atividade reprodutiva nos estados avaliados, cada uma das amostras foi considerada independente no modelo de avaliação. Assumiu-se que o grau de correlação entre os resultados negativos de uma mesma granja não seria elevado, devido ao curto período de incubação da PSC (2 a 14 dias) (RIDPATH, FLORES, 2007; OIE, 2009) e a periodicidade normalmente maior que duas semanas de encaminhamento de reprodutores para o abate. A mesma granja poderia ser testada novamente no mesmo ano, ou até mesmo no mesmo mês, mas refletiria um novo monitoramento da população-alvo diante de um risco constante de introdução da doença. A sensibilidade de rebanho $(\mathrm{SeH})$ alcançada por cada amostrada coletada foi, então, calculada em $4,6 \%$ e os resultados de sensibilidade deste componete para o RS e SC estão descritos na Tabela 8.

Tabela 8. Dados de vigilância sorológica para Peste Suína Clássica nos estados do Rio Grande do Sul e Santa Catarina, nos anos de 2013 a 2015, referentes ao componente 3 do sistema (Avaliação sorológica em matadouros-frigoríficos).

\begin{tabular}{c|c|c|c|c|cc}
\hline \multirow{2}{*}{ COMPONENTE 3 } & \multicolumn{3}{|c|}{ RS } & \multicolumn{3}{c}{ SC } \\
\cline { 2 - 7 } & 2013 & 2014 & 2015 & 2013 & 2014 & 2015 \\
\hline Suínos testados & 3140 & 2366 & 3044 & 2751 & 4479 & 7546 \\
\hline CSe & $76,4 \%$ & $66,3 \%$ & $75,4 \%$ & $71,8 \%$ & $87,2 \%$ & $96,9 \%$ \\
\hline IC 95\% & {$[75,1-77,7]$} & {$[64,9-67,7]$} & {$[74-76,6]$} & {$[70,4-73,1]$} & {$[86,2-88,2]$} & {$[96,4-97,3]$} \\
\hline
\end{tabular}


As sensibilidades anuais e VPN ao final do período de avaliação do Sistema de Vigilância da PSC nos estados do Rio Grande do Sul e Santa Catarina, considerando apenas os três componentes de vigilância sorológica aplicada à população de suínos comerciais e uma $\mathrm{P}^{*_{\mathrm{H}}}$ igual a $1 \%$, estão descritas na Tabela 9.

Ao final dos três anos de avaliação do Sistema de Vigilância de Peste Suína Clássica nos estados do Rio Grande do Sul e Santa Catarina, o nível de confiança médio da região estar realmente livre da doença (VPN) foi superior a 99,5\%, considerando um risco de introdução da doença durante o ano de $1 \%$ e uma probabilidade prévia de estar livre da doença desconhecida $(\mathrm{P}=0,5)$.

Tabela 9. Sensibilidade anual e VPN ao final do período de avaliação do Sistema de Vigilância de Peste Suína Clássica nos estados do Rio Grande do Sul e Santa Catarina, nos anos de 2013 a 2015, simulando $\mathrm{P}^{*} \mathrm{H}=0,01$.

\begin{tabular}{c|c|c|c|c|c|c}
\hline \multirow{2}{*}{$\begin{array}{c}\text { SISTEMA DE } \\
\text { VIGILÂNCIA }\end{array}$} & \multicolumn{3}{|c|}{ RS } & \multicolumn{3}{c}{ SC } \\
\cline { 2 - 7 } & 2013 & 2014 & 2015 & 2013 & 2014 & 2015 \\
\hline SSE & $91,1 \%$ & $84,5 \%$ & $86,5 \%$ & $87,0 \%$ & $93,7 \%$ & $98,6 \%$ \\
\hline IC 95\% & {$[90,3-92]$} & {$[83,4-85,7]$} & {$[85,5-87,6]$} & {$[85,5-88,7]$} & {$[92,8-94,6]$} & {$[98,2-98,8]$} \\
\hline VPN (\%) (3 anos) & \multicolumn{3}{|c|}{$99,7[99,7-99,8]$} & \multicolumn{3}{c}{$99,97[99,96-99,98]$} \\
\hline
\end{tabular}

A estimativa prévia de ausência da PSC em cada uma das unidades federativas sob estudo igual a 50\%, indicou o Valor Preditivo Negativo (VPN) do Sistema de Vigilância em um cenário pessimista, já que a probabilidade da mesma região estar infectada, considerando os resultados dos inquéritos sorológicos para reconhecimento da zona livre brasileira e a metodologia empregada (BRASIL, 2014), poderia ser estimada abaixo de 0,05. Assim, os índices de confiança nos resultados atuais do sistema de Vigilância hoje poderiam ser alcançados com o conjunto de dados de apenas um ano e valores próximos a 99,9\% em apenas dois anos.

Os resultados da avaliação do impacto de cada um dos componentes do Sistema de Vigilância estão apresentados na Tabela 10. As sensibilidades anuais e o VPN ao final dos três anos foram calculados para sete cenários diferentes, em comparação com os resultados obtidos com o conjunto de dados levantados no período. Os resultados finais consideraram a ausência de componentes, a redução ou aumento das atividades executadas ao final de cada ano, e buscaram refletir os principais questionamentos dos órgãos de defesa sanitária do RS e 
SC, quanto à eficácia e importância de cada componente de vigilância. Observou-se que os dados de vigilância nos abatedouros foram os que mais contribuíram atualmente para alcance do nível de confiança na ausência da PSC nos dois estados. As demais atividades previstas são executadas, atualmente, em pequeno número ou propiciaram um baixo impacto para a certificação da zona livre, por estarem voltadas para algumas poucas propriedades de menor risco (GRSC).

Tabela 10. Sensibilidade anual média e VPN médio ao final período de avaliação do Sistema de Vigilância de Peste Suína Clássica nos estados do Rio Grande do Sul e Santa Catarina em diversos cenários alternativos de composição do sistema, considerando os dados reais dos anos de 2013 a 2015.

\begin{tabular}{|c|c|c|c|c|c|c|c|c|}
\hline \multirow{2}{*}{ SISTEMA DE VIGILÂNCIA } & \multicolumn{3}{|c|}{ RS (\%) } & \multirow{2}{*}{$\begin{array}{l}\mathrm{VPN}(\%) \\
\text { (3anos) }\end{array}$} & \multicolumn{3}{|c|}{ SC (\%) } & \multirow{2}{*}{$\begin{array}{l}\mathrm{VPN}(\%) \\
\text { (3anos) }\end{array}$} \\
\hline & 2013 & 2014 & 2015 & & 2013 & 2014 & 2015 & \\
\hline SSe & 91,1 & 84,5 & 86,5 & 99,6 & 86,9 & 93,7 & 98,5 & 99,97 \\
\hline \multicolumn{9}{|l|}{ Simulações: } \\
\hline 1. Sem o componente 1 & 88,6 & 80,6 & 83,2 & 99,4 & 79,47 & 89,91 & 97,63 & 99,92 \\
\hline 2. Sem componente 2 & 81,7 & 73,03 & 80,1 & 98,7 & 82,07 & 92,06 & 98,06 & 99,95 \\
\hline 3. Sem componente 3 & 62,3 & 53,83 & 45,3 & 90,3 & 53,67 & 50,58 & 52,24 & 89,21 \\
\hline $\begin{array}{l}\text { 4. Monitoramento anual } \\
\text { GRSC }\end{array}$ & 90,9 & 84,21 & 86,2 & 99,6 & 86,43 & 93,49 & 98,47 & 99,97 \\
\hline $\begin{array}{l}\text { 5. Redução de } 50 \% \text { das } \\
\text { amostras componente } 3\end{array}$ & 81,7 & 73,22 & 72,8 & 98,3 & 75,4 & 82,37 & 91,6 & 99,52 \\
\hline $\begin{array}{l}\text { 6. Redução de } 10 \% \text { das } \\
\text { amostras componente } 3\end{array}$ & 89,7 & 82,68 & 84,5 & 99,5 & 85,18 & 92,27 & 97,90 & 99,95 \\
\hline $\begin{array}{l}\text { 7. Redução de } 50 \% \text { das } \\
\text { amostras componente } 2 \text { e } \\
\text { monitoramento anual GRSC }\end{array}$ & 86,6 & 79,2 & 83,4 & 99,3 & 84,3 & 92,7 & 98,25 & 99,96 \\
\hline
\end{tabular}

Os resultados de sensibilidade do sistema (SSe), alterando somente a estimativa da $\mathrm{P}^{*} \mathrm{H}(0,5 \%)$, como base para os cálculos das EPI das tipologias de granjas estudadas são apresentados na Tabela 11. Nota-se que apesar do modelo simular um cenário de mais difícil detecção da PSC pelas atividades de vigilância previstas e alcançar valores médios máximos anuais de sensibilidade de 70,2\% no RS e 91,6\% em SC, a confiança de a região estar livre da doença ao final dos 3 anos de vigilância avaliados continua relativamente alta, acima dos 95\% em ambos os estados. A manutenção de índices de sensibilidade semelhantes aos do último ano de avaliação levaria a valores de VPN próximos a 99,5\% ao final de mais 2 anos de vigilância. 
Tabela 11. Sensibilidade anual e VPN ao final período de avaliação do Sistema de Vigilância de Peste Suína Clássica nos estados do Rio Grande do Sul e Santa Catarina, nos anos de 2013 a 2015, simulando $\mathrm{P}_{\mathrm{H}}=0,005$.

\begin{tabular}{c|c|c|c|c|c|c}
\hline \multirow{2}{*}{$\begin{array}{c}\text { SISTEMA DE } \\
\text { VIGILÂNCIA }\end{array}$} & \multicolumn{3}{|c|}{ RS } & \multicolumn{3}{c}{ SC } \\
\cline { 2 - 7 } SSE & 2013 & 2014 & 2015 & 2013 & 2014 & 2015 \\
\hline IC 95\% & 70,2 & 60,6 & 63,3 & 75,7 & 82,6 & 91,7 \\
\hline VPN (\%) (3 anos) & {$[68,9-71,7]$} & {$[59,2-62,2]$} & {$[61,9-64,8]$} & {$[73,3-78,7]$} & {$[80,7-84,8]$} & {$[90,6-92,9]$} \\
\hline \multicolumn{3}{|c}{$96,1[95,6-96,6]$} & \multicolumn{3}{c}{$99,5[99,3-99,6]$} \\
\hline
\end{tabular}

\section{Discussão}

Vigilância em saúde animal tem sido definida como o conjunto de esforços dispendidos para observar e avaliar o padrão de ocorrência de uma doença e suas eventuais alterações, incluindo ações como a coleta sistemática, análise, interpretação e discussão dos dados levantados (STÄRK et al, 2002; HOINVILLE et al., 2013). O desafio de um sistema de vigilância é sempre maximizar a confiabilidade das informações produzidas considerando a realidade e correta interpretação do processo (GROSBOIS et al, 2015). As suas etapas de avaliação e discussão são o que basicamente a difere de um simples monitoramento da população (STÄRK et al., 2002) e devem frequentemente ser realizadas, para guiar as tomadas de decisão referentes ao sistema aplicado (DREWE et al, 2012).

O modelo proposto de avaliação do Sistema de Vigilância da PSC na zona livre do Brasil, aplicado aos estados de SC e RS, incluiu evidências técnicas e temporais da ausência da doença, e os seus resultados corroboram com a manutenção da condição sanitária dos estados estudados. Demonstra o grau de confiança conferido pela vigilância sorológica hoje executada e a credibilidade da certificação dos estados estudados como zona livre de PSC.

Sabendo que os resultados de uma avaliação quantitativa baseada em estimativas pouco credíveis ou acuradas podem apenas refletir as incertezas inseridas no modelo e não proporcionar a utilização prática das suas conclusões (SOUZA MONTEIRO et. al., 2012), o modelo apresentado foi construído com base em algumas metodologias de análise já bem conceituadas no meio científico e buscou sempre fundamentar seus critérios de escolha. Foram coletados dados primários que guiaram a criação de uma escala de vulnerabilidade das tipologias produtivas existentes na suinocultura dos dois estados e as estimativas dos riscos relativos para introdução da Peste Suína Clássica para cada fase da cadeia produtiva (Capítulo 
1). A parametrização do modelo analítico foi embasada em opiniões técnicas dos especialistas dos órgãos de defesa sanitária local e nacional e grupos de estudo referências na área de vigilância e sanidade suídea. As prevalências de delineamento, aspectos cruciais para obtenção das conclusões, podem ser consideradas conservadoras, dado o histórico de mais de 15 anos de ausência de focos e vacinação no Rio Grande do Sul e Santa Catarina, assim como nas suas fronteiras internacionais (Argentina e Uruguai) (BRASIL, 2014). A utilização de uma $\mathrm{P}_{\mathrm{H}}$ igual a $1 \%$, simulou um cenário pessimista para a atual suscetibilidade da população suína da região (DONAHUE et al., 2012; RIDPATH, FLORES, 2007), e mesmo diante da estimativa de $\mathrm{P}^{*}{ }_{\mathrm{H}}$ menores $(0,5 \%)$, a confiança da região realmente estar livre da doença ao final dos 3 anos de vigilância executados continuou relativamente alta em ambos os estados. A prevalência intra-rebanho também foi inserida considerando um baixo índice de infectividade $(5 \%)$, sendo que numa população extremamente suscetível cepas de alta virulência podem alcançar taxas próximas a 100\% (DONAHUE et al., 2012; RIDPATH, FLORES, 2007).

As simulações dos sete cenários realizadas no modelo de avaliação tiveram como objetivo descrever futuras realidades prática de execução das atividades de vigilância e buscaram reflitir os principais questionamentos acerca da relevância e necessidade de cada um dos componentes hoje estabelecidos. Assim, foi possível visualizar o real impacto de cada um dos componentes de vigilância do sistema para o alcance do nível atual de confiança na ausência da PSC, no RS e em SC. Em ambos os estados, a avaliação sorológica em matadouros-frigoríficos foi o componente do sistema que mais contribuiu para o aumento da sensibilidade global do sistema (SSe). Enquanto, o componente de monitoramento sorológico nas GRSC no RS e o de acompanhamento sorológico nas granjas comerciais em SC foram os que menos interferiram nos resultados finais do modelo de avaliação do sistema de vigilância da PSC. Esta diferença pode ser explicada diretamente pelo número de amostras coletadas e granjas testadas em cada componente nos dois estados. A vigilância desencadeada pela notificação de índices sanitários acima do esperado e suspeitas de lesões hemorrágicas em granjas comerciais foi realizada somente em torno de 35 granjas por ano em SC, sendo que no mesmo período este número representou apenas $25 \%$ das granjas GRSC no estado que sofreram monitoramento sorológico. Apesar das GRSC terem uma Efetiva Probabilidade de Infecção (EPI) mais baixa que as demais granjas inseridas no modelo de avaliação proposto, e consequentemente os seus resultados negativos gerarem um VPN menor para o sistema, o número reduzido de granjas comerciais visitadas das demais tipologias não conseguiu superar 
a sensibilidade alcançada pelo componente 1, nos períodos de avaliação no estado de SC. Já no RS, o número de notificações de suspeitas de PSC que geraram coleta de material sorológico para diagnóstico foi significativamente maior que no estado de SC, e o efeito da amostragem de granjas com maior risco de infecção pôde ser demonstrado pelo alcance de índices de confiança nos resultados negativos mais altos pelo componente 2 do sistema de vigilância.

O número de reprodutores de descarte testados anualmente nos dois estados supera bastante o número de amostras coletadas de forma continuada nas propriedades suinícolas atualmente, estando em torno de 2500 animais no RS e ultrapassando os 7500 em SC. As simulações de redução do número de coletas neste componente por ano foram propostas para verificação da eficiência do sistema (RISKSUR, 2013) e fundamentaram-se na baixa probabilidade da PSC, caso reintroduzida na região, mostrar-se de forma inaparente, pela alta suscetibilidade da população. Este componente é muito importante para a demonstração de ausência de casos subclínicos e crônicos da Peste Suína Clássica (MARTIN et al., 2007), principalmente aqueles oriundos de cepas de baixa virulência, mas poderia estar sendo executado em volume maior do que o necessário para o alcance de VPN semelhantes ao longo do tempo. Assim, observou-se que a redução de $10 \%$ do número de amostras neste componente, que pode equivaler a mais de 750 amostras laboratoriais por ano, ainda resulta em valores preditivos negativos altos ao final de três anos, mesmo com o baixo impacto das demais atividades do sistema de vigilância atualmente.

A simulação do monitoramento sorológico anual nas GRSC, com a redução pela metade do número de amostras coletadas anualmente em cada granja de reprodutores suídeos, trouxe resultados semelhantes para certificação da zona livre, com valores preditivos negativos ao final dos três anos de avaliação bem próximos aos dos resultados finais com o monitoramento semestral, em ambos os estados. Assim, seria alcançado um bom nível de confiança na demonstração de ausência de doença pelo sistema de vigilância hoje implementado com maior simplicidade (CDC, 2001; RISKSUR, 2013), pelo menor aporte financeiro e redução de atenção e tempo despendidos neste componente. Porém, antes de qualquer mudança na forma de execução desta e demais atividades previstas atualmente ser sugerida, cabe ressaltar, que as tomadas de decisão para otimização do Sistema de Vigilância da PSC na zona livre do Brasil devem ser justificadas sempre considerando todos os seus objetivos. Os resultados desta avaliação não devem ser confundidos com a capacidade de detecção precoce da PSC pelo sistema, caso ela fosse reintroduzida no RS ou SC. Esta 
característica está mais associada à sensibilidade da vigilância clínica à campo e aos diversos índices de oportunidade do sistema, como o tempo normalmente decorrido entre o surgimento de sinais clínicos suspeitos da doença e a notificação, entre a notificação e a visita da propriedade, entre o envio do material biológico para o diagnóstico laboratorial e o descarte da suspeita (CDC, 2001; DREWE et al., 2012; RISKSUR, 2013; RODRÍGUEZ-PRIETO et al., 2014). Para melhor orientação de possíveis mudanças no Sistema de Vigilância seria preciso, então, considerar a avaliação de atributos como os últimos sugeridos, em conjunto com os resultados daqueles aqui quantificados.

Os resultados de outro componente que também não devem ser interpretados nesta avaliação associados ao conceito de detecção precoce são os do componente 2. Apesar das sorologias coletadas nas Granjas Comerciais terem seu papel para o alcance de bons índices de confiança na ausência da doença nos estados estudados, contribuem pouco para a obtenção dos resultados finais, não justificando, por exemplo, os esforços dispendidos atualmente em coletas de soro em propriedades cuja suspeita de PSC pode ser clinicamente descartada. Mas, a simulação de redução das coletas neste componente não deve ser confundida com a redução de visitas às propriedades suínas com sinais de doença hemorrágica ou altos índices de mortalidade. Pelo contrário, é possível inclusive afirmar que a vigilância da PSC deve ser reforçada neste componente. Nele vemos o reflexo do número relativamente baixo de suspeitas levantadas por ano em cada um dos estados pela vigilância clínica e passiva, considerando o total da população existente. Os resultados atuais sugerem a necessidade de intensificação das ações de vigilância nas granjas comerciais por parte dos órgãos de defesa sanitária estaduais visando o aumento do número de visitas e registro destas atividades, sem a obrigatoriedade da coleta de sorologias dos animais. Normalmente diante de um cenário de subnotificações de origem passiva, ações de vigilância ativa podem ser consideradas para o incremento da sensibilidade do sistema de vigilância como um todo (HADORN, STÄRK, 2008).

\section{Conclusão}

O sistema de vigilância da PSC na zona livre do Brasil prevê atividades representativas e eficazes para demonstração de ausência da doença, caso sejam rotineiramente aplicadas, como ocorre no RS e em SC. As atividades de vigilância sorológica executadas anualmente por estes estados indicaram índices de sensibilidade suficientes para o alcance de um nível de confiança na ausência de Peste Suína Clássica superior a 99,5\%, ao 
final de três anos de trabalho, supondo uma prevalência de rebanho de 1\%, um risco de introdução da doença durante o ano nesta frequência especificada também de $1 \%$ e uma probabilidade prévia de estar livre da doença desconhecida. O componente de vigilância que mais contribuiu para o alcance de tais resultados foi aquele aplicado em reprodutores de descarte em matadouros-frigoríficos. Os demais geraram um baixo impacto para a certificação da ausência da PSC na região estudada, por serem executados em menor volume ou terem como população-alvo granjas suínas com baixo risco de introdução da doença.

A simulação da sorologia anual nas GRSC, assim como da redução da coleta sorológica nos abatedouros e nas granjas comerciais pelo requisito da fundamentação clínica da suspeita de PSC geraram valores preditivos negativos semelhantes àqueles obtidos, considerando a forma como tais atividades foram executadas ao longo do período de avaliação. A discussão e reestruturação destes componentes poderão aperfeiçoar o sistema de vigilância da peste suína clássica da zona livre do Brasil, quanto ao seu objetivo de demonstração de ausência de doença.

\section{$\underline{\text { Referências }}$}

Associação Brasileira de Proteína Animal (ABPA). Relatório Anual de atividades. 2016. Disponível em: http://abpa-br.com.br/storage/files/versao_final_para_envio_digital_1925a _final_abpa_relatorio_anual_2016_portugues_web1.pdf Acessado em: 21 jun 2016.

BRASIL. Ministério da Agricultura, Pecuária e Abastecimento. Programa Nacional de Sanidade Suídea - PNSS. Disponível em: http://www.agricultura.gov.br/animal/sanidadeanimal/programas/sanidade-suidea. Acessado em: 04 abr 2016.

BRASIL. Ministério da Agricultura, Pecuária e Abastecimento. Secretaria de Defesa Agropecuária. Instrução Normativa no 6, de 22 de fevereiro de 2010. Ementa: Declara zona livre de peste suína clássica as Unidades Federativas do Acre, Bahia, Distrito Federal, Espírito Santo, Goiás, Mato Grosso, Mato Grosso do Sul, Minas Gerais, Paraná, Rio de Janeiro, Rio Grande do Sul, Rondônia, Santa Catarina, São Paulo, Sergipe, Tocantins e os Municípios de Guajará, Boca do Acre, sul do município de Canutama e sudoeste do município de Lábrea, pertencentes ao Estado do Amazonas.

BRASIL. Ministério da Agricultura, Pecuária e Abastecimento. Secretaria de Defesa Agropecuária. Departamento de Saúde Animal. Norma Interna DSA n ${ }^{\circ} 5$ de 2009. Ementa: 
Aprova o manual de procedimentos do sistema de vigilância sanitária na zona livre de peste suína clássica.

BRASIL. Ministério da Agricultura, Pecuária e Abastecimento. Secretaria de Defesa Agropecuária. Application for recognition of a Classical Swine Fever-free Zone covering the States of Rio Grande do Sul and Santa Catarina. Relatório. 2014

BRASIL. Ministério da Agricultura, Pecuária e Abastecimento. Secretaria de Defesa Agropecuária. Instrução Normativa no 47, de 18 de junho de 2004a. Ementa: Aprova o Regulamento Técnico do Programa Nacional de Sanidade Suídea - PNSS.

BRASIL. Ministério da Agricultura, Pecuária e Abastecimento. Secretaria de Defesa Agropecuária. Instrução Normativa no 27, de 20 de abril de 2004b. Ementa: Aprovar o Plano de contingência para peste suína clássica.

BRASIL. Ministério da Agricultura, Pecuária e Abastecimento. Gabinete do Ministro. Instrução Normativa $n^{\circ}$ 6, de 9 de março de 2004c. Ementa: Aprova as Normas para a Erradicação da Peste Suína Clássica a serem observadas em todo o Território Nacional.

BRASIL. Ministério da Agricultura, Pecuária e Abastecimento. Secretaria de Defesa Agropecuária. Instrução normativa n⿳ 19, de 15 de fevereiro de 2002. Ementa: Aprova as Normas a serem cumpridas para a Certificação de Granjas de Reprodutores Suídeos.

BRONSVOORT, B.M.C.; ALBAN,L.; GREINER,M. Quantitative assessment of the likelihood of the introduction of classical swine fever virus into the Danish swine population. Preventive Veterinary Medicine, v.85, p. 226-240, 2008.

CDC. Updated guidelines for evaluating public health surveillance systems: recommendations from the Guidelines Working Group. MMWR Recomm. Rep. 50, p.1-35. 2001.

DONAHUE, B. C. et al. Analysis of clinical samples for early detection of classical swine fever during infection with low, moderate, and highly virulent strains in relation to the onset of clinical signs. Journal of virological methods, v. 179, n. 1, p. 108-15, jan. 2012.

DREWE, J. A. et al. Evaluation of animal and public health surveillance systems: a systematic review. Epidemiology and Infection, v. 140, n. 04, p. 575-590, 2012.

EFSA. EUROPEAN FOOD SAFETY AUTHORITY .KRAMER, M., STAUBACH, C., KOENEN, F., HAEGEMAN, A., POL, F., LE POTIER, M.F., GREISER-WILKE, I (org). 
Scientific report submitted to EFSA: Scientific review on Classical Swine Fever, p.1-92. 2009.

FREITAS, T. R. P. et al. Classical Swine Fever in Brazil: study for the survey of classical swine fever outbreaks in Brazil from 1978 to 2004. Semina: Ciencias Agrarias (Londrina), v. 28 , n. 2, p. 277-286, 2007.

GROSBOIS, V. et al. A rationale to unify measurements of effectiveness for animal health surveillance. Preventive Veterinary Medicine, v. 120, n. 1, p. 70-85, 2015.

GUBERTI, V.; STANCAMPIANO, L. FERRARI, N. Surveillance, monitoring and surveys of wildlife diseases: a public health and conservation approach. Hystrix, the Italian Journal of Mammalogy. 2014. Disponível em: http://www.italian-journal-ofmammalogy.it/article/view/10114/pdf. Acessado em: 05 nov 2014.

HADORN,D.C.; STÄRK, K.D.C. Evaluation and optimization of surveillance systems for rare and emerging infectious diseases. Veterinary Research, v.39,n.6, 12p. 2008.

HOINVILle, L., ALBAN, L., DREWE, J., GIBBENS, J., GUSTAFSON, L., HÄSLER, B., SAEGERMAN, C., SALMAN, M.,STÄRK, K. Proposed terms and concepts for describing and evaluating animal-health surveillance systems. Preventive veterinary medicine, v. 112, 12p. 2013.

KLINKENBERG, D. et al. The effectiveness of classical swine fever surveillance programmes in The Netherlands. Preventive Veterinary Medicine, v. 67, p.19-37, 2005.

MARTIN, P. A J.; CAMERON, A R.; GREINER, M. Demonstrating freedom from disease using multiple complex data sources 1: a new methodology based on scenario trees. Preventive veterinary medicine, v. 79, n. 2-4, p. 71-97, 16 maio 2007.

MARTIN, P.A.J. et al. Demonstrating freedom from disease using multiple complex data sources 2: Case study - Classical swine fever in Denmark. Preventive Veterinary Medicine, v. 79, p.98-115, 2007.

MICROSOFT CORPORATION. 2008. Microsoft Office Excel, versão 2007. Parte do Microsoft Office Enterprise 2007.

OIE. World Organization for Animal Health (OIE). Technical Disease Card: Classical Swine Fever, 2009. Disponível em: 
http://www.oie.int/fileadmin/Home/eng/Animal_Health_in_the_World/docs/pdf/Disease_card s/CLASSICAL_SWINE_FEVER.pdf. Acessado em: 11 mai 2016

OIE. World Organization for Animal Health (OIE). Manual of Diagnostic Tests and Vaccines for Terrestrial Animals,v.2, sessão 2.8, cap. 2.8.3, 2014. Disponível em: http://www.oie.int/fileadmin/Home/eng/Health_standards/tahm/2.08.03_CSF.pdf. Acessado em: 11 mai 2016.

OIE. World Organization for Animal Health (OIE). Terrestrial Animal Health Code, vol.2, sessão $15, \quad$ cap. 15.2, 2015a Disponível em: http://www.oie.int/index.php?id=169\&L=0\&htmfile=chapitre_csf.htm. Acessado em: 11 mai 2016.

OIE. World Organization for Animal Health (OIE).List of CSF free member Counties, 2016. Disponível em: http://www.oie.int/animal-health-in-the-world/official-diseasestatus/classical-swine-fever/list-of-csf-free-member-countries/ .Acessado em: 11 mai 2016.

PALISADE CORPORATION. 2012. @ Risk Professional. Versão 6.0.1. Add-In do Microsoft® Excel para Simulação e Análise de Riscos. Ithaca, NY: Palisade Corporation.

RIDPATH, J.F.; FLORES, E.F. Flaviviridae. In: FLORES, E.F (Org.). Virologia Veterinária, Santa Maria: Ed. Da UFMS, 2007. Cap. 22. p. 563-591.

RISKSUR. The evaluation attributes used for evaluating animal health surveillance systems. Disponível em: <www.fp7-risksur.eu>. Acesso em: 11 maio. 2016.

RODRÍGUEZ-PRIETO, V. et al. Systematic review of surveillance systems and methods for early detection of exotic, new and re-emerging diseases in animal populations. Epidemiology and Infection, p. 1-25, 12 set. 2014.

SCHROEDER, S. et al. Evaluation of classical swine fever virus antibody detection assays with an emphasis on the differentiation of infected from vaccinated animals. Rev .sci. tech. Off. int. Epiz. , v. 31, p. 997-1010, 2012

SCHUPPERS,M.E. et al. Implementing a probabilistic definition of freedom from infection to facilitate trade of livestock: putting theory into praxis for the example of bovine herpes virus1. Preventive Veterinary Medicine, v. 105, p. 195-201, 2012.

SOUZA MONTEIRO, D. M. et al. Robust surveillance of animal diseases: an application to 
the detection of bluetongue disease. Preventive veterinary medicine, v. 105, n. 1-2, p. 1724, 1 jun. 2012.

STÄRK, K. D. C. et al. A review of approaches to quality assurance of veterinary systems for health-status certification. Preventive veterinary medicine, v. 56, n. 2, p. 129-40, 18 dez. 2002.

STÄRK, K.D.C. et al. Concepts for risk-based surveillance in the field of veterinary medicine and veterinary public health: Review of current approaches. BMC Health Serv. Res, v. 6, 20p., 2006.

STÄRK, K.D.C; SALMAN,M.; TEMPELMAN,Y.; KIHN,U. A review of approaches to quality assurance of veterinary systems for health-status certification. Preventive Veterinary Medicine, v. 56, p. 129-140, 2002.

WTO. World Trade Organization (WTO). Agreement on the Application of Sanitary and Phytosanitary Measures. 1995. Disponível em:

https://www.wto.org/english/docs_e/legal_e/15-sps.pdf. Acessado em: 04 fev 2016.

ZEPEDA, C. et al. The role of veterinary epidemiology and veterinary services in complying with the World Trade Organization SPS agreement. Preventive veterinary medicine, v. 67, n. 2-3, p. 125-40, fev. 2005. 


\section{REFERÊNCIAS}

AMASS, S. F.; CLARK, L. K. Biosecurity considerations for pork production units. Journal of Swine Health and Production, v. 7, n. 5, p. 217-228, 1999.

Associação Brasileira de Proteína Animal (ABPA). Relatório Anual de atividades. 2016. Disponível em: http://abpa-br.com.br/storage/files/versao_final_para_envio_digital_1925a _final_abpa_relatorio_anual_2016_portugues_web1.pdf Acessado em: 21 jun 2016.

BOKLUND, A et al. Comparing the epidemiological and economic effects of control strategies against classical swine fever in Denmark. Preventive veterinary medicine, v. 90, n. 3-4, p. 180-93, 1 ago. 2009.

BOKLUND, A; DAHL, J.; ALBAN, L. Assessment of confidence in freedom from Aujeszky's disease and classical swine fever in Danish pigs based on serological sampling-effect of reducing the number of samples. Preventive veterinary medicine, v. 110, n. 2, p. 214-22, 1 jun. 2013.

BOKLUND, A. et al. Biosecurity in 116 Danish fattening swineherds: Descriptive results and factor analysis. Preventive Veterinary Medicine, v. 66, n. 1-4, p. 49-62, 2004.

BRASIL. Ministério da Agricultura, Pecuária e Abastecimento. Programa Nacional de Sanidade Suídea - PNSS. Disponível em: http://www.agricultura.gov.br/animal/ sanidadeanimal/programas/sanidade-suidea. Acessado em: 04 abr 2016.

BRASIL. Ministério da Agricultura, Pecuária e Abastecimento. Secretaria de Defesa Agropecuária. Instrução Normativa no 6, de 22 de fevereiro de 2010. Ementa: Declara zona livre de peste suína clássica as Unidades Federativas do Acre, Bahia, Distrito Federal, Espírito Santo, Goiás, Mato Grosso, Mato Grosso do Sul, Minas Gerais, Paraná, Rio de Janeiro, Rio Grande do Sul, Rondônia, Santa Catarina, São Paulo, Sergipe, Tocantins e os Municípios de Guajará, Boca do Acre, sul do município de Canutama e sudoeste do município de Lábrea, pertencentes ao Estado do Amazonas.

BRASIL. Ministério da Agricultura, Pecuária e Abastecimento. Secretaria de Defesa Agropecuária. Departamento de Saúde Animal. Norma Interna DSA n ${ }^{\circ} 5$ de 2009. Ementa: Aprova o manual de procedimentos do sistema de vigilância sanitária na zona livre de peste suína clássica. 
BRASIL. Ministério da Agricultura, Pecuária e Abastecimento. Secretaria de Defesa Agropecuária. Application for recognition of a Classical Swine Fever-free Zone covering the States of Rio Grande do Sul and Santa Catarina. Relatório. 2014.

BRASIL. Ministério da Agricultura, Pecuária e Abastecimento. Secretaria de Defesa Agropecuária. Instrução Normativa no 47, de 18 de junho de 2004a. Ementa: Aprova o Regulamento Técnico do Programa Nacional de Sanidade Suídea - PNSS.

BRASIL. Ministério da Agricultura, Pecuária e Abastecimento. Secretaria de Defesa Agropecuária. Instrução Normativa no 27, de 20 de abril de 2004b. Ementa: Aprovar o Plano de contingência para peste suína clássica.

BRASIL. Ministério da Agricultura, Pecuária e Abastecimento. Gabinete do Ministro. Instrução Normativa $\mathbf{n}^{\circ}$ 6, de 9 de março de 2004c. Ementa: Aprova as Normas para a Erradicação da Peste Suína Clássica a serem observadas em todo o Território Nacional.

BRASIL. Ministério da Agricultura, Pecuária e Abastecimento. Secretaria de Defesa Agropecuária. Instrução normativa no 19, de 15 de fevereiro de 2002. Ementa: Aprova as Normas a serem cumpridas para a Certificação de Granjas de Reprodutores Suídeos.

BRASIL. Secretaria Nacional de Defesa Agropecuária. Secretaria de Defesa Sanitária Animal. As doenças dos animais no Brasil. Histórico das primeiras observações. - Brasília: SNAD/SDSA, 1988. 101p. Boletim de Defesa Sanitária Animal, número especial.

BRONSVOORT, B.M.C.; ALBAN,L.; GREINER,M. Quantitative assessment of the likelihood of the introduction of classical swine fever virus into the Danish swine population. Preventive Veterinary Medicine, v.85, p. 226-240, 2008.

CANNON, R. M. Demonstrating disease freedom - combining confidence levels. Preventive Veterinary Medicine, v. 52, p. 227-249, 2001

CASAL, J. et al. Biosecurity measures on swine farms in Spain: Perceptions by farmers and their relationship to current on-farm measures. Preventive Veterinary Medicine, v. 82, n. 12, p. 138-150, 2007.

CDC. Updated guidelines for evaluating public health surveillance systems: recommendations from the Guidelines Working Group. MMWR Recomm. Rep. 50, p.1-35. 2001. 
DELPHINO, M.K.V.C. Avaliação da biosseguridade das propriedades produtoras de suínos. Relatório. 2009.

DIAS, A. C. et al. Manual Brasileiro de Boas Práticas Agropecuárias na Produção de Suínos. 1a. ed. Concordia: Embrapa Suinos e Aves, 2011.

DONAHUE, B. C. et al. Analysis of clinical samples for early detection of classical swine fever during infection with low, moderate, and highly virulent strains in relation to the onset of clinical signs. Journal of virological methods, v. 179, n. 1, p. 108-15, jan. 2012.

DORNELAS, M.F. Avaliação da Biossegurança em Granjas Suínas Comerciais do Rio Grande do Sul. 2015. 89p. (Monografia de graduação em Medicina Veterinária) Universidade de Brasília, Brasília, 2015.

DREWE, J. A. et al. Evaluation of animal and public health surveillance systems: a systematic review. Epidemiology and Infection, v. 140, n. 04, p. 575-590, 2012.

EFSA. EUROPEAN FOOD SAFETY AUTHORITY .KRAMER, M., STAUBACH, C., KOENEN, F., HAEGEMAN, A., POL, F., LE POTIER, M.F., GREISER-WILKE, I (org). Scientific report submitted to EFSA: Scientific review on Classical Swine Fever, p.1-92. 2009.

ELBERS, A. R. W. et al. The classical swine fever epidemic $1997 \pm 1998$ in the Netherlands : descriptive epidemiology. Preventive veterinary medicine, v. 42, n. 3-4, p. 157-84, 1999.

FAO; OIE. Good practices for biosecurity in the pig sector. [s.l: s.n.], 2010.

FRAILE, L., ALEGRE, A., LÓPEZ-JIMÉNEZ, R., NOFRARÍAS, M., SEGALÉS, J. Risk factors associated with pleuritis and cranio-ventral pulmonary consolidation in slaughter-ages pigs. The Veterinary Journal, v.184, p. 326-333. 2010.

FREITAS, T. R. P. et al. Classical Swine Fever in Brazil: study for the survey of classical swine fever outbreaks in Brazil from 1978 to 2004. Semina: Ciencias Agrarias (Londrina), v. 28, n. 2, p. 277-286, 2007.

FUNDESA. Fundo de Desenvolvimento e Defesa Sanitária Animal. Recomendações Básicas de Biosseguridade na Produção de Suínos. Disponível em: http://www.fundesa.com.br/_arquivos/criterios_basicos_biosseguranca_da_suinocultura.pdf Acessado em: 11 mai 2016. 
GELAUDE, P. et al. Biocheck.UGent: a quantitative tool to measure biosecurity at broiler farms and the relationship with technical performances and antimicrobial use. Poultry science, v. 93, n. 11, p. 2740-51, 2014.

GROSBOIS, V. et al. A rationale to unify measurements of effectiveness for animal health surveillance. Preventive Veterinary Medicine, v. 120, n. 1, p. 70-85, 2015.

GUBERTI, V.; STANCAMPIANO, L. FERRARI, N. Surveillance, monitoring and surveys of wildlife diseases: a public health and conservation approach. Hystrix, the Italian Journal of Mammalogy. 2014. Disponível em: http://www.italian-journal-ofmammalogy.it/article/view/10114/pdf. Acessado em: 05 nov 2014.

HADORN,D.C.; STÄRK, K.D.C. Evaluation and optimization of surveillance systems for rare and emerging infectious diseases. Veterinary Research, v.39,n.6, 12p. 2008.

HOINVILlE, L., ALBAN, L., DREWE, J., GIBBENS, J., GUSTAFSON, L., HÄSLER, B., SAEGERMAN, C., SALMAN, M.,STÄRK, K. Proposed terms and concepts for describing and evaluating animal-health surveillance systems. Preventive veterinary medicine, v. 112, 12p. 2013.

KLINKENBERG, D. et al. The effectiveness of classical swine fever surveillance programmes in The Netherlands. Preventive Veterinary Medicine, v. 67, p.19-37, 2005.

LAANEN, M. et al. Relationship between biosecurity and production/antimicrobial treatment characteristics in pig herds. Veterinary Journal, v. 198, n. 2, p. 508-512, 2013.

LOHSE, L.; NIELSEN, J.; UTTENTHAL, A. Early pathogenesis of classical swine fever virus (CSFV) strains in Danish pigs. Veterinary microbiology, v. 159, n. 3-4, p. 327-36, 12 out. 2012.

MAES, D., SEGAlES, J., MEYNS, T., SIBILA, M., PIETERS, M., HAESEBROUCK, F. Control of Mycoplasma hyopneumoniae infections in pigs. Veterinary Microbiology, v.126, p. 297-309. 2008.

MARTIN, P. A J.; CAMERON, A R.; GREINER, M. Demonstrating freedom from disease using multiple complex data sources 1: a new methodology based on scenario trees. Preventive veterinary medicine, v. 79, n. 2-4, p. 71-97, 16 maio 2007. 
MARTIN, P.A.J. et al. Demonstrating freedom from disease using multiple complex data sources 2: Case study_Classical swine fever in Denmark. Preventive Veterinary Medicine, v. 79, p.98-115, 2007b.

MEYNS, T., VAN STEELANT, J., ROLLY, E., DEWULF, J., HAESEBROUCK, F., MAES, D. A cross-sectional study of risk factors associated with pulmonary lesions in pigs at slaughter. The Veterinary Journal, v.187, p. 388-392. 2011.

MICROSOFT CORPORATION. 2008. Microsoft Office Excel, versão 2007. Parte do Microsoft Office Enterprise 2007.

MINTIENS, K. et al. Risk analysis of the spread of classical swine fever virus through 'neighbourhood infections' for different regions in Belgium. Preventive Veterinary Medicine, v.60 p. 27-36, 2003.

OIE. World Organization for Animal Health (OIE). Technical Disease Card: Classical Swine $2009 . \quad$ Fever, Disponível em: http://www.oie.int/fileadmin/Home/eng/Animal_Health_in_the_World/docs/pdf/Disease_card S/CLASSICAL_SWINE_FEVER.pdf. Acessado em: 11 mai 2016

OIE. World Organization for Animal Health (OIE). Manual of Diagnostic Tests and Vaccines for Terrestrial Animals, v.2, sessão 2.8, cap. 2.8.3, 2014. Disponível em: http://www.oie.int/fileadmin/Home/eng/Health_standards/tahm/2.08.03_CSF.pdf. Acessado em: 11 mai 2016.

OIE. World Organization for Animal Health (OIE). OIE-Listed diseases, infections and infestations in force in 2016. Disponível em: http://www.oie.int/en/animal-health-in-theworld/oie-listed-diseases-2016/ Acessado em: 11 mai 2016.

OIE. World Organization for Animal Health (OIE). Terrestrial Animal Health Code, vol.2, sessão $15, \quad$ cap. 15.2, 2015a Disponível em: http://www.oie.int/index.php?id=169\&L=0\&htmfile=chapitre csf.htm. Acessado em: 11 mai 2016.

OIE. World Organization for Animal Health (OIE).List of CSF free member Counties, 2016. Disponível em: http://www.oie.int/animal-health-in-the-world/official-diseasestatus/classical-swine-fever/list-of-csf-free-member-countries/ .Acessado em: 11 mai 2016. 
PALISADE CORPORATION. 2012. @ Risk Professional. Versão 6.0.1. Add-In do Microsoft ${ }^{\circledR}$ Excel para Simulação e Análise de Riscos. Ithaca, NY: Palisade Corporation.

PINTO, C. J.; URCELAY, V. S. Biosecurity practices on intensive pig production systems in Chile. Preventive Veterinary Medicine, v. 59, n. 3, p. 139-145, 2003.

RELUN, A. et al. Multivariate analysis of traditional pig management practices and their potential impact on the spread of infectious diseases in Corsica. Preventive Veterinary Medicine, v. 121, n. 3-4, p. 246-256, 2015.

RIBBENS, S. et al. A survey on biosecurity and management practices in Belgian pig herds. Preventive veterinary medicine, v. 83, n. 3-4, p. 228-41, 17 mar. 2008.

RIBBENS, S., DEWULF, J., KOENEN, F., LAEVENS, H., de KRUIF, A. Transmission of classical swine fever.A review. Vet.Q., v. 26, p.146-155. 2004.

RIDPATH, J.F.; FLORES, E.F. Flaviviridae. In: FLORES, E.F (Org.). Virologia Veterinária, Santa Maria: Ed. Da UFMS, 2007. Cap. 22. p. 563-591.

Rio Grande do Sul (RS). Secretaria de Agricultura, Pecuária e Irrigação. Sistema de Vigilância Sanitária na Zona Livre de Peste Suína Clássica. Relatório Anual. 2014

RISKSUR. The evaluation attributes used for evaluating animal health surveillance systems. Disponível em: <www.fp7-risksur.eu>. Acesso em: 11 maio. 2016.

RODRÍGUEZ-PRIETO, V. et al. Systematic review of surveillance systems and methods for early detection of exotic, new and re-emerging diseases in animal populations. Epidemiology and Infection, p. 1-25, 12 set. 2014.

SCHROEDER, S. et al. Evaluation of classical swine fever virus antibody detection assays with an emphasis on the differentiation of infected from vaccinated animals. Rev .sci. tech. Off. int. Epiz. , v. 31, p. 997-1010, 2012

SCHUPPERS,M.E. et al. Implementing a probabilistic definition of freedom from infection to facilitate trade of livestock: putting theory into praxis for the example of bovine herpes virus1. Preventive Veterinary Medicine, v. 105, p. 195-201, 2012. 
SERGEANT, ESG, 2009. Epitools epidemiological calculators. AusVet Animal Health Services and Australian Biosecurity Cooperative Research Centre for Emerging Infectious Disease. Disponível em: http://epitools.ausvet.com.au.

SIEKKINEN, K. M.; HEIKKILÄ, J.; TAMMIRANTA, N.; ROSENGREN. H. Measuring the costs of biosecurity on poultry farms: A case study in broiler production in Finland. Acta Vet. Scand., vol 54, n.12, 2012.

SIPS. Sindicato das Indústrias de Produtos Suínos do Rio Grande do Sul. Manual de Procedimentos Sanitários para a Suinocultura Disponível em: http://www.sips.com.br/relatorio.php?ID=8 Acessado em: 11 mai 2016.

SOUZA MONTEIRO, D. M. et al. Robust surveillance of animal diseases: an application to the detection of bluetongue disease. Preventive veterinary medicine, v. 105, n. 1-2, p. 1724, 1 jun. 2012.

STÄRK, K. D. C. et al. A review of approaches to quality assurance of veterinary systems for health-status certification. Preventive veterinary medicine, v. 56, n. 2, p. 129-40, 18 dez. 2002.

STÄRK, K.D.C. et al. Concepts for risk-based surveillance in the field of veterinary medicine and veterinary public health: Review of current approaches. BMC Health Serv. Res, v. 6, 20p., 2006.

STATACORP. 2011. Stata: Release 12. Statistical Software. College Station, TX: StataCorp LP.

WTO. World Trade Organization (WTO). Agreement on the Application of Sanitary and Phytosanitary Measures. 1995. Disponível em:

https://www.wto.org/english/docs_e/legal_e/15-sps.pdf . Acessado em: 04 fev 2016.

ZEPEDA, C. et al. The role of veterinary epidemiology and veterinary services in complying with the World Trade Organization SPS agreement. Preventive veterinary medicine, v. 67, n. 2-3, p. 125-40, fev. 2005. 
ANEXOS

ENTREVISTA - Avaliação da Biosseguridade das propriedades produtoras de suínos

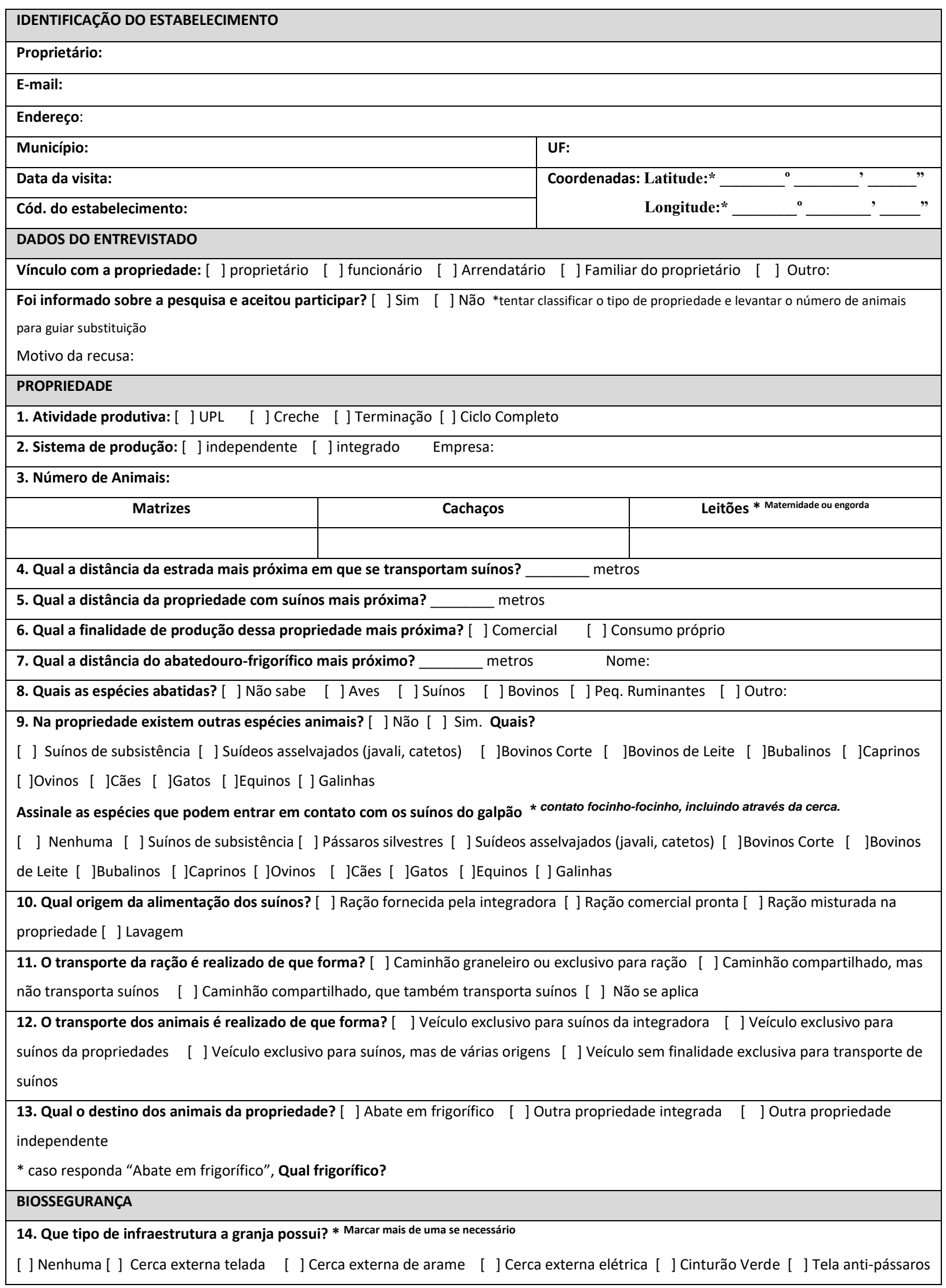


adequada( malha no 2, sem falhas) [ ] Rampa de embarque/desembarque no perímetro da cerca [ ] Silo que possibilita descarregamento externo à cerca [ ] Escritório [ ] Vestuário com chuveiro para ingresso na granja [ ] Outros:

15. Quais medidas de isolamento abaixo são realizadas na granja?

[ ] Nenhuma [ ] Controle do fluxo de pessoas ( livro de visitas) [ ] Controle do fluxo de veículos [ ] Placa de "Acesso Proibido" [ ] Banho para entrar no galpão [ ] Utilização de uniforme e calçado exclusivo no interior da granja [ ] Outros:

16. A mão de obra utilizada na suinocultura é exclusiva para esta atividade na propriedade?

[ ] Sim [ ] Não, e lida com outros animais [ ] Não, mas não lida com outros animais.

17. As pessoas que lidam diretamente com os suínos: [ ] Residem na propriedade [ ] Residem fora da propriedade, sem criação de suínos e/ou bovinos

[ ] Residem fora da propriedade e possuem bovinos e/ou suínos

18. Quem entra no galpão, além das pessoas responsáveis pelos suínos?

[ ] Assistência técnica da granja [ ] Veterinários do Serviço Oficial [ ] Funcionários de serviços terceirizados [ ] Familiares alheios à produção [ ] Vizinhos [ ] Outros:

19. Realiza lavagem e desinfecção dos caminhões de ração e de animais, caso entrem na granja? [ ] Não se aplica [ ] Não [ ] Sempre [ ] Às vezes

20. Os materiais e/ou equipamentos que ingressam na granja sofrem algum tipo de desinfecção [ ] Não [ ] Sempre [ ] Às vezes

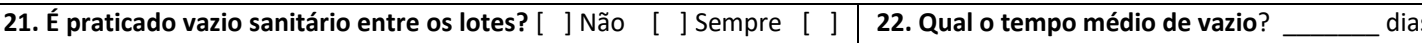
Às vezes

23. Qual o destino dado aos dejetos? [ ] Bioesterqueiras [ ] Lagoas de tratamento [ ] Esterqueira (sem proteção de fundo) [ ] Fossa

[ ] Não trata os dejetos

24. Os locais de tratamento de dejetos são protegidos de acesso animal? [ ] Sim ～[ ] Não

25. Qual a utilização dos dejetos? [ ] Lavouras da propriedade [ ] Lavouras fora da propriedade

26. Qual o destinos das carcaças e outros restos animais ( umbigo, testículos)? [ ] Compostagem [ ] Fossa séptica [ ] Enterrio

27. Realiza controle de roedores e insetos com que frequência? [ ] Não realiza [ ] Sempre [ ] Às vezes

28. Qual a origem da água fornecida aos animais? [ ] Rede pública [ ] Poço Artesiano [ ] Fonte de superfície

29. A agua é clorada? [ ] Sim [ ] Não

SANIDADE

\begin{tabular}{|l|l} 
30. Possui assistência técnica? [ ] Sim [ ] Não & 31. De que tipo? [ ] Profissional do Sistema de Integração [ ] Particular
\end{tabular}

32. Qual a frequência da assistência técnica recebida? [ ] Semanal [ ] Quinzenal [ ] Mensal [ ] Outras:

33. Quando costuma acionar a assistência técnica ou serviço oficial, fora do período agendado? [ ] Não aciona, sempre espera a próxima visita agendada [ ] Morte/doença de um animal [ ] Morte/doença de animais acima do esperado [ ] Somente quando as mortes/doenças persistem após tentativa de tratamento por iniciativa do produtor [ ] Outro:

*Atenção: granjas com animais de várias idades, uma atitude pode ser relacionada a um sítio em específico.

34. Faz registro das doenças e índices zootécnicos (morte, abortos etc)? [ ] Não registra [ ] Sim, por animal [ ] Sim , por lote (Ficha de lotes - FAL)

35. A aquisição de animais é realizada com testes laboratoriais prévios? ］］ Não ［］Sempre ［ ] Às vezes

36. Existe área destinada ao isolamento dos animais doentes? [ ] Não [ ] Sim

37. A granja possui quarentenário? [ ] Não [ ] Sim

38. A mão de obra do quarentenário é exclusiva? [ ] Não [ ] Sim ～[ ] Não se aplica

39. Qual a distância do quarentenário das instalações dos suínos? ___ metros

40. Como é o sistema de cobertura das porcas? [ ] Monta natural com macho da propriedade [ ] Monta natural com macho de outra propriedade [ ] Inseminação artificial [ ] Não se aplica

41. Qual o destino das matrizes de descarte? [ ] Frigorífico Nome [ ] Revenda [ ] Abate na propriedade [ ] Devolve para a empresa integradora ～[ ] Não se aplica

42. Cite as doenças que ocorreram nos últimos 6 meses: 
43. Recebeu visita do serviço Veterinário Oficial nos últimos 6 meses? [ ] Sim ～～] Não ］ ] Não sabe Motivo:

44. Já ouviu falar de Peste Suína Clássica? [ ] Sim [ ] Não

45. Sabe dizer algum sinal dessa doença? [ ] Sim [ ] Não Cite:

46. Essa doença está presente no Rio Grande do Sul? [ ] Sim ［ ] Não ［ ] Não sabe

47. E sobre Febre Aftosa, já ouviu falar? [ ] Sim [ ] Não

48. Sabe dizer algum sinal dessa doença? [ ] Sim [ ] Não Cite:

49. E a Febre Aftosa está presente no Rio Grande do Sul? [ ] Sim [ ] Não [ ] Não sabe

50. Onde ouviu falar sobre essas doenças? [ ] TV [ ]Rádio [ ] Internet [ ]Assistência Técnica [ ]Vizinhos [ ]Serviço Oficial

[ ]Palestras

51. Como acredita que pode ajudar no controle dessas doenças? [ ] Evitar contato com animais de outras localidades [ ] Tratar/sacrificar os animais suspeitos [ ] Retirar/vender da propriedade os animais suspeitos [ ] Avisar sobre casos suspeitos

[ ] Outros:

* caso responda "Avisar sobre os casos suspeitos", Quem você avisaria primeiramente?

[ ] Integradora/Patrão [ ] Serviço Veterinário Oficial [ ] Vizinho [ ] Outro:

52. Existe algum programa oficial do governo de vigilância e controle dessas doenças? [ ] Sim, das duas [ ] Sim, só de Febre Aftosa

[ ] Sim, só de PSC [ ] Não, de nenhuma [ ] Não sabe

Esquema da região: (usar escala em metros - demonstrando distâncias)

Propriedade com suínos

$\triangle$ Propriedade com bovinos

Outras propriedades

X Abatedouro(nomear quando possível)

- Rodovias(nomear quando possível) 